\title{
LAS PYME: QUIÉNES SON, CÓMO SON Y QUÉ HACER CON ELLAS*
}

\author{
Ángel Cabrera, Sergio de la Cuadra, \\ Alexander Galetovic y Ricardo Sanhueza
}

\section{PRÓLOGO}

En 2001 la Sociedad de Fomento Fabril lanzó su Agenda Pro Crecimiento y, como parte de ella, encargó un estudio sobre las pyme. El resultado fue "Las pyme: quiénes son, cómo son y qué hacer con ellas” (Las pyme). Entregado en enero de 2002, el mimeo circuló con

Ángel Cabrera. Master en Economía, Universidad de Harvard. Forecast Consultoría e Inversiones S.A.

Sergio de la Cuadra. Master en Economía, Universidad de Chicago. Forecast Consultoría e Inversiones S.A.

Alexander Galetovic. Doctor en Economía, Universidad de Princeton. Profesor de la Universidad de los Andes e investigador del CEP.

Ricardo Sanhueza. Doctor en Economía, Universidad de Maryland. Profesor de la Universidad de los Andes.

* Este trabajo fue encargado por la Sociedad de Fomento Fabril (Sofofa). Sin embargo, su contenido es de nuestra exclusiva responsabilidad y no compromete de manera alguna a la Sofofa. Agradecemos las útiles conversaciones con Roberto Álvarez, Patricio Arrau, Harald Beyer, Pablo Bosch, Juan Braun, Rodrigo Cárcamo, Juan Claro, Andrés Concha, José Cox, Gustavo Crespi, Jaime Crispi, Gonzalo de la Cerda, Ronald Fischer, Bernardo Fontaine, Rodrigo Fuentes, Juan José Gana, Eduardo Engel, Enrique Marshall, Claudio Martínez, Claudio Muñoz, Jaime Pizarro, Mauricio Ramos, Gonzalo Rivas, Cristián Rodríguez, Mauricio Rojas, Andrés Sanfuentes, Rodrigo Valdés, Gustavo Verdugo, Christian Wallem y Max Winter. También agradecemos la eficiente ayuda de Pamela Arellano y Sergio Quintana; a Eduardo Engel por facilitarnos su panel de plantas industriales construido a partir de la ENIA; y al SII por facilitarnos datos sobre ventas.

Estudios Públicos, 116 (primavera 2009). 
alguna reserva durante un par de meses y fue presentado en varias universidades y centros de estudios. La recepción fue muy positiva, quizás porque con cierto asombro y alivio, lectores y audiencias concluían que la situación de las pyme distaba mucho de ser desesperada. Más aun, el trabajo recopilaba evidencia convincente de que las políticas asistencialistas - fuente inagotable de desperdicio de recursos fiscales - eran innecesarias y dañinas. No es exagerado decir que cuando el diario La Segunda publicó un extenso reportaje sobre el estudio en agosto de 2002, el debate sobre las pyme había cambiado de foco.

A pesar de su amplia difusión, nunca publicamos el estudio. La intención era transformarlo en un libro, corrigiendo imprecisiones y agregando material. Pero los apuros del día a día postergaron indefinidamente el proyecto hasta que en algún momento se le dio por abandonado. ¿Por qué publicarlo casi ocho años después sin cambios?

Una razón es que Las pyme fue bastante exitoso. Como se dijo, el debate serio cambió de foco y desde entonces el peso de la prueba recae en quienes abogan por las políticas asistencialistas. Más importante aun, los planes de rescate de pymes se postergaron durante años, evitándose el consiguiente desperdicio de recursos y, seguramente, retardar aun más el crecimiento de la productividad.

Sin embargo, hay otra razón que justifica publicarlo y es que como plan de acción Las pyme fracasó, porque no logró cambiar el foco de las políticas públicas. Tal como argumentamos en el epílogo, la premisa de nuestros gobiernos sigue siendo que el Estado debe enseñarles a los empresarios a gestionar mejor. Por eso, no es sorprendente que, a pesar de varios planes de competitividad y un estatuto pyme, poco se haya hecho durante estos años para disminuir la burocracia, bajar el costo de hacer negocios, intensificar la competencia entre bancos, aliviar el peso de las regulaciones laborales, ambientales y sanitarias o evaluar el impacto de la legión de programas asistenciales y de fomento que el Estado sigue manteniendo y financiando.

Por el contrario, el punto de fondo de Las pyme es que la maraña regulatoria tejida por nuestro Estado es el principal problema. Así, por un largo rato la política pyme debiera consistir en eliminar trabas para que el proceso de experimentación y aprendizaje que hace crecer la productividad pueda ocurrir con eficacia. Nuestros gobiernos y políticos no comparten ese diagnóstico y, mientras así sea, un estudio como Las pyme sigue teniendo vigencia. 


\section{INTRODUCCIÓN Y RESUMEN}

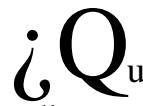
ué se debería hacer con las pyme? ${ }^{1}$ Desde hace varios años se discute acaloradamente sobre la situación y destino de las pequeñas y medianas empresas. Se sostiene que las pyme están en crisis, que la crisis es dañina para el desarrollo del país y que, por lo tanto, el Estado debiera apoyarlas con créditos y programas de fomento. La principal conclusión de este trabajo es algo distinta. Si bien es un hecho que en Chile las micro, pequeñas y medianas empresas fracasan a tasas elevadas y más que las empresas grandes, este patrón coincide con la dinámica del nacimiento, evolución y salida de empresas documentada para una serie de países, tanto en vías de desarrollo como desarrollados. Muchos estudios muestran que la mayoría de las empresas nacen pequeñas y salen a los pocos años de haber sido creadas porque no logran ser exitosas; sólo unas pocas tienen éxito y sobreviven y aun menos llegan a ser grandes luego de varios años ${ }^{2}$. Por lo tanto, gran parte de lo que estamos viendo no es consecuencia de la recesión sino del conveniente funcionamiento habitual de la economía, que refleja el proceso de ensayo y error, sin el cual la productividad agregada de la economía no crece y no se pueden crear empleos estables. De hecho, la evidencia internacional indica que gran parte del crecimiento de la productividad en cada industria se debe al reemplazo de plantas y empresas ineficientes por otras eficientes. Políticas que apoyen a las pyme en problemas sólo retardarán la salida de un gran número de empresas relativamente menos productivas, desperdiciarán recursos públicos que podrían destinarse a usos alternativos urgentes y entrabarán el crecimiento de la productividad, el empleo, los salarios y la economía.

El trabajo se organiza de la siguiente manera. En la sección 2 presentamos la economía básica de las pyme, que nos permitirá entender las fuentes de la gran heterogeneidad que ellas esconden. En la sección 3 examinamos las implicancias de la economía básica que

${ }^{1}$ Pyme: este acrónimo de "pequeña y mediana empresa” es de uso tan frecuente que se lo considera como un nombre común y como tal se escribe con letra minúscula inicial. Cuando es plural se acompaña del artículo "las” y se conserva la condición del acrónimo en singular: "las pyme”.

2 En adelante por "nacer" o "entrar" entenderemos la creación de una nueva empresa. Por "morir" o "salir", que la empresa dejó de funcionar debido a una quiebra pero más frecuentemente por simple disolución de la empresa. 
permiten analizar críticamente una serie de afirmaciones que se hacen habitualmente sobre las pyme. En la sección 4 analizamos los problemas que usualmente se asocian a la categoría pyme: mala gestión, baja productividad y financiamiento insuficiente y caro. En la sección 5 analizamos los efectos que tienen las políticas públicas — regulaciones y programas de fomento- que afectan a la pyme. En el resto de esta introducción resumimos las principales conclusiones del estudio y mencionamos algunas propuestas concretas. Al lector con poco tiempo le sugerimos partir con esta introducción y luego, para más detalle, continuar con los principales hallazgos y conclusiones de cada sección, los que hemos resumido en "hechos" numerados desde 1 a $63 .$.

\section{1. ¿Quiénes son las pyme?}

La primera dificultad cuando se discute sobre pyme consiste en determinar de qué tipo de empresa estamos hablando. Existen varias definiciones de la categoría "pequeña y mediana empresa" que dependen de la variable usada para medir su tamaño (v. g. por ventas, empleo o capital invertido), pero con todas se concluye que existen alrededor de 90.000 pequeñas empresas y 13.000 medianas. Esto las distingue de, por un lado, más de 500.000 microempresas y, por el otro, de 6.000 grandes empresas que existen en Chile (véase el Cuadro $\mathrm{N}^{\circ} 1$ ).

Clasificar a las empresas por tamaño es útil para formarse una idea de su magnitud, relevantes en el tema que nos ocupa. Pero a poco andar se concluye que la categoría "pyme” es demasiado amplia y analíticamente engañosa porque esconde la heterogeneidad que caracteriza a este grupo de empresas ${ }^{3}$. Más importante aún, los errores de juicio son casi inevitables si se ignora la heterogeneidad. Por ejemplo, se suele señalar que las pyme exportadoras son exitosas - lo que es cierto-, para luego concluir que se debe estimular las exportaciones directas de la generalidad de las pyme. Esta receta, sin embargo, es equivocada, porque ignora que una pyme tendrá éxito exportando directamente sólo si el tamaño eficiente de su operación es suficientemente pequeño, el producto sirva a un nicho diferenciado y el costo de abrir mercados no sea grande, condiciones que satisfacen muy pocas empresas y productos. Más generalmente, hay la tendencia a proponer

${ }^{3}$ En este trabajo no analizaremos las microempresas. El lector interesado puede consultar el estudio de la microempresa de Irarrázabal (2001). 


\begin{tabular}{lrrrrrr}
\hline & $\begin{array}{c}(1) \\
\text { Micro }\end{array}$ & $\begin{array}{c}(2) \\
\text { Pequeña }\end{array}$ & $\begin{array}{c}(3) \\
\text { Mediana }\end{array}$ & $\begin{array}{c}(\mathbf{4}) \\
\text { Pyme }\end{array}$ & $\begin{array}{c}(5) \\
\text { Grande }\end{array}$ & $\begin{array}{c}\text { (6) } \\
\text { Total }\end{array}$ \\
\hline $\begin{array}{l}\text { Número de empresas } \\
\text { Participación (\%) }\end{array}$ & 535.338 & 93.923 & 13.164 & $\mathbf{1 0 7 . 0 8 7}$ & 6.066 & 648.491 \\
& 82,55 & 14,48 & 2,03 & $\mathbf{1 6 , 5 1}$ & 0,94 & $100 \%$ \\
Participación en ventas (\%) & 3,7 & 10,1 & 10,1 & $\mathbf{2 0 , 2}$ & 76,1 & $100 \%$ \\
Venta promedio en UF & 456 & 7.161 & 51.096 & $\mathbf{1 2 . 5 6 2}$ & 836.395 & 10.274 \\
& & & & & & \\
Empleo (Corfo) (\%) & 38,7 & 35,2 & 12,5 & $\mathbf{4 7 , 7}$ & 9,7 & $100 \%$ \\
Empleo (Casen) (\%) & 40,4 & 36,6 & 13,0 & $\mathbf{4 9 , 6}$ & 10,1 & $100 \%$ \\
Exportaciones (\%) & 0,1 & 1,3 & 3,5 & $\mathbf{4 , 8}$ & 95,1 & $100 \%$ \\
\hline
\end{tabular}

Nota: Las ventas de las empresas de menor tamaño probablemente subestiman las ventas verdaderas porque estas empresas evaden más.

Fuente: La fuente de las ventas y del número de empresas es el SII. La fuente de las exportaciones es la Corfo. Microempresas son aquellas que venden anualmente hasta UF 2.400; las empresas pequeñas venden más de UF 2.400 y hasta UF 25.000; las empresas medianas venden más de UF 25.000 y hasta UF 100.000; las empresas grandes son aquellas que venden más de UF 100.000.

como "solución" a los problemas de la generalidad de las pyme aquello que hace exitoso a un grupo de ellas. Así, según sea el caso, se observa que algunas pyme exitosas crecen y se transforman en grandes, otras desarrollan relaciones de largo plazo con empresas más grandes o bien se asocian entre ellas para compartir costos, de lo que se concluye que se las debe estimular a crecer, establecer relaciones de largo plazo con empresas grandes y asociarse. Sin embargo, éstas no son condiciones del éxito sino consecuencias de características económicas más fundamentales que no son inherentes a la generalidad de las pyme y que varían sistemáticamente entre ellas ${ }^{4}$.

\subsection{La economía básica de las pyme}

Por lo anterior, nuestro análisis se sustenta en tres características fundamentales que permiten entender la heterogeneidad que se observa entre las pyme.

\footnotetext{
${ }^{4}$ Técnicamente hablando, cuando se analiza a las pyme es indispensable poner atención a los sesgos de selección.
} 
Escala eficiente de operación. La primera característica es bien conocida: las pyme se observarán en sectores cuya escala de operación eficiente es pequeña, vale decir, donde las economías de escala no son importantes. Grosso modo, esto ocurre en actividades que no requieren incurrir en costos fijos o hundidos considerables y tampoco con productos que precisen marcas sostenidas por publicidad masiva - por ejemplo, las panaderías-. Por el contrario, cuando la escala eficiente de operación es considerable o los productos requieren de publicidad masiva, no puede tratarse de pyme. Por ejemplo, no es razonable pretender que la mayoría de los productores de fruta fresca, que por lo general son pyme, exporten directamente porque se requieren escalas de operación considerables. Similarmente, las pyme no producen cigarrillos.

Nichos y diferenciación de productos. La segunda razón detrás de la heterogeneidad es que las pyme pueden coexistir con empresas grandes creando productos parecidos cuando son capaces de explotar nichos de demanda que valoran la diferenciación de productos. Por ejemplo, en el mercado de la televisión coexisten canales pequeños, que apuntan a nichos pequeños (v.g. ETC TV, ARTV, ABT), con canales grandes que apuntan a audiencias masivas (PSN, ESPN, Canal 13, TVN).

La dinámica industrial: entrada, desarrollo y salida de empresas. La tercera característica económica fundamental, sin la cual es imposible dar cuenta de la gran heterogeneidad entre las pyme, es la dinámica de las industrias, en particular el ciclo de entrada, evolución y salida de empresas. En los últimos 15 años se ha estudiado sistemáticamente en distintos países (incluyendo a Chile) el ciclo de vida de un gran número de empresas individuales por períodos de varios años y es extremadamente útil comparar lo que ocurre en Chile con lo que se observa en el resto del mundo.

Los estudios han permitido establecer que en prácticamente todas las industrias, en todos los países y todo el tiempo, muchas empresas se crean, unas pocas son exitosas y el resto fracasa y sale. Para formarse una idea de cuán grandes son las tasas de salida es conveniente partir notando que normalmente, en casi todos los países que se han estudiado, entre el 5 y 10\% del total de firmas muere cada año por razones que tienen poco que ver con el ciclo económico. La tasa de 
salida es más alta para firmas más jóvenes y para las firmas más pequeñas. Por ejemplo, alrededor del $10 \%$ de las firmas muere antes de cumplir un año, la tasa de fracaso cae lentamente en los años siguientes y al cabo de diez años las tasas de mortalidad superiores al $60 \%$ no son infrecuentes. Por otro lado, la tasa de salida es mayor cuanto más pequeñas sean las firmas, en parte porque entran nuevas firmas de escala muy pequeña, y por tanto alejadas del tamaño eficiente de operación, y porque las empresas que declinan tienden a perder ventas (y por ende tamaño) por varios años. Sin embargo, las firmas que sobreviven tienden a crecer más rápido mientras más pequeñas son. Vale decir, el fracaso y salida de empresas y su reemplazo por firmas nuevas es parte sustantiva de la dinámica de las industrias.

Tal como en el resto del mundo, en Chile ocurren entradas y salidas de empresas en número considerable todo el tiempo. Mostramos evidencia detallada de que entre 1986 y 1997, el período de crecimiento económico más rápido de toda la historia de Chile, en promedio poco menos del 7\% de las plantas salió todos los años; más del $10 \%$ de las plantas industriales salió apenas un año después de haber entrado; y al cabo de diez años más del 50\% había salido. Más aún, hay evidencia concluyente de que las pyme fracasan más que las empresas grandes. En efecto, de acuerdo con la evidencia disponible, el $51 \%$ de las plantas industriales pyme sale en un período de diez años, pero sólo el 26\% de las plantas grandes corre esa suerte.

Lo anterior tiene tres implicancias cruciales si se quiere poner en perspectiva el debate sobre las pyme que actualmente está en curso. Primero, los números chilenos de entrada y salida de las pyme son de magnitudes similares a los que se observan tanto en países en desarrollo como en los desarrollados. Segundo, una parte importante de lo que observamos es el proceso de ensayo, error y aprendizaje tal que las firmas entran pequeñas para ver cómo les va. Las que aprenden resultan ser eficientes o aciertan con su producto, sobreviven y crecen; el resto sale. Por eso, en todo momento, independientemente de si se trata de auge o recesión, veremos que en términos relativos hay más pyme en problemas que empresas grandes en problemas. Esto ocurre precisamente porque ser grande es, en muchos casos, consecuencia y no causa de haber aprendido, de ser más eficiente o de haber diseñado el producto o servicio preciso. Por contraste, aunque el tamaño natural de muchas empresas sea pequeño o mediano, las pyme exitosas coexisti- 
rán con muchas otras cuya experimentación está en vías de fracasar. Tercero, y por lo mismo, entre las pyme habrá diferencias apreciables de productividad y eficiencia. De hecho, la evidencia muestra que en Chile la eficiencia de una pyme promedio es entre 60 y $70 \%$ de la alcanzada por las empresas más eficientes. Sin embargo, esto no es señal de que exista un problema: tal dispersión de productividad es similar a la observada en otros países, incluso en los desarrollados.

\subsection{Implicancias y conclusiones}

Las características fundamentales descritas tienen numerosas implicancias y algunas de ellas son muy importantes a la hora de analizar la supuesta crisis que atraviesan las pyme y las medidas y políticas que se han propuesto para solucionarla; a continuación resumimos las principales implicancias y conclusiones.

Es normal observar altas tasas de entrada y salida de pyme, independientemente del ciclo económico. Para comenzar, es normal esperar que en todo momento se observen tasas altas de entrada y salida de empresas y diferencias sustantivas de productividad entre ellas. Así, una fracción importante de las pyme que están hoy en problemas lo estarían también si estuviéramos en auge económico. Por lo tanto, si tomamos una "foto" de las pyme en cualquier momento, inevitablemente se vería que muchas tienen problemas y su productividad es mucho menor que la de las empresas que producen bienes similares pero que son más exitosas. Pero eso no indica que haya una crisis. Por eso, una de nuestras principales conclusiones es que no existe evidencia de que las pyme estén atravesando por una crisis, mucho menos que la sobrevivencia de la categoría pyme esté amenazada en el mediano o largo plazo.

Las pyme no pueden sobrevivir cuando los costos fijos son altos. Una implicancia directa de la economía básica de las pyme es que no pueden subsistir cuando los costos fijos o hundidos son altos. En ocasiones se trata de características de la forma como se produce y entonces hay poco que hacer. Sin embargo, una de las principales fuentes de costos fijos y hundidos son regulaciones similarmente onerosas, independientemente del tamaño de la empresa, pero que, por lo 
mismo, afectan más a las empresas más pequeñas. Existe amplio margen para mejorar en Chile. A modo de ejemplo, en Canadá iniciar legalmente una empresa requiere dos trámites que se completan en dos días hábiles y cuestan el equivalente a poco más de 106 dólares. En Chile se requieren 10 trámites que requieren a lo menos 28 días hábiles para completarse y cuestan, en dinero y tiempo, el equivalente a más de 1.150 dólares o un cuarto del PGB per cápita. Este solo costo explica por qué un número muy grande de micro y pequeñas empresas elige la informalidad: el costo de cumplir con los trámites oficiales equivale a más de un mes de ventas de la microempresa promedio y (suponiendo un margen de utilidad de $20 \%$ sobre ventas) a cerca de la mitad de sus utilidades anuales.

El “problema de la selección” y un principio básico. La heterogeneidad inherente a las pyme también implica que parte fundamental de la actividad económica consiste en averiguar cuáles son las empresas competentes y separarlas de las que no lo son, y esto es particularmente relevante cuando se trata de pyme. El "problema de la selección” tiene vastas implicancias y muchas facetas: lo enfrenta una empresa cuando elige a sus proveedores o distribuidores (¿producen el insumo que necesito?, ¿son confiables y responsables?); lo enfrenta también un financista cuando presta o invierte (¿es un gestor competente?, ¿tiene demanda el producto que quiere vender?, ¿está dispuesto a trabajar duro?, ¿está arriesgando su patrimonio en este negocio tan "bueno”?); y cuando elige una institución de fomento como la Corfo; o, incluso, la misma persona que decide comenzar una empresa (¿tengo las habilidades necesarias para este negocio?, ¿ estoy dispuesto a trabajar sin horario y asumir el riesgo?). Pero en todos los casos se trata de un problema similar que impone restricciones parecidas. En vista de que en el mejor de los casos la tasa de errores será alta, la única forma conocida de manejar este problema es que los incentivos sean apropiados.

Qué tipo de incentivos son “adecuados” depende del caso y una extensa literatura muestra que el diseño de mecanismos apropiados para hacer frente al problema de selección es materia compleja. Sin embargo, el principio general es bastante simple: para que los incentivos sean "adecuados” la selección debe hacerla quien al mismo tiempo se remunera principalmente con el valor (o los excedentes) creados y asume el costo de equivocarse. 
Es bastante evidente cómo opera este principio cuando se trata del financiamiento. Pero el principio tiene implicancias que van mucho más allá del financiamiento. Por ejemplo, no es casualidad observar que las pyme que logran establecer relaciones de largo plazo con una empresa grande suelen ser más exitosas. Una empresa grande tiene incentivos para encontrar a las pyme competentes, y en ocasiones incluso para capacitarlas y transferirles tecnología, porque se beneficia con el excedente creado.

El problema de la selección condiciona al financiamiento. Reconocer la magnitud del problema de la selección permite entender una serie de prácticas que se observan en el mercado del crédito que buscan alinear los incentivos del deudor con el interés del que le presta el dinero, pero que se suelen confundir con fallas del mercado o se interpretan como discriminación en contra de las pyme. Estas prácticas, que han sido investigadas exhaustivamente en los últimos 30 años, son indispensables para moderar lo que se conoce por "asimetrías de información”: el deudor conoce con mayor precisión la información relevante para evaluar su capacidad de pago.

En efecto, si bien es razonable pensar que a veces hay proyectos buenos que no reciben financiamiento, muchas más veces quienes tienen ideas no saben que son malas y experimentar es más barato cuando es otro quien pone el capital. Para evitar que la tasa de fracasos sea alta, los que prestan, en Chile y en el resto del mundo, necesitan recurrir a prácticas tales como recabar información directamente de los deudores, compartir información sobre su comportamiento pasado, exigir garantías, prestar a plazos cortos renovando sólo si el comportamiento del deudor es satisfactorio e, inevitablemente, rechazar a un gran número de empresas que fracasarán en cualquier caso y a quienes no es prudente prestarles. Más aún, como vimos, es un hecho que las empresas de menor tamaño fracasan más que las grandes. Si se considera, además, que muchos costos de intermediación son fijos y no dependen del tamaño de la deuda, se sigue que es natural esperar que las empresas más pequeñas paguen tasas de interés más altas. Esto no es discriminación sino simple consecuencia de que el costo de prestarles sea más alto.

Por último, la supuesta falta de crédito de largo plazo respaldado por meros flujos no es una falla de mercado, sino simple consecuencia 
de que la tasa de fracasos de empresas a plazos largos es alta. Esta alta tasa de fracasos implica que los deudores que pagan deberán compensar el incumplimiento de los muchos que no lo hagan. Esto encarece fuertemente el crédito de largo plazo; a un buen deudor le conviene más endeudarse a corto plazo e ir renovando el crédito año a año.

\section{Muchas propuestas para mejorar el financiamiento ignoran el pro-} blema de la selección. Existen varias propuestas para mejorar el acceso al financiamiento de las pyme que parten de la premisa de que el acceso a su financiamiento es caro e insuficiente. Por eso, consisten ya sea en subsidiar la tasa de interés a la que se les presta o reducirles las exigencias de garantías o prudenciales, y se sustentan en que el Estado asuma parte del riesgo de no pago. Estimamos que estas medidas son inapropiadas porque ignoran el problema de la selección, exacerbando sus consecuencias indeseables. Con toda probabilidad, políticas de crédito más liberales financiadas con recursos públicos plantean el riesgo de que gran parte de los fondos terminen financiando proyectos malos. Es importante recalcar que mejorar el acceso al financiamiento de las pyme implica que la selección de empresas se haga de mejor manera y necesariamente, entonces, muchas empresas no recibirán crédito porque no son buenos deudores. Sin embargo, esto es beneficioso porque aumenta la disponibilidad de financiamiento para buenos proyectos y les disminuye el costo.

No existe evidencia de que el acceso al financiamiento de las pyme sea malo en Chile. En relación con lo anterior, se suele afirmar que el acceso al financiamiento de las pyme en Chile es insuficiente y caro. Sin embargo, la evidencia no sugiere eso. Para comenzar, la participación relativa de las pyme en el crédito bancario es apreciablemente mayor que su participación en las ventas; de hecho, de acuerdo con datos del Ministerio de Economía, en 1998 la razón crédito bancario a ventas de las pyme era 1,28, mientras que la de empresas grandes era sólo 0,82. Segundo, los indicadores de acceso a crédito bancario de empresas pequeñas en Chile son similares a los de Estados Unidos, el país con los mercados de capitales más desarrollados del mundo. En efecto, en ese país el 50\% de las empresas pequeñas no tiene créditos bancarios de ninguna especie, sólo se les presta a plazos largos cuando la contrapartida es adquisición de activos prendables (v.g. inmuebles, vehícu- 
los) y el resto es crédito de corto plazo. Tercero, no hay evidencia de que la regulación prudencial de bancos discrimine a las pyme. Estas normas prudenciales no discriminan por tamaño de las empresas sino por las características de riesgo del deudor. Si bien es posible que las provisiones impuestas por la regulación para deudores más riesgosos sean excesivas, esto es aún mera especulación, porque no se ha hecho ningún estudio al respecto. Cuarto, como se dijo, es natural esperar que las empresas más pequeñas paguen tasas de interés más altas. Lamentablemente, no hay estudios que permitan conocer si aun así la tasa de interés que pagan las empresas pequeñas es mayor que la competitiva. Quinto, las tasas de créditos incobrables en Chile son especialmente bajas comparadas con las internacionales. Esto favorece a los buenos deudores porque les permite acceder a tasas más bajas.

Es cierto que en Chile no existe aún una industria de capital de riesgo, pero cuantitativamente esto no es muy relevante para las pyme. En efecto, en los Estados Unidos los capitalistas de riesgo aportan menos del 2\% del financiamiento total de las empresas pequeñas y poco más del 3\% de la deuda. La razón es que el capital de riesgo es una forma de financiamiento apropiada sólo para empresas pequeñas con gran potencial de transformarse en grandes. Muy pocas empresas satisfacen esa característica. Sería deseable que en Chile existiera una industria de capital de riesgo porque seguramente facilitaría el desarrollo de ese tipo de empresas, pero eso no cambiaría apreciablemente el panorama financiero del grueso de las pyme.

Es improbable que los programas de fomento funcionen. El problema de la selección también permite dar contenido a la afirmación que se hace frecuentemente en el sentido de que los programas de fomento financiados con dineros públicos, ya sean subsidios, créditos o garantías, tienden a desperdiciar recursos porque financian a muchas empresas que fracasarán en cualquier caso. La evidencia sobre la dinámica de las industrias indica que el problema no es que se les preste o subsidie a empresas o proyectos que fracasan —algo esperable porque forma parte del proceso de ensayo, error y aprendizaje-; antes bien, la naturaleza de las instituciones públicas no permite que la remuneración del que toma las decisiones de prestar y fomentar dependa de los excedentes creados ni tampoco que asuma las pérdidas de financiar proyectos y empresas equivocadas —el costo de los errores lo asume 
el tesoro público-. Por lo tanto, su tasa de fracasos tenderá a ser considerablemente más alta e incluso puede llegar a ser cercana al $100 \%$. Por eso, para justificar un determinado programa de fomento o apoyo a las pyme no basta con señalar que se pretende corregir una falla de mercado e identificarla. Tanto o más importante es que se explique cómo se pretende resolver el problema que supone identificar y separar a los buenos proyectos y empresas y se diseñen mecanismos apropiados para hacerlo.

Programas de fomento financiero. Hay una serie de programas de crédito que otorga la Corfo destinados a aumentar el financiamiento para determinadas actividades. Entre 1990 y 2001 se realizaron 12.346 operaciones de crédito por casi 1.500 millones de dólares (vale decir, cada operación fue de alrededor de 120.000 dólares en promedio). El monto promedio anual de colocaciones fue US\$ 124 millones, equivalente al 2,1\% del crédito comercial total extendido durante el año 2000. Estos programas de financiamiento parten de la premisa de que existen imperfecciones de mercado que requieren crédito subsidiado.

La virtud de los programas de financiamiento Corfo es que en su gran mayoría son intermediados por bancos comerciales que asumen el costo de la pérdida cuando prestan mal. De esta forma existe cierta garantía de que a los deudores se les evaluará cuidadosamente. Por lo mismo, pensamos que los programas que garantizan parte de los créditos (por ejemplo, el Fogape, los Cubos; las garantías otorgadas por el Estado a las deudas reprogramadas por las pyme, y el sistema nacional de garantías para créditos a pyme propuesto por el Ministerio de Economía) son inconvenientes. Cuando el Estado garantiza créditos privados, en la práctica subsidia la toma de riesgos del banco y, además, facilita que malos deudores obtengan crédito.

Excluyendo a los programas que otorgan garantías, el resto consiste fundamentalmente en subsidiar el costo del endeudamiento, ya sea a través de tasas menores o de plazos más generosos. Nuevamente esto se justifica sólo si existieran fallas de mercado, tales como externalidades que hagan que el retorno social de los proyectos sea mayor que el privado, y estudios detallados que las hayan identificado y cuantificado. No tenemos noticia de estos estudios previos y la impresión general que nos formamos es que gran parte de los programas de financiamiento Corfo no mitigan fallas de mercado. Por ejemplo, el 
objetivo del principal programa de financiamiento, la línea B11, que representó el $61 \%$ de los fondos prestados por Corfo en los últimos tres años, es muy amplio, a saber: financiar a largo plazo inversiones en activos fijos requeridos por empresas para el desarrollo productivo —inversión en general- Más aún, el programa incluye a empresas con ventas anuales de hasta UF 1.200 .000 (aproximadamente US\$ 30 millones), muy por encima de las UF 100.000 que separan a las empresas medianas de las grandes. De esta forma, se les está prestando con subsidio principalmente a empresas medianas y sobre todo grandes que no tienen mayores problemas de acceso a crédito cuando la calidad de los proyectos lo justifica. Esta generalidad se repite en la mayoría de los programas de crédito.

La reprogramación de deudas. El diagnóstico que sustenta los programas de reprogramación de deudas es que la recesión debilitó financieramente a las pyme y que la gran mayoría son viables si se les extiende el plazo para pagar. El principal programa consiste en subsidiar la reprogramación de deuda bancaria de las pyme garantizando parte de la deuda reprogramada (30 ó 40\%, según sea el caso) y alargando el plazo para pagar, que será entre 30 meses y seis años.

El principal defecto del programa de reprogramación (y de las reprogramaciones en general) es que parte de la premisa equivocada: que gran parte de las pyme en problemas, y que los bancos no quieren rescatar sin subsidios, son viables en el mediano plazo. Esto ignora que aun durante un auge económico el número de las pyme "en problemas" es significativo: por ejemplo, de acuerdo a la ENIA, el 15\% de las plantas industriales pyme que existen hoy saldría incluso sin recesión en los próximos dos años. Este porcentaje aumenta en recesiones, pero en su gran mayoría se trata de empresas que no son viables en el mediano plazo. Por lo tanto, mientras más “exitoso" sea un programa de reprogramación de deudas, en el sentido de llegar a un mayor número de pyme, mayor será la fracción del financiamiento que llegará a empresas que fracasarán en cualquier caso y serán mantenidas vivas un tiempo más por el subsidio. Esto sugiere que las reprogramaciones son potencialmente una gran fuente de mal uso de recursos. El mal uso será mayor mientras más generosas sean las garantías estatales, mayor el plazo para pagar los créditos reprogramados y mayor el subsidio de tasas. 
Programas de fomento no financieros para pyme. La Corfo ejecuta una serie de programas de fomento no financiero, pero sólo algunos están diseñados específicamente para las pyme. Estimamos que los programas de fomento no financiero para pyme que existen actualmente (los así llamados Profos, PDP y FAT) adolecen de problemas de diseño que hacen muy probable que su rentabilidad social sea baja o incluso negativa. Primero, a los consultores que intermedian los programas se les remunera por el número de proyectos que gestionan y no por el valor que generan. Segundo, en el caso de los tres programas, de los beneficios que generan se apropian principalmente las empresas beneficiadas, sin embargo la Corfo cofinancia un porcentaje significativo del costo de los proyectos. Tercero, los criterios de selección son muy generales y no consideran que ciertos programas (v.g. de asociatividad) sólo serán exitosos si las empresas cumplen con determinadas características económicas.

En esta línea, creemos que los programas de fomento de la asociatividad y mejora de gestión de las pyme, y que parten de la premisa de que Corfo es capaz de disminuir costos de transacción, no deben cofinanciar los costos directos del proyecto. El aporte de Corfo debe limitarse a coordinar y disminuir los costos de coordinación; si la asociación es socialmente rentable, las partes deberían estar dispuestas a pagar los costos directos una vez que el problema de coordinación haya sido resuelto. Más generalmente, estimamos que se debe evaluar la rentabilidad social alcanzada por los programas. A la fecha las evaluaciones que existen son sólo cualitativas.

\section{La baja productividad de algunas pyme y su gestión deficiente no} son consecuencia de fallas de mercado. Nuestro análisis también permite poner en contexto el diagnóstico ampliamente difundido de que la productividad de las pyme es baja porque, entre otras cosas, son mal gestionadas, tecnológicamente atrasadas, incapaces de aprovechar economías de escala y no acceden a recursos para invertir ${ }^{5}$. En primer lugar, tal afirmación ignora la heterogeneidad que la categoría pyme esconde. Por un lado, existen muchas pyme bien gestionadas, que ocupan la tecnología apropiada y operan en su escala eficiente. Por el otro, en todo momento coexisten con otras que son menos eficientes.

${ }^{5}$ Estas afirmaciones fueron recurrentes en las entrevistas que sostuvimos y también se encuentran en numerosos escritos sobre las pyme. 
Algunas van en camino de salir, pero otras recién están entrando y aprendiendo.

En segundo lugar, el estándar que parece subyacer en muchos de estos diagnósticos es el que imponen las empresas grandes o la gestión de pyme en países más desarrollados. Con tal estándar es casi inevitable concluir que muchas pyme se gestionan mal porque es palmario que el nivel de productividad de las pyme chilenas ( $\mathrm{y}$ de las empresas grandes chilenas y del Estado chileno) es inferior al de sus equivalentes en países desarrollados. Sin embargo, tal comparación nos parece inapropiada, porque ignora que el capital humano, principal determinante de la calidad de la gestión, es relativamente más escaso en Chile que en países desarrollados. Por eso, en nuestro país es natural esperar que las personas más capacitadas se concentren en administrar y gestionar empresas más grandes y es también esperable que la calidad de la gestión de las pyme sea, en promedio, inferior a la que se observa en países desarrollados. Visto de esta forma, queda claro también que el problema de la gestión deficiente no es una falla del mercado; la manera de "solucionarlo" es acumulando capital humano —algo que no se puede hacer sino gradualmente en el tiempo-.

Las políticas de apoyo generalizado a las pyme no generan empleos estables y son dañinas para el crecimiento. Es un hecho bien conocido que poco menos de la mitad de la fuerza laboral trabaja en las pyme. Por eso, en ocasiones se concluye que la supuesta crisis por la que pasan las pyme pone en riesgo estos empleos. En la misma línea se suele afirmar que el reemplazo de pyme por empresas grandes menos intensivas en trabajo que ha ocurrido en los últimos 20 años (de lo cual existe evidencia) disminuiría el empleo. Así, de estos hechos se suele concluir que a las pyme se les debe apoyar con programas especiales de crédito financiados o garantizados por el Estado para mantener el empleo y estabilizarlo. Sin embargo, estas políticas de apoyo son inadecuadas y contraproducentes. Es equivocado pensar que estas políticas mantendrán empleos o los harán más estables; lo contrario es más probable. Más aún, dichas políticas entraban el crecimiento de la productividad, los salarios y la economía.

Primero, es natural que, a medida que una economía crece y el capital físico se hace más abundante, aumente la proporción de firmas más grandes; esto ha ocurrido en Chile durante los últimos 20 años. 
Pero es equivocado concluir que esto disminuye el empleo: si bien las firmas más intensivas ocupan menos trabajadores por unidad de capital, cuando el capital es más abundante el número de empleos en firmas grandes aumenta.

Segundo, la evidencia internacional muestra que en casi todas las economías alrededor del $10 \%$ de los empleos se destruye cada año y se reasignan a otras empresas. En parte, esto no es sino reflejo de la dinámica de las industrias ya mencionada (la que implica que todo el tiempo se crea y desaparece gran número de empresas); pero también es consecuencia de los ajustes de la dotación de trabajadores realizados por cada empresa que, la evidencia indica, suelen ser de magnitud considerable. Por las razones ya mencionadas, gran parte de las empresas que nacen, mueren y se ajustan son las más pequeñas y es natural que sus empleos sean más inestables. Por lo mismo, la dinámica de las industrias también implica que los empleos estables son los de empresas de más edad y tamaño, porque éstas salen y mueren menos. Sin embargo, no se puede "estimular" a estas firmas porque son resultado de la selección que ocurre en los mercados. Por eso, desde el punto de vista del empleo, las políticas de apoyo a las pyme que subsidian su creación, o bien tratan de mantenerlas funcionando, tienden a crear más empleos inestables, porque estimulan la entrada de empresas más ineficientes y retardan, pero no evitan, la salida de las que fracasan.

Las políticas de estímulo masivo también son dañinas para el crecimiento de la productividad, los salarios y el desarrollo económico. La evidencia indica que una parte muy importante de las mejoras de la productividad agregada de la economía, independientemente de si se trata de una economía desarrollada o no, proviene de la reasignación de recursos desde empresas menos eficientes a las más eficientes. La reasignación aumenta la productividad porque las empresas que entran y sobreviven son más productivas que las que salen. Los estudios muestran que inicialmente la productividad de los que entran es sólo un poco mayor que la de quienes salen. Pero esto esconde que muchos de los que entran fracasan a poco andar, precisamente por no ser muy eficientes. Con el tiempo, las plantas y empresas que sobreviven tienden a ser significativamente más eficientes que las que salen y esto arrastra el crecimiento de la productividad. Los programas de apoyo masivo a las pyme disminuyen el crecimiento de la productividad porque retardan la salida de empresas poco productivas que no fueron 
capaces de competir con otras empresas que hacen lo mismo pero más eficientemente. Más aún, al competir por fondos con las empresas más productivas y competir favorecidas por subsidios, probablemente retardan el crecimiento de las empresas de mayor potencial. Por eso es hasta cierto punto paradójico que se justifiquen estos programas por la supuesta importancia de las pyme como fuente de empleo. La única manera de aumentar sostenidamente los salarios reales es mediante mejoras de la productividad. Las políticas de apoyo generalizado a pyme tendrán precisamente el efecto contrario.

\subsection{Algunas propuestas}

A continuación resumimos algunas propuestas concretas para mejorar el ambiente económico donde se desempeñan las pyme.

Eliminar el impuesto de timbres y estampillas. El impuesto de timbres y estampillas encarece el costo de los créditos y relaja la intensidad de la competencia entre bancos. En efecto, no basta que un banco de la competencia le ofrezca a un deudor una mejor tasa que su banco actual; el cambio se encarece porque, de hacerlo, se deberá pagar nuevamente el impuesto. Este mayor costo le permite al banco actual cobrar una tasa más alta. Los cambios introducidos por la Ley de Mercado de Capitales a partir del 1 de enero de este año, que aumentó el impuesto a 1,6\% pero eliminó el requerimiento de pagarlo si se trata de una renovación del crédito, exacerban este efecto anticompetitivo. Creemos que la medida más sana sería eliminar el impuesto de timbres y estampillas.

Crear una central de garantías que disminuya su costo de trasladarlas de un banco a otro. Un obstáculo adicional que relaja la competencia entre bancos es la dificultad de liberar las garantías cuando un deudor refinancia su deuda con otro banco. La consecuencia derivada es similar a la del impuesto de timbres y estampillas. Alzar las garantías en un banco para constituirlas en favor de otro es caro, y el costo de cambiar de banco eleva la tasa que puede cobrar el banco. Creemos que sería conveniente estudiar cómo establecer un registro centralizado de garantías que le permita a un deudor cambiar su garantía de banco 
simplemente cambiando el registro. Este sistema sería muy similar al de los almacenes generales (o warrants), que ya existe y opera fluidamente para prendas sobre materias primas, productos en proceso o terminados.

Eliminar regulaciones que relajan la competencia entre bancos e introducir una que la estimule. Más generalmente, para las pyme es extremadamente importante que la competencia entre los intermediarios financieros sea lo más intensa posible. A pesar del acalorado debate reciente, no existe ningún estudio que evidencie problemas serios de competencia en el mercado bancario. Sea como fuere, es posible modificar un par de regulaciones además de las ya señaladas que seguramente aumentarían la intensidad de la competencia favoreciendo a todas las empresas pero particularmente a las pyme.

En primer lugar, es conveniente estudiar si se justifica mantener la exclusividad de los bancos en el negocio de la correduría de dinero. Actualmente sólo los bancos y financieras pueden captar dinero para prestarlo a terceros. Probablemente es conveniente que se permita a otras empresas (v.g. compañías de factoring, casas comerciales, distribuidoras de maquinaria, equipos y vehículos, empresas que financian a productores agrícolas) emitir bonos y efectos de comercio (bonos de corto plazo) para financiar a sus clientes. Estas empresas suelen manejar buena información sobre los deudores y, al facilitarles la captación de fondos, se estaría mejorando el acceso al crédito de las pyme que tratan con ellas y forzando a los bancos a competir más intensamente.

En segundo lugar, hay una serie de regulaciones que les imponen costos fijos a los bancos y que encarecen la entrada al mercado y aumentan la escala mínima de operación. Muchas de estas restricciones se deben a la intención de regular conductas en vez de multar los comportamientos indebidos. Estas regulaciones inhiben a los bancos de nicho porque, por pequeños que sean, deben cumplir con los mismos costos regulatorios que los grandes.

En tercer lugar, los bancos actualmente en el mercado tienen una serie de acuerdos que los ligan en red y que hacen casi imposible la entrada de un banco nuevo si éste no es admitido al club. La banca controla la red única que los conecta a los comercios para permitir las operaciones de tarjetas de crédito (Transbank), una red casi exclusiva de cajeros automáticos (Redbanc), y una cámara de compensación de 
pagos electrónicos única (CCA). Un banco entrante que no es admitido al club (y actualmente no existe ninguna obligación de hacerlo) tendría que duplicar las redes para ofrecer servicio similar al resto de los bancos. Una amplia literatura demuestra que la negativa de interconexión es una barrera a la entrada efectiva y por tanto anticompetitiva. Por lo tanto, se justifica que se obligue a los bancos dueños del club a que acepten nuevos miembros en condiciones no discriminatorias - la interconexión debiera ser obligatoria—.

Introducir el credit scoring y las centrales de información. La falta de buena información sobre las pyme contribuye a exacerbar los problemas de selección adversa y daño moral. Hay una herramienta técnica llamada credit scoring que, de adoptarse generalizadamente, permitiría mitigar estos problemas. El credit scoring consiste en reunir la mayor cantidad posible de información sobre los deudores y ordenarla de acuerdo a un conjunto de características o atributos de ellos de tal manera de poder realizar análisis estadístico de su riesgo. Esta forma de evaluar el riesgo es de antigua data especialmente en el crédito de consumo. Por otro lado, las centrales de información son organismos que construyen y administran un banco de información. Recurriendo a diversas fuentes forman bases de datos y sus correspondientes series históricas suficientemente grandes que permiten crear un banco de credit scoring.

Los detalles de la propuesta deben estudiarse con cuidado, pero proponemos revisar la legislación con el propósito de facilitar el desarrollo de centrales de información de crédito. En particular, se debería revisar la legislación en lo referente a la recolección y distribución de información detallada de crédito por parte de personas legalmente autorizadas para dicho objeto.

Diseñar estados financieros estandarizados que faciliten el control de gestión que hagan las pyme. Una manera adicional de mejorar la información sobre las pyme es desarrollar cuentas financieras estandarizadas especialmente diseñadas para empresas pequeñas. En Suecia se desarrolló con gran éxito un manual estándar de contabilidad (el manual BAS) que en un breve lapso se transformó en el estándar comúnmente usado en Suecia por pequeñas y medianas empresas. Las cuentas estandarizadas permitirían evaluar mejor a las pyme y hacerlas compa- 
rables y agrupables en categorías similares de riesgo y seguramente mejorarían el acceso al crédito de los buenos deudores. La naturaleza de bien público del diseño de este sistema de cuentas estandarizadas justifica un subsidio público.

Eliminar la tasa máxima convencional y la limitación de los cobros por gastos de cobranza. Las pyme son deudores más caros por peso prestado y lo que corresponde es que paguen por ese costo más alto. Sin embargo, en Chile la tasa de interés que se puede cobrar tiene un tope, la tasa máxima convencional, igual a 1,5 veces la tasa promedio del sistema financiero en cada categoría de crédito. Esta regulación tiene su origen en el intento de impedir la usura, pero consecuencia probable es marginar del mercado a las pyme cuyo costo de intermediación sea mayor, aunque existan bancos que estén interesadas en financiarlas. Este efecto se ve reforzado por la nueva Ley de Cobranza Extrajudicial que limitó los cobros por cobranza de créditos impagos. Creemos que ni la tasa máxima convencional ni los topes a las cobranzas se justifican y que sería conveniente eliminarlos.

Título ejecutivo de facturas. Creemos necesario estudiar la posibilidad de otorgar a las facturas la categoría de título ejecutivo. Es posible que esto mejore el acceso al financiamiento porque probablemente reforzaría el desarrollo de la industria del factoring y, además, permitiría el uso de las facturas como garantía crediticia, lo que incrementaría la base de garantías de las pyme.

Impuestos a las utilidades retenidas y el financiamiento de las pyme. La selección adversa y el daño moral implican que gran parte del financiamiento de las pyme debería provenir del patrimonio personal de los socios y de las utilidades retenidas por la empresa. Éste es un patrón que se observa no sólo en Chile sino que también en los países desarrollados. Por tanto, los mismos problemas implican que sería sano que los bancos les exijan garantías a las empresas. Por eso, las utilidades retenidas también son importantes porque permiten que la empresa tenga más garantías. Por estas razones, estimamos que sería conveniente estudiar la posibilidad de que las pyme tributen sólo por las utilidades que reparten y no por las que retienen. Estamos conscientes de que esta medida podría facilitar la evasión y elusión de impuestos, 
pero, por otro lado, es muy probable que disminuya el costo de financiamiento de las pyme y por ello debería considerarse seriamente.

El rol de las asociaciones gremiales. Las asociaciones gremiales presentan varias ventajas que las tornan potencialmente eficientes para coordinar actividades que beneficien a un grupo de empresas. Identificar las oportunidades de asociación que sean económicamente valiosas requiere conocer los problemas de la industria y que son comunes a un grupo de empresas. Obviamente, los miembros de la industria son quienes los conocen mejor, por lo que las asociaciones gremiales tienen ventajas a la hora de identificar programas asociativos. Asimismo, es menos probable que los programas conjuntos sean deficientes cuando los promueve una asociación gremial. A los directivos de la asociación gremial les va bien si entregan servicios valiosos a sus asociados, es decir se benefician si crean valor entre sus asociados. Por lo tanto, tienen incentivos para identificar programas valiosos y contratar los prestadores de servicios calificados. Creemos que existe margen amplio para que las asociaciones gremiales se desarrollen como prestadoras de servicios a sus asociados.

Desburocratización y regulación innecesaria. Finalmente, proponemos que se haga un esfuerzo serio y persistente por desburocratizar estudiando detalladamente los procesos para simplificarlos. Esto se ha repetido muchas veces, pero la evidencia que se presenta en este trabajo indica que el costo impuesto por las regulaciones y trámites innecesarios es muy alto porque encarece el proceso de ensayo y error que es fundamental para el crecimiento y, por ser costos mayoritariamente fijos, perjudican en particular a las empresas más pequeñas. Como se vio, la evidencia internacional indica que Chile tiene un margen amplio para mejorar. Gran parte de este esfuerzo debe consistir en eliminar trámites inútiles, regulaciones redundantes o dañinas; el resto en simplificar los que queden.

\section{LA ECONOMÍA BÁSICA DE LAS PYME}

La categoría "pyme" agrupa y esconde gran diversidad y heterogeneidad. Para comenzar, su importancia relativa difiere entre sectores (véase el Cuadro $\mathrm{N}^{\circ}$ 2). Además, dentro de un sector determinado 
CUADRO N ${ }^{\circ}$ 2: $\quad$ DISTRIBUCIÓN DE TAMAÑOS DE EMPRESAS MANUFACTURERAS POR SUBSECTOR

(1997, en \%)

CIIU Glosa

Tamaño de planta

Micro Pequeña Mediana Grande

3140 Industria del tabaco

3530 Refinería de petróleo

3845 Fabricación de aeronaves

3133 Elaboración de bebidas malteadas

3115 Fabricación de aceites y grasas

3118 Fabricación y refinería de azúcar

3721 Industria básica del cobre

3692 Fabricación de cemento y cal

3513 Fabricación de resinas sintéticas

3132 Industria vitivinícola

3116 Productos de molinería

3121 Elaboración de productos alimenticios

3112 Fabricación de productos lácteos

3114 Elaboración de pescados y otros productos marinos

3523 Fabricación de jabón, productos de limpieza y tocador

3113 Envasado y conservado de frutas y legumbres

3131 Destilación y mezclas de bebidas alcohólicas

3560 Fabricación de productos plásticos

3211 Hilados, tejidos y acabados de textiles

3311 Aserraderos y barracas

3420 Imprentas y editoriales

3691 Fabricación de productos de arcilla para la construcción

3240 Fabricación de calzados de cuero

3214 Fabricación de tapices y alfombras

3233 Fabricación de productos de cuero (excepto calzado)

3117 Fabricación de productos de panadería

Min

$\begin{array}{rrrr} & & & \\ - & - & - & 100,0 \\ - & - & - & 100,0 \\ - & - & - & 100,0 \\ - & 11,1 & - & 88,9 \\ - & 8,2 & 8,2 & 83,7 \\ - & - & 16,7 & 83,3 \\ 17,4 & - & 4,4 & 78,3 \\ 8,3 & 8,3 & 8,3 & 75,0 \\ - & 28,6 & - & 71,4 \\ 6,1 & 16,3 & 18,4 & 59,2 \\ 2,3 & 20,5 & 20,5 & 56,8 \\ 3,6 & 25,5 & 20,0 & 50,9 \\ - & 31,2 & 21,3 & 47,5 \\ 9,3 & 19,9 & 25,8 & 45,0 \\ 10,3 & 28,2 & 18,0 & 43,6 \\ 3,0 & 19,0 & 36,0 & 42,0 \\ - & 58,3 & - & 41,7 \\ 0,4 & 35,2 & 37,8 & 26,6 \\ 6,0 & 31,6 & 40,6 & 21,8 \\ 5,6 & 44,7 & 28,3 & 21,4 \\ 3,7 & 51,4 & 28,5 & 16,4 \\ - & 47,4 & 36,8 & 15,8 \\ 2,7 & 61,6 & 21,9 & 13,9 \\ 12,5 & 37,5 & 43,8 & 6,3 \\ - & 61,1 & 33,3 & 5,6 \\ 2,3 & 87,6 & 7,8 & 2,3\end{array}$

Notas: (1) La clasificación por tamaño es la siguiente: microempresa es una planta con ventas anuales de hasta UF 2.400; la pequeña vende entre UF 2.401 y UF 25.000 al año; la mediana vende entre UF 25.001 y UF 100.000 al año, y la grande vende anualmente sobre las UF 100.000. (2) Las microempresas están subrepresentadas en la muestra porque el INE sólo encuesta plantas de diez o más trabajadores.

Fuente: Elaborado a partir de la ENIA de 1997.

suelen coexistir empresas de tamaños distintos produciendo bienes parecidos. Por último, en todo momento se observan diferencias apreciables de productividad entre empresas del mismo sector y, simultáneamente, tasas elevadas de entrada y salida de empresas.

Esta sección tiene dos objetivos. En la primera parte mostramos que la diversidad de tamaños de empresas entre sectores distintos y dentro de cada sector tiene causas económicas simples pero a la vez 
fundamentales. En la segunda parte resumimos las principales regularidades de la dinámica industrial. Una serie de estudios empíricos hechos en varios países, entre ellos Chile, muestra que la entrada y salida de empresas es inherente a la forma como opera el sistema económico y que lo normal es que siempre coexistan empresas más productivas con otras que lo son menos. El hecho fundamental es que la mayoría de las empresas fracasan y salen a poco andar.

\section{1. ¿Por qué y cuándo existen pyme?}

Una mirada rápida a los datos basta para concluir que en algunos sectores la gran mayoría de las empresas son grandes, mientras que en otros predominan las pyme. Por ejemplo, el $84 \%$ de las plantas que fabrican aceite y grasas vegetales son empresas grandes, y la proporción es similar en las bebidas malteadas (89\%), la refinación de azúcar (83\%), la fabricación de resinas sintéticas (71\%), la industria básica del cobre $(78 \%)$ o la fabricación de cemento y yeso $(75 \%)^{6}$. En otros sectores, por el contrario, la mayoría de las empresas son pyme. Por ejemplo, el 89\% de las plantas que elaboran productos de panadería son pequeñas o medianas. Algo similar ocurre con el calzado de cuero (84\%), los aserraderos y barracas (73\%), las imprentas (80\%), los productos de caucho (82\%), el plástico (73\%) o los productos de arcilla (84\%). Y, en el otro extremo, gran parte de los taxis o los quioscos de revistas son explotados por sus dueños y tienen volúmenes de venta tan bajos que califican, apropiadamente, como "microempresas” (ver el Recuadro $\mathrm{N}^{\circ}$ 2). ¿Por qué existen muchas pyme que son panaderías o imprentas pero muy pocas que refinen azúcar o produzcan cemento?

Para responder esta pregunta mostraremos que hay un par de características económicas fundamentales que determinan cuándo las empresas pequeñas o medianas son económicamente viables. Partiremos discutiendo la condición necesaria para que existan pyme: para desarrollar la actividad debe no ser necesario incurrir en costos fijos de gran magnitud. Sin embargo, una vez cumplida esta condición, mostraremos que las condiciones de demanda también son importantes: las pyme sobreviven e incluso conviven exitosamente con empresas gran-

${ }^{6}$ Los datos provienen de la Encuesta Nacional Industrial Anual (ENIA) que realiza el INE. La agregación sectorial es a cuatro dígitos CIIU. 
des cuando los consumidores valoran la diversidad de productos. Por el contrario, las pyme son inviables cuando la demanda por un producto responde a la publicidad o esfuerzos de venta masivos. Por último, estudiaremos bajo qué condiciones se dan relaciones más permanentes entre empresas grandes y pyme.

\section{La explicación fundamental: escala, indivisibilidades y costos fijos.} La economía da una explicación engañosamente simple a la pregunta de por qué existen las pyme. En breve, para que en un sector determinado predominen las pyme se deben cumplir dos condiciones necesarias ${ }^{7}$. Primero, la inversión necesaria para poner en marcha una planta u operación -lo que también se conoce por "tamaño de operación eficiente" - no debe ser muy grande, pero tampoco muy pequeña; si existen indivisibilidades o costos fijos o hundidos importantes, las pyme no son económicamente viables ${ }^{8}$. Segundo, el producto no debe requerir esfuerzos de venta o publicidad masivos.

De esta forma, las pyme casi no producen cemento ni refinan petróleo porque la tecnología necesaria para hacerlo requiere una escala de operación demasiado grande y por lo tanto una empresa pequeña o mediana simplemente no es económicamente viable. Similarmente, no se observan pyme produciendo cigarrillos ni máquinas de afeitar (ni siquiera en mercados enormes como los Estados Unidos), porque estos productos requieren publicidad masiva. En el otro extremo, la mayoría de los taxistas o dueños de quioscos son microempresarios, porque la inversión necesaria es muy pequeña —es decir, la inversión es muy divisible - En cambio, en aquellos sectores donde la participación de las pyme es importante (v.g. panaderías, fábricas de plástico, curtiembres o barracas), dichas indivisibilidades, si bien existen, ocurren a escalas de producción pequeñas. Los distintos niveles de ventas por categoría (ver el Recuadro $\mathrm{N}^{\mathrm{o}} 1$ ) sugieren que las diferencias de escala entre empresas son apreciables. El año 2000 una microempresa vendió

${ }^{7}$ Tanto la teoría como la evidencia han sido desarrolladas y sintetizadas por Sutton (1991). Para un análisis de los determinantes de la existencia de pyme en el sector industrial chileno véase Álvarez y Crespi (2001).

${ }^{8}$ Un costo es fijo cuando no depende del número de unidades producidas, el número de transacciones ejecutadas, etc. Los costos fijos aumentan la escala necesaria para ser económicamente viable. "Indivisibilidad" es un término técnico que indica que la capacidad de producción no se puede fraccionar. Por lo tanto, cuando cae la producción la empresa está obligada a mantener capacidad ociosa. 


\section{RECUADRO No 1: ¿QUIÉNES SON LAS PYME?}

Las definiciones de empresa pequeña y mediana utilizadas normalmente son ad hoc, y se basan ya sea en las ventas anuales o bien en el número de empleados. El problema de estas métricas es su escaso significado económico. El que una empresa venda más o menos, o que contrate un número mayor o menor de trabajadores, no dice mucho sobre cuáles son las características inherentes a este tipo de empresas que las hacen escencialmente distintas. Sin embargo, estos criterios tradicionales sirven para tener una idea de cuán importantes son las pyme en el concierto empresarial.

El Ministerio de Economía clasifica las empresas de acuerdo al nivel de ventas. Considera que las empresas con ventas anuales de hasta UF 2.400 (aproximadamente \$ 3,2 millones mensuales) son microempresas. La empresas pequeñas son las que venden entre UF 2.400 y UF 25.000 al año (entre \$ 3,2 millones y \$33,3 millones mensuales). Las empresas medianas venden más de UF 25.000 al año pero menos que UF 100.000 (ventas mensuales entre \$33,3 millones y \$133,3 millones). Las empresas con ventas superiores a este monto son consideradas grandes.

Los datos del SII muestran que en el año 2000 existían 648.491 empresas, y de ellas 107.087 eran pyme. Así, las pyme eran el 16,51\% del total de empresas del país. Gran parte de ellas eran empresas pequeñas $(14,48 \%)$ y una proporción menor, medianas (2,03\%). Si bien las pyme no son el grupo de empresas más numeroso (las microempresas representan un poco más del $82 \%$ del total), tienen una participación importante en las ventas totales. Sus ventas representaron el 20,2\% del total, con una participación igualitaria de las empresas pequeñas y medianas. Quizás el rasgo más distintivo de las pyme es su importancia en el empleo agregado. Los datos de Corfo muestran que en 1997 cerca del $48 \%$ de la fuerza laboral trabajaba en las pyme. Estos datos son muy similares a los que se desprenden de la encuesta Casen del año 1996 (ver Cuadro No 1).

UF 456 en promedio, mucho menos que las UF 7.161 que vendía una pequeña empresa, las UF 51.096 que vendía una empresa mediana, o las UF 836.395 de una gran empresa.

Hecho 1. Las pyme pueden existir cuando el tamaño eficiente de operación y sus costos fijos asociados no son considerables.

¿Cuáles son las principales fuentes de costos fijos que determinan si una empresa pequeña o mediana es económicamente viable? 
RECUADRO No 2: LAS PYME EN DISTINTOS SECTORES MANUFACTUREROS

Dependiendo del subsector, en el sector manufacturero se observan patrones muy disímiles en cuanto a la importancia de las empresas pequeñas y medianas. Los datos de la ENIA de 1997 muestran que en un grupo de subsectores existe un número muy limitado de pyme y la gran mayoría, si no la totalidad, son grandes empresas (ver Cuadro $\mathrm{N}^{\mathrm{o}}$ 2). Entre estos subsectores destaca la industria del tabaco, la refinación de petróleo, la fabricación de aeronaves, la elaboración de bebidas malteadas, la fabricación de aceites y grasas vegetales, la refinación de azúcar, la industria básica del cobre, la fabricación de resinas sintéticas y la fabricación de cemento y cal. La característica común de estos subsectores es que la indivisibilidad de la tecnología impone que el tamaño de operación eficiente sea suficientemente grande para que en general no existan pymes.

Hay, sin embargo, otro subconjunto de actividades industriales en las que prevalecen las pyme. Son los subsectores en que destacan: las panaderías, las fábricas de artículos de cuero, las fábricas de calzados, los aserraderos y barracas, las imprentas, la fabricación de artículos de plástico, la fabricación de productos de arcilla para la construcción y la fabricación de tapices y alfombras. A diferencia de las otras actividades, en estos subsectores no se dan importantes indivisibilidades y por lo tanto las pyme son económicamente viables. Más aún, en muchas de estas actividades no sólo el tamaño de operación eficiente es pequeño sino que también se da la ventaja de que las empresas se instalen cercanas a donde se encuentran los consumidores. Por ejemplo, las personas valoran que la panadería esté cerca de su casa para comprar pan fresco.

Finalmente, también es posible distinguir un tercer grupo de subsectores manufactureros en los que coexisten empresas grandes y pyme. Algunos ejemplos son: la producción de lácteos, el envasado de frutas y legumbres, las fábricas de jabones y productos de limpieza, la elaboración de pescados y productos marinos, la elaboración de productos alimenticios, la industria vitivinícola, la destilación y mezcla de bebidas alcohólicas, la fabricación de textiles y los molinos. Un caracter distintivo de algunas de estas actividades es que suelen coexistir empresas que producen bienes en los que la calidad y la marca son importantes - y por lo tanto requieren escalas de producción elevadas para ser económicamente viables-, con un segmento de empresas cuyos productos están orientados a público que no valora la calidad y la marca, por lo que es posible operar sin una marca masivamente conocida. Un ejemplo son los helados. Las grandes empresas basadas en una estrategia de marca y alta calidad subsisten junto con productores pequeños que comercializan sus productos en segmentos del mercado que no están dispuestos a pagar por calidad ni por la marca. 
Para organizar la discusión que sigue resultará útil clasificar a los costos fijos en tres categorías. Primero, los directamente asociados con la producción (v.g. el costo de inversión de una planta para refinar petróleo, los hornos para producir pan) o la operación de la empresa (v.g. un vehículo de reparto o un sistema de manejo centralizado de inventarios para una cadena de farmacias). Segundo, los asociados a la administración y gestión de la empresa (v. g. un gerente, un contador, un sistema de control de gestión). Tercero, los gastos de publicidad y esfuerzo de ventas.

Más allá de las categorías que nosotros podamos sugerir, es importante notar que en todos los casos las pyme serán viables económicamente sólo si la suma de estos costos fijos no exige volúmenes de operación muy grandes para financiarlos. O, puesto de manera levemente distinta, en cualquier actividad, la viabilidad de las pyme depende de que los costos fijos necesarios para desarrollarla no sean muy grandes. Como veremos en la sección 3 , este principio engañosamente simple resulta extremadamente importante y útil para entender cuándo es razonable esperar que las pyme tengan éxito.

La demanda: diferenciación de productos y nichos. Ahora bien, existen mercados o industrias donde conviven las pyme y empresas grandes. Por ejemplo, el mercado de las bebidas gaseosas lo dominan productores grandes como Coca Cola o CCU, quienes gastan cantidades apreciables en publicidad y esfuerzo de venta; pero también existen productores pequeños que no hacen publicidad (p. ej. Rari Cola) o que producen las marcas de supermercado (p. ej. Ekono Cola). Algo similar ocurre con otros alimentos, tales como los helados (Panda vs. Savory), las galletas (Amor vs. Nestlé) o los vinos y también se observa en otras industrias. ¿Cómo es posible que coexistan empresas de tamaños tan disímiles produciendo bienes similares? Después de todo, el tipo de empresa que adopte el tamaño eficiente de operación debería sacar al resto del mercado.

Cuando se mira con más cuidado se descubre que las empresas de distinto tamaño producen bienes diferenciados vertical u horizontalmente y los venden a segmentos de mercado distintos ${ }^{9}$. Así, para que

${ }^{9}$ Se dice que dos variedades de un mismo producto se diferencian horizontalmente cuando distintos consumidores prefieren distintas variedades del producto. Por ejemplo, algunos consumidores prefieren la cerveza rubia a la negra, mientras que para 
coexistan pyme y empresas más grandes produciendo bienes similares deben darse dos condiciones. Por el lado de la producción, las indivisibilidades no deben ocurrir a escalas muy grandes cuando se trata de variedades producidas por pyme. Por el lado de la demanda, deben existir nichos de mercado que estén dispuestos a comprar esas variedades. Si así ocurre, las pyme no necesitan crecer para sobrevivir ${ }^{10}$.

¿Cuándo se segmenta la demanda en nichos distintos? Las razones son múltiples pero aquí discutiremos las tres principales: se demanda mayor calidad a medida que aumentan los ingresos; los consumidores valoran la variedad; la publicidad masiva diferencia a los productos.

La principal fuente de diferenciación vertical se debe a que los consumidores están dispuestos a pagar por mayor calidad a medida que aumentan sus ingresos. Dependiendo de las circunstancias o del tipo de bien de que se trate, la demanda por mayor calidad puede estimular o limitar el desarrollo de las pyme. Por ejemplo, muchos pequeños y medianos productores de alimentos envasados sobreviven hoy porque los consumidores de ingresos bajos, que son muchos, no están dispuestos a pagar por mejor calidad, garantía de higiene, conservación, marca, etc. En este caso, la escala de producción es pequeña y por eso existen muchos productores pequeños y medianos de bienes de baja calidad. Pero en otros casos el estímulo a las pyme viene de la demanda por mayor calidad. Por ejemplo, casi todos los restaurantes de buena calidad son pyme. El Recuadro $\mathrm{N}^{\circ} 3$ muestra cómo la diferenciación de productos permite que coexistan grandes empresas y pyme en la industria de las bebidas gaseosas.

En segundo lugar, los consumidores valoran la variedad porque sus gustos difieren. La diferenciación horizontal resultante puede estimular o limitar a las pyme. Ambos casos se aprecian, por ejemplo, en el mercado de la TV. Por un lado, la televisión por cable admite canales pequeños que apuntan a nichos también pequeños (v. g. cultura, televisión infantil, televisión de contenido universitario, noticias locales). Por el

otros la cerveza negra es la preferida. Se dice que dos variedades de un mismo producto se diferencian verticalmente cuando los consumidores coinciden en que una variedad es mejor que otra. Por ejemplo, un computador Pentium es verticalmente superior a un computador 286; si se vendieran al mismo precio, todos preferirían el computador Pentium. Para más detalles sobre diferenciación de productos, véase cualquier texto estándar de organización industrial, por ejemplo Tirole (1988), Carlton y Perloff (1990) o Church y Ware (2000).

${ }^{10}$ Ésta es la teoría de "nichos estratégicos” de Porter (1979) y Caves y Porter (1977). 


\section{RECUADRO No 3: DIFERENCIACIÓN DE PRODUCTOS EN EL MERCADO DE GASEOSAS}

La industria de las bebidas gaseosas es un claro caso en que la diferenciación de productos permite que coexistan pyme y empresas grandes. Durante los últimos años han entrado varias empresas medianas y pequeñas a producir sustitutos de las marcas y líneas tradicionales de gaseosas (las bebidas cola, ginger ale, naranja genéricas). Esto ha sido posible por dos motivos. Por el lado de la producción, las condiciones del mercado permiten que existan pyme porque el mercado internacional de concentrados (el insumo esencial para producir gaseosas) es muy competitivo y la inversión necesaria para montar una planta de bebidas envasadas en botellas plásticas no retornables de pete es alrededor de un millón de dólares (la producción de gaseosas consiste, básicamente, en mezclar concentrado con agua carbonada). Por el lado de la demanda están consumidores dispuestos a comprar bebidas genéricas si se venden con un descuento suficientemente grande. De esta forma, las pyme han entrado en el segmento de envases no retornables de dos litros.

Por el contrario, no se observan pyme produciendo bebidas en envases retornables (éstos requieren inversiones sustantivamente mayores en los envases, las plantas son mucho más grandes porque se necesita lavar los envases, se requieren camiones de reparto especiales, etc.) ni tampoco haciendo publicidad masiva. Así, el segmento de marcas sostenidas por publicidad masiva sigue siendo dominado por Coca Cola y CCU porque los consumidores valoran las marcas y lo que ellas implican (al menos la evidencia es que están dispuestos a pagar más por las bebidas de marca que por las genéricas).

otro, la proliferación de canales ha forzado a la televisión abierta a concentrarse en programas en vivo con escenografías llamativas que requieren estudios de gran tamaño y personajes de mucha figuración, lo que los hace muy costosos y que aumente con ello su escala mínima.

Hecho 2. En un mercado dado, las pyme pueden sobrevivir cuando producen variedades tales que el tamaño eficiente de operación para producirlas y venderlas no sea considerable.

La tercera fuente importante de diferenciación, que siempre va asociada a empresas grandes, es aquella que se logra con campañas 
publicitarias masivas. En algunos tipos de bienes o segmentos del mercado el esfuerzo de ventas o la publicidad masiva aumentan la demanda (v.g. los cigarrillos, la cerveza, las máquinas de afeitar). Sutton (1991) ha mostrado que los mercados de ese tipo de productos son naturalmente concentrados y admiten sólo a un número pequeño de firmas de gran tamaño. La razón, en términos simples, es que la competencia entre empresas las induce a escalar sus gastos de publicidad y esfuerzo de ventas, lo que genera un costo hundido de entrada a la industria que admite sólo un número limitado de empresas grandes.

Hecho 3. Las pyme no pueden existir en segmentos del mercado en que la publicidad o el esfuerzo de ventas masivas aumentan la demanda considerablemente.

Por supuesto, no siempre se valora la diversidad y diferenciación de productos y entonces los bienes tienden a ser estandarizados (v.g. el papel, los envases plásticos, los vidrios). Muchas veces, la estandarización permite aprovechar economías de escala y en esos casos la producción se concentrará en empresas grandes.

Hecho 4. Cuando los consumidores prefieren bienes estandarizados cuya producción eficiente ocurre a escalas de operación considerables se tenderá a observar menos pyme.

Pyme, grandes empresas y relaciones de largo plazo. Una encuesta realizada por Álvarez et al. (1999) encontró que una de las principales preocupaciones de las empresas pequeñas es conseguir contratos de venta de largo plazo. Más generalmente existe la percepción de que una relación permanente con una empresa grande favorece a una pyme más allá de reducirle la incertidumbre. Por ejemplo, en las entrevistas escuchamos repetidamente que estas pyme son empresas mejor gestionadas, más confiables o con menores riesgos bancarios ${ }^{11}$. ¿Será conveniente (y posible) “estimular” las relaciones con empresas grandes como medio para mejorar las pyme?

Tal como en los casos anteriores, es importante notar que las relaciones más permanentes entre empresas obedecen a determinantes económicos concretos y no son convenientes per se. En este caso,

${ }^{11} \mathrm{Al}$ respecto, véase también Foxley (1999). 
para entender cuándo una pyme establecerá una relación de largo plazo con una empresa grande es conveniente partir de la observación de que las empresas deciden constantemente cuáles actividades realizar internamente y cuáles externalizar. La externalización es ventajosa cuando simplifica la gestión y permite beneficiarse de la competencia entre proveedores - en general, es más difícil forzar a los propios empleados a controlar costos porque dentro de la empresa hay poca competencia y la supervisión es costosa-. Pero la externalización también tiene desventajas, porque disminuye el control de la empresa sobre la calidad del producto que compra y la confiabilidad del abastecimiento. Por eso, la gran ventaja de la producción interna es que se puede controlar mejor la calidad ${ }^{12}$.

Lo anterior implica que las empresas tenderán a externalizar cuando es fácil verificar la calidad de lo que se está comprando y a internalizar si controlar la calidad del proceso es muy importante para el resultado final. Así, en la práctica es posible observar una gama amplia de transacciones. En un extremo, cuando es muy fácil verificar la calidad de lo que se compra y existen muchos proveedores alternativos, se tenderá a ver que las empresas externalizan sin establecer relaciones permanentes. Es el caso, por ejemplo, de las compras de insumos tales como la papelería o de actividades como la construcción de un galpón. En el otro extremo, cuando es muy importante controlar la calidad del proceso, se tenderá a observar que la actividad se internaliza.

Un tipo particular de externalización es aquel en que las empresas establecen una relación más permanente. Muchas veces las relaciones de largo plazo surgen porque la externalización obliga a que las partes adapten sus procesos a las peculiaridades de la otra invirtiendo en activos específicos y, cuando hay inversiones específicas de por medio, las partes estarán dispuestas a invertir solamente si esperan que la relación sea de largo plazo ${ }^{13}$. En ocasiones se trata de activos físicos

12 Hay una amplia literatura que trata sobre la decisión de externalizar o producir internamente que parte con Coase (1937). Un resumen de esta literatura se encuentra en Besanko et al. (1996).

${ }^{13}$ Un activo es específico en una relación cuando su valor en su mejor actividad alternativa es apreciablemente menor. Por ejemplo, la inversión que hace un concesionario McDonald's en equipos y local es, en gran medida, específica a su relación con McDonald's. Si el concesionario pierde el contrato con McDonald's, el valor de sus inversiones es mucho menor. 
y tangibles. Por ejemplo, los transportistas contratados por D\&S para abastecer supermercados desde su centro de distribución deben invertir en camiones cuyas especificaciones técnicas son, en alguna medida, específicas a la operación de D\&S. En otros casos se invierte en activos intangibles que son necesarios para producir bienes de calidad apropiada, tales como mejoras de los procesos de producción o traspaso de know-how técnico. Por ejemplo, los agricultores que siembran remolacha para Iansa o aquellos que venden fruta a las grandes compañías exportadoras (v.g. Dole, Chiquita, Unifrutti, David del Curto) deben adaptar sus procesos para poder entregar productos de calidad apropiada.

La segunda explicación de las relaciones de largo plazo es que en todo momento conviven en el mercado empresas de calidad diversa. A las empresas les gustaría tratar con proveedores y distribuidores "buenos" (es decir, los honestos, diligentes y capaces), pero en el mercado también hay "malos" (los deshonestos, flojos e incapaces) y es difícil saber a priori quién es quién ${ }^{14}$. Separar a los proveedores o distribuidores confiables de quienes no lo son toma tiempo (en realidad, también es una inversión) y una vez que se descubre a un buen proveedor se tiende a seguir con él, aun si no es necesario hacer inversiones específicas para establecer la relación.

La discusión anterior plantea bajo qué condiciones se observarán relaciones de largo plazo entre empresas grandes y pyme:

Hecho 5. Las relaciones de largo plazo entre las pyme y empresas grandes tenderán a observarse cuando (a) la calidad de lo que produce la pyme es suficientemente fácil de evaluar; (b) el tamaño eficiente de operación para realizar la actividad externalizada es pequeño; (c) se requieren algunas inversiones específicas de la relación para realizar la actividad externalizada; (d) es difícil distinguir a priori a las buenas de las malas empresas.

Resulta fácil apreciar ahora por qué tienden a ser “mejores” las pyme que tienen relaciones de largo plazo con empresas grandes. En parte se debe a que las obligan a invertir en activos específicos, ya sean

${ }^{14} \mathrm{El}$ lector ya se debe haber dado cuenta de que éste es exactamente el problema de quienes le prestan servicios a una empresa — separar a los buenos riesgos de los malos riesgos-. Volveremos sobre esto cuando discutamos sobre las pyme y financiamiento. 
tangibles o intangibles, y estas inversiones de por sí ya mejoran a la pyme. Pero también se da un sesgo de selección: las pyme que establecen relaciones de largo plazo son, precisamente, las más confiables, capaces y diligentes.

En resumen. El punto central de esta subsección es que el tamaño de las empresas es el resultado de condiciones económicas concretas que se pueden observar y distinguir en la práctica. No es sorprendente que exista mucha diversidad entre pequeñas y medianas empresas porque estas condiciones económicas concretas varían mucho entre sectores.

Las categorías que desarrollamos en esta sección permiten identificar cuándo son económicamente viables las pyme. La condición sine qua non para que existan pequeñas y medianas empresas es que no haya indivisibilidades o costos fijos importantes. Si estas indivisibilidades son poco relevantes se tenderán a observar microempresas - - v.g. los quioscos o los taxis-. Por el contrario, si son importantes, sólo habrá empresas grandes — - v. g. las refinerías o la producción de cemento- Entre estos dos extremos hay espacio para las pyme.

Una vez satisfecha la condición anterior, se observarán pyme si existen nichos de mercado que demanden la combinación precio-calidad que empresas pequeñas o medianas pueden ofrecer. Es perfectamente posible que en un mismo mercado sobrevivan pyme y empresas grandes, siempre y cuando los consumidores valoren la diversidad horizontal o vertical de productos similares.

Finalmente, las empresas grandes establecerán relaciones de largo plazo con las pyme cuando encuentren conveniente externalizar actividades o bien un proveedor o distribuidor resulte confiable, diligente y capaz.

\subsection{Nacimiento, desarrollo y muerte de empresas: la dinámica de las pyme}

Es frecuente escuchar que las pyme son muy vulnerables, en el sentido de que tienden a fracasar "demasiado" y que, por lo tanto, se requieren programas de fomento para apoyarlas. Sin embargo, como veremos a continuación, la "vulnerabilidad" es una característica de casi todas las empresas. En todas las economías del mundo, desarrolla- 
das o no, todo el tiempo se crean nuevas empresas, unas pocas crecen hasta transformarse en grandes y muchas también mueren.

Dinámica industrial: la evidencia internacional. El primer hecho que se desprende de la evidencia internacional es el siguiente:

Hecho 6. En prácticamente todas las industrias y todo el tiempo muchas empresas se crean, unas pocas son exitosas y muchas fracasan $y$ salen.

Esta regularidad ha sido establecida en numerosos estudios efectuados para distintos países ${ }^{15}$. Para formarse una idea de los órdenes de magnitud envueltos, el Cuadro $\mathrm{N}^{\circ}$ 3, tomado de Audretsch (1995b), muestra la tasa de sobrevivencia por sector industrial de 11.152 firmas industriales creadas en 1976 en los Estados Unidos. Diez años después de haber sido creadas, apenas el 35,4\% de las firmas seguía existiendo. $\mathrm{Y}$ a pesar de que hay bastante variabilidad entre sectores, en todos ellos la tasa de sobrevivencia es menor que $46 \%$ y puede llegar a ser tan baja como 23,1\% (en el sector de equipo de transporte).

Similarmente, también en los Estados Unidos, pero esta vez entre 1963 y 1982, Geroski (1995) reporta que el 61,5\% de las empresas que entraron habían muerto al cabo de cinco años, y el 79,6\% había salido al cabo de diez años. En Canadá, el 59,8\% de las firmas que había entrado en 1971 había muerto en 1982. Por su parte, la Small Business Administration de los Estados Unidos estima que alrededor del 24\% de las empresas pequeñas muere al cabo de dos años y el $53 \%$ al cabo de cuatro años por fracaso, quiebra, jubilación del dueño o cambio de actividad ${ }^{16}$.

Un cuadro similar surge cuando se examinan las tasas de creación y destrucción de empleos en distintos países. El Cuadro $\mathrm{N}^{\circ} 4$ indica que, por ejemplo, en Canadá cada año se crearon empleos equivalentes al 10,9\% del total de empleos existentes en manufactura, y se destruyeron $11,1 \%$ del total de empleos ${ }^{17}$. Como se aprecia en el

${ }^{15}$ Para resúmenes de la literatura véanse Audretsch (1995a), Geroski (1991, 1995), Geroski y Schwalbach (1991) y Sutton (1997).

16 Véase U. S. Small Business Administration (1995, Tabla A.14, p. 243). La Small Business Administration clasifica como "pequeña” a una firma con menos de 500 empleados.

${ }^{17}$ Se crea un empleo cuando el número de trabajadores en una planta o empresa aumenta; se destruye cuando ocurre lo contrario. 
CUADRO No 3: $\quad$ SOBREVIVENCIA DE EMPRESAS QUE ENTRARON EN 1976 (Estados Unidos)

\begin{tabular}{|c|c|c|c|c|}
\hline Sector & $\begin{array}{c}\text { (1) } \\
\text { Número } \\
\text { que entra } \\
(1976)\end{array}$ & $\begin{array}{c}(2) \\
\text { Tasa de } \\
\text { entrada (\%) } \\
1976\end{array}$ & $\begin{array}{l}\text { (3) } \\
\text { Número que } \\
\text { sobrevive } \\
\text { (1986) }\end{array}$ & $\begin{array}{c}\text { (4) } \\
\text { Tasa de } \\
\text { sobrevivencia } \\
(3) /(1)\end{array}$ \\
\hline Alimenticio & 474 & 2,5 & 144 & 30,4 \\
\hline Textil & 308 & 3,9 & 84 & 27,3 \\
\hline Prendas de vestir & 864 & 3,8 & 236 & 27,3 \\
\hline Madera aserrada & 794 & 3,7 & 256 & 32,2 \\
\hline Muebles & 531 & 3,7 & 141 & 26,6 \\
\hline Papel & 126 & 3,0 & 57 & 45,2 \\
\hline Imprentas & 805 & 2,9 & 768 & 95,4 \\
\hline Químicos & 322 & 3,0 & 114 & 35,4 \\
\hline Petróleo & 41 & 3,2 & 11 & 26,8 \\
\hline Caucho & 430 & 4,7 & 176 & 40,9 \\
\hline Industria del cuero & 124 & 3,0 & 30 & 24,2 \\
\hline Piedra, arcilla y vidrio & 545 & 3,9 & 182 & 33,4 \\
\hline Metales básicos & 168 & 3,0 & 72 & 42,9 \\
\hline Productos de metal & 962 & 3,2 & 394 & 41,0 \\
\hline Maquinaria no eléctrica & 1.519 & 3,1 & 675 & 44,4 \\
\hline Equipos eléctricos & 635 & 4,4 & 196 & 30,9 \\
\hline Equipos de transporte & 420 & 4,0 & 97 & 23,1 \\
\hline Instrumentos & 312 & 3,9 & 120 & 38,5 \\
\hline Otros & 772 & 3,6 & 185 & 24,0 \\
\hline Total & 10.152 & 3,6 & 3.938 & 35,4 \\
\hline
\end{tabular}

Nota: La tasa de entrada se define como el porcentaje de empresas contabilizadas como nuevas firmas. La tasa de sobrevivencia se define como el porcentaje de firmas que entró en 1976 y todavía continuaba activo en 1986.

Fuente: Audretsch (1995b, Cuadro No 1).

cuadro, estas tasas de creación y destrucción de empleos son similares entre países, independientemente de su nivel de desarrollo.

¿Qué interpretación cabe darle al hecho 6? Como lo indica Audretsch (1995a), la evidencia sugiere que la entrada y salida frecuentes de firmas forma parte del proceso de selección de las empresas más eficientes. Para comenzar, en industrias donde nacen muchas empresas la tasa de muerte y salida también es mayor: los entrantes exitosos tienden a reemplazar a firmas más viejas. Por ejemplo, de acuerdo a Geroski (1995), entre 1974 y 1979 se crearon 50 firmas en promedio en el Reino Unido en cada industria definida con tres dígitos, 
CUADRO No 4: $\quad$ CREACIÓN Y DESTRUCCIÓN ANUAL DE EMPLEO

\begin{tabular}{|c|c|c|c|c|c|}
\hline País & $\begin{array}{c}\text { (1) } \\
\text { Período }\end{array}$ & $\begin{array}{c}(2) \\
\text { Cobertura }\end{array}$ & $\begin{array}{c}\text { (3) } \\
\text { Unidad } \\
\text { empleadora }\end{array}$ & $\begin{array}{c}(4) \\
\text { Creación } \\
\text { de empleos } \\
(\%)\end{array}$ & $\begin{array}{c}\text { (5) } \\
\text { Destrucción } \\
\text { de empleos } \\
\text { (\%) }\end{array}$ \\
\hline
\end{tabular}

Países de ingreso alto

$\begin{array}{llllrr}\text { Canadá } & 1974-92 & \text { Manufactura } & \text { Planta } & 10,9 & 11,1 \\ \text { Canadá } & 1983-91 & \text { Todos los trabajadores } & \text { Firma } & 14,5 & 11,9 \\ \text { Dinamarca } & 1981-91 & \text { Manufactura } & \text { Planta } & 12,0 & 11,5 \\ \text { Dinamarca } & 1983-89 & \text { Sector privado } & \text { Planta } & 16,0 & 13,8 \\ \text { Finlandia } & 1986-91 & \text { Todos los trabajadores } & \text { Planta } & 10,4 & 12,0 \\ \text { Francia } & 1985-91 & \text { Manufactura } & \text { Firma } & 10,2 & 11,0 \\ \text { Francia } & 1984-92 & \text { Sector privado } & \text { Planta } & 13,9 & 13,2 \\ \text { Alemania } & 1983-90 & \text { Todos los trabajadores } & \text { Planta } & 9,0 & 7,5 \\ \text { Italia } & 1984-93 & \text { Sector privado } & \text { Firma } & 11,9 & 11,1 \\ \text { Países Bajos } & 1979-93 & \text { Manufactura } & \text { Firma } & 7,3 & 8,3 \\ \text { Nueva Zelanda } & 1987-92 & \text { Sector privado } & \text { Planta } & 15,7 & 19,8 \\ \text { Noruega } & 1976-86 & \text { Manufactura } & \text { Planta } & 7,1 & 8,4 \\ \text { Suecia } & 1985-92 & \text { Todos los trabajadores } & \text { Planta } & 14,5 & 14,6 \\ \text { Reino Unido } & 1985-91 & \text { Todos los trabajadores } & \text { Firma } & 8,7 & 6,6 \\ \text { Estados Unidos } & 1973-93 & \text { Manufactura } & \text { Planta } & 8,8 & 10,2 \\ \text { Estados Unidos } & 1979-83 & \text { Manufactura } & \text { Planta } & 10,2 & 11,5 \\ \text { Estados Unidos } & 1979-83 & \text { Sector privado } & \text { Planta } & 11,4 & 9,9\end{array}$

Países con ingreso medio y bajo

$\begin{array}{llllrl}\text { Chile } & \mathbf{1 9 8 1 - 9 2} & \text { Manufactura } & \text { Planta } & \mathbf{1 6 , 7} & \mathbf{1 3 , 6} \\ \text { Colombia } & 1977-91 & \text { Manufactura } & \text { Planta } & 12,5 & 12,2 \\ \text { Estonia } & 1992-94 & \text { Todos los trabajadores } & \text { Firma } & 9,7 & 12,9 \\ \text { Marruecos } & 1984-89 & \text { Manufactura } & \text { Firma } & 18,6 & 12,1\end{array}$

Nota: La creación de trabajo es el número de empleos nuevos como porcentaje del número total de empleos existentes. La destrucción de trabajo es el número de empleos que se acaban como porcentaje del número total de empleos existentes. Por ejemplo, en Chile entre 1981 y 1992 cada año se crearon empleos equivalentes al 16,7\% del total de empleos y se destruyeron empleos equivalentes al 13,6\% de todos los existentes.

Fuente: Caballero y Hammour (2001, Cuadro No 1); para Chile la fuente es Camhi et al. (1997, Cuadro $\mathrm{N}^{\circ}$ 1).

pero salieron 38. La tasa neta de creación de empresas fue apenas algo mayor que el 1\%. Similarmente, Baldwin y Gorecki (1991) encuentran a similar nivel de agregación que durante la década de los setenta la tasa de entrada de nuevas firmas en Canadá fue, en promedio, de $5 \%$. Sin embargo, la tasa de salida fue $6,5 \%$, lo que da una tasa neta de entrada de $-1,5 \%$ en promedio — salen más firmas que las que entran- 
Hecho 7. En industrias donde nacen muchas empresas la tasa de muerte y salida también es mayor.

En segundo lugar, las empresas tienden a entrar y operan a escala considerablemente más pequeña que la de empresas ya establecidas, independientemente del sector del que se trate. Por ejemplo, Audretsch (1995b) reporta que las poco más de 11.000 empresas industriales que entraron en 1976 en los Estados Unidos empleaban 7,63 trabajadores en promedio, con varianza pequeña que no difiere dramáticamente entre sectores. En vista de que el tamaño eficiente de operación difiere entre sectores, esto sugiere que muchas firmas operan a escala ineficientemente pequeña. Así, no es sorprendente que tanto en Chile como en otros países se observe que las empresas pequeñas en una determinada industria tienden a ser también más ineficientes ${ }^{18}$. Podría pensarse que esto obedece a que los entrantes deben comenzar pequeños porque no tienen acceso a crédito para hacerlo a escalas eficientes. Sin embargo, Geroski (1995, p. 426) indica que la performance de empresas que entran grandes tiende a ser peor que la de empresas ya establecidas. Vale decir, ya que se va a experimentar, parece más conveniente hacerlo a escalas pequeñas. Es algo más sorprendente que el tamaño al que se experimente tenga poco que ver con el tamaño eficiente de operación de la industria.

Hecho 8. La entrada de nuevas empresas tiende a ser en escalas ineficientemente pequeñas que no difiere mucho entre industrias. Sin embargo, eso no significa que sea conveniente entrar grande.

¿Cómo es posible que sobrevivan firmas que operan a escala ineficiente? En gran medida, no lo hacen. Si bien estas firmas tienden a pagarles menos a sus factores productivos ${ }^{19}$, la evidencia indica que existe una relación estable entre sobrevivencia y crecimiento de las firmas por un lado, y su tamaño y edad por el otro. Así, la probabilidad de que una firma sobreviva crece con su tamaño y edad ${ }^{20}$. Vale decir,

\footnotetext{
${ }^{18}$ Para evidencia sobre Chile, véase Álvarez et al. (1999). Para evidencia sobre Estados Unidos y Japón véase Audretsch (1995a, cap. 6.3).

${ }^{19}$ Véase Audretsch (1995a, cap. 6).

${ }^{20}$ Véase, por ejemplo, Audretsch (1991), Audretsch y Mahmood (1995) y Hall (1987). Evidencia para Portugal ha sido proporcionada por Mata (1994), Mata y Portugal (1994) y Mata, Portugal y Guimaraes (1995). Para Canadá véase Baldwin (1995), Baldwin y Gorecki (1991) y Baldwin y Rafiquzzaman (1995). Para Alemania véase Wagner (1994).
} 
llevado al contexto chileno, es razonable esperar que las pyme fracasen más. Sin embargo, la tasa de crecimiento de las empresas que sobreviven es menor mientras mayor es su tamaño; una empresa pequeña que consigue sobrevivir tiende a crecer más rápido que las empresas más grandes $^{21}$. Y, para cualquier tamaño dado, la tasa de crecimiento proporcional de la firma cae con su edad, pero la probabilidad de sobrevivir aumenta.

Hecho 9. Las firmas más grandes y de más edad sobreviven más. Sin embargo, las firmas pequeñas que sobreviven crecen más rápido.

Los hechos anteriores tienen implicancias interesantes. Primero, si la mayoría de las empresas comienza muy pequeña sin que existan grandes diferencias entre sectores y, a la vez, la escala de operación eficiente difiere fuertemente entre sectores, uno debería esperar grandes tasas de fracaso en sectores con grandes indivisibilidades. En estos sectores, gran parte de las empresas que salen y mueren deberían ser entrantes que operan a escala pequeña y que no fueron capaces de crecer. Segundo, en estos sectores las pocas empresas que entran y sobreviven deberían crecer muy rápidamente. Tercero, en sectores sin indivisibilidades mayores, las empresas nuevas deberían fracasar menos y un mayor porcentaje de las muertes debería ser de empresas establecidas. De hecho, Audretsch (1995a, cap. 7) encuentra precisamente eso. Grosso modo, las empresas jóvenes representan una fracción mayor de las muertes en aquellas industrias donde la escala eficiente de operación es considerable.

Los hechos anteriores indican que en todo momento muchas empresas se están creando, pero que muchas también están muriendo y que este proceso de entrada y salida es mucho más intenso entre las empresas más pequeñas comparado con el de las más grandes. Como veremos a continuación, la evidencia disponible para Chile confirma estas regularidades.

Dinámica industrial: la evidencia chilena. La ENIA permite comparar la dinámica de las plantas industriales chilenas con los patrones

${ }^{21}$ Véanse Dune, Roberts y Samuelson (1988 y 1989a, b y c) y Evans (1987a y b). 
internacionales que hemos descrito ${ }^{22}$. La Figura $\mathrm{N}^{\mathrm{o}} 1$ muestra la tasa de promedio de sobrevivencia de plantas industriales entre 1980 y 1997. En promedio, el 18\% de las plantas creadas en un año dado sale al cabo de un año de vida. Vale decir, de acuerdo con estos números la probabilidad de que una planta creada en 2001 siga al final de 2002 es de 0,82 . Cinco años después de nacer, la tasa de mortalidad es de $42 \%$ y al cabo de diez años la tasa de mortalidad es de $56 \%$ (vale decir, en promedio, sólo el $44 \%$ de las plantas vive diez o más años) $)^{23}$.

FIGURA N $N^{\circ}$ 1: SOBREVIDA DE LAS PLANTAS MANUFACTURERAS CHILENAS

(Pymes y grandes, 1980-1999)

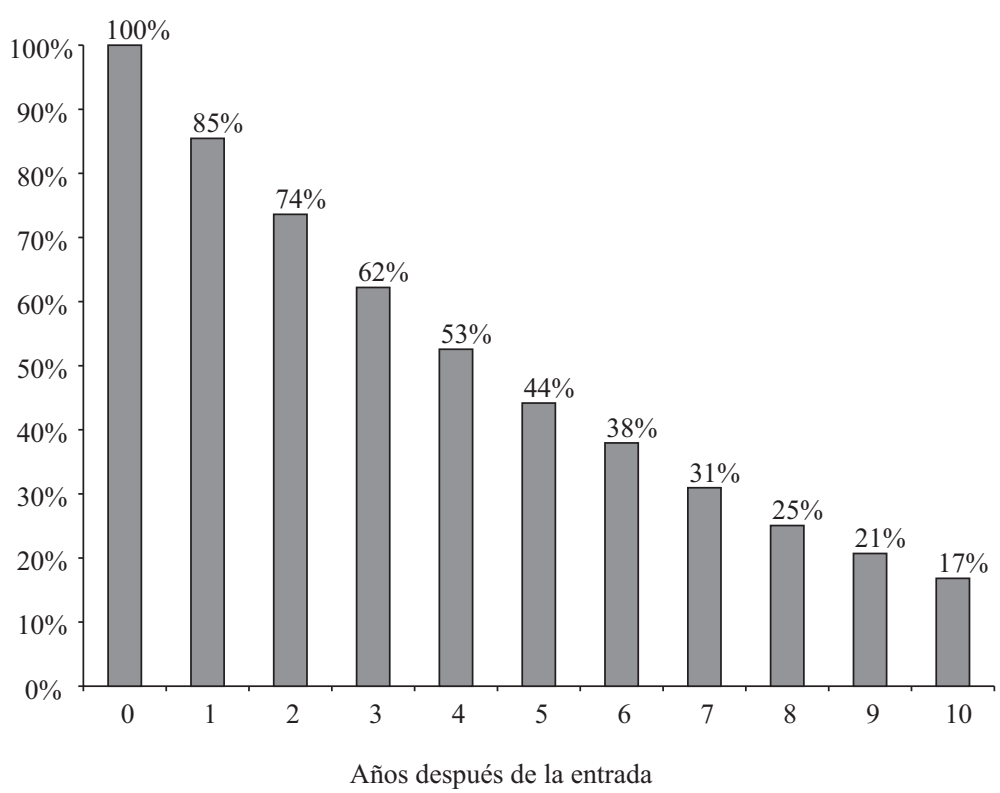

Fuente: ENIA.

${ }^{22}$ La ENIA considera todas las plantas que en algún año tuvieron al menos diez empleados. Si en algún año anterior estas plantas tuvieron menos de diez trabajadores, la ENIA no registra el número correspondiente. El número promedio de plantas consideradas por año es aproximadamente 3.500. Se debe notar que esta división deja fuera a la gran mayoría de las microempresas y, probablemente, a las informales, porque a esa escala es difícil evadir a los inspectores y los costos de la informalidad son importantes (véase, por ejemplo, Klein y Tokman [1996]).

${ }^{23}$ Salvo para el primer año, las cifras son muy similares para el período 1984-1997, que excluye la depresión de 1982. La tasa de salida a un año entre 1984 y 1987 es 14\%. 
Hecho 10. Al igual que en los demás países, en Chile la mortalidad de las empresas manufactureras chilenas es alta.

¿Cómo se diferencia el comportamiento de las plantas dependiendo de su tamaño? El Cuadro $\mathrm{N}^{\circ} 5$ muestra que el 58,07\% de las plantas que entran son pequeñas, el 26,32\% medianas y sólo el 11,52\% son grandes. Sin embargo, a medida que pasa el tiempo, la participación de las plantas grandes va en aumento, y entre las plantas de cinco o más años, más del $25 \%$ son grandes.

Hecho 11. Tal como ocurre en los demás países, la mayor parte de las empresas que entran son pequeñas.

La participación relativa de las plantas grandes puede aumentar ya sea porque las empresas pequeñas crecen y llegan a ser grandes o bien porque las empresas pequeñas salen más. El Cuadro $\mathrm{N}^{\circ} 6$ muestra que en promedio sólo el 3,2\% de las plantas grandes sale cada año, mientras que de las medianas lo hace el $4,8 \%$ y las chicas el $8,6 \%$. A consecuencia de esto, mientras el $79,1 \%$ de las plantas grandes tiene cinco años o más, sólo el $64,7 \%$ del total de plantas pequeñas tiene cinco o más años.

CUADRO N N $^{\circ}$ DISTRIBUCIÓN DE TAMAÑOS DE LAS PLANTAS POR EDAD (Promedio 1986-1997)

\begin{tabular}{lccccc}
\hline Edad & $\begin{array}{c}(1) \\
\text { Micro }\end{array}$ & $\begin{array}{c}(2) \\
\text { Pequeña }\end{array}$ & $\begin{array}{c}(3) \\
\text { Mediana }\end{array}$ & $\begin{array}{c}(4) \\
\text { Grande }\end{array}$ & Todas \\
\hline \multirow{2}{*}{ Nuevas } & & & & & \\
1 & $4,09 \%$ & $58,07 \%$ & $26,32 \%$ & $11,52 \%$ & $100 \%$ \\
2 & $2,37 \%$ & $54,74 \%$ & $28,48 \%$ & $14,42 \%$ & $100 \%$ \\
3 & $2,14 \%$ & $52,37 \%$ & $28,92 \%$ & $16,57 \%$ & $100 \%$ \\
4 & $2,10 \%$ & $51,02 \%$ & $29,64 \%$ & $17,24 \%$ & $100 \%$ \\
$\geq 5$ & $2,62 \%$ & $49,11 \%$ & $29,97 \%$ & $18,30 \%$ & $100 \%$ \\
Edad promedio & $1,68 \%$ & $45,29 \%$ & $26,14 \%$ & $26,89 \%$ & $100 \%$ \\
& & & & & \\
\end{tabular}

Notas: (1) Se considera que una planta "sale" si, habiendo sido encuestada en el pasado, no es vuelta a encuestar en el presente. Por lo tanto, puede efectivamente haber cerrado, o bien redujo el número de trabajadores a menos de diez. (2) El panel de empresas cubre el período entre 1980 y 1997. Sin embargo, datos de ventas, que permiten hacer la clasificación por tamaño, están disponibles sólo desde 1986.

Fuente: Elaboración propia a partir de un panel de empresas encuestadas por el INE entre 1986 y 1997. La clasificación es la misma que en el Cuadro $\mathrm{N}^{\circ} 2$. 
CUADRO No 6: $\quad$ DISTRIBUCIÓN DE LA EDAD DE PLANTAS SEGÚN TAMAÑO

(promedio 1986-1997)

\begin{tabular}{lrrrrrrrr}
\hline & \multicolumn{7}{c}{ Edad en años } \\
\cline { 2 - 8 } Tamaño de planta & Nuevas & 1 & 2 & 3 & 4 & $\geq 5$ & Salen & Total \\
\hline (1) Pequeña & 10,1 & 7,9 & 6,7 & 5,6 & 5,0 & 64,7 & 8,6 & $100 \%$ \\
(2) Mediana & 8,2 & 7,3 & 6,7 & 6,0 & 5,5 & 66,3 & 4,8 & $100 \%$ \\
(3) Grande & 4,2 & 4,3 & 4,4 & 4,1 & 3,9 & 79,1 & 3,2 & $100 \%$ \\
\hline
\end{tabular}

Nota: Se excluyen las microempresas porque la muestra es poco representativa.

Fuente: Elaboración propia a partir de un panel de empresas encuestadas por el INE entre 1986 y 1997. La clasificación es la misma que en el Cuadro $\mathrm{N}^{\circ} 2$.

Hecho 12. En Chile, las plantas pequeñas mueren más que las grandes.

Por otro lado, muy pocas empresas recorren el ciclo pequeñamediana-grande. El Cuadro $N^{\circ} 7$ muestra la matriz de transición de las plantas del mismo tamaño a diez años plazo. Por ejemplo, si estas cifras se repitieran en los próximos diez años implicarían que, de la totalidad de plantas pequeñas del año 2002, en el año 2011 el 1\% habría

CUADRO N ${ }^{\circ}$ 7: $\quad$ MATRIZ DE TRANSICIÓN A DIEZ AÑOS

\begin{tabular}{lccccc}
\hline $\begin{array}{c}\text { En } t+10 \rightarrow \\
\text { En } t \downarrow\end{array}$ & Microempresa & Pequeña & Mediana & Grande & Salen \\
\hline Microempresa & 0,16 & 0,11 & 0,03 & 0,03 & 0,66 \\
Pequeña & 0,01 & 0,37 & 0,10 & 0,01 & 0,51 \\
Mediana & 0,01 & 0,09 & 0,34 & 0,21 & 0,35 \\
Grande & 0,01 & 0,01 & 0,04 & 0,68 & 0,26 \\
\hline
\end{tabular}

Nota: La matriz de transición se construyó de la siguiente manera: en el año $t$ se toman todas las plantas existentes y se clasifican por tamaño de acuerdo al criterio enunciado en el Cuadro $N^{\circ} 5$. Luego, diez años más tarde se ve cuál es el tamaño de la planta. Por ejemplo, la matriz indica que, en promedio, el $1 \%$ de las empresas pequeñas se transformó en microempresas, el $37 \%$ siguió siendo pequeña, el 10\% creció a mediana, el $1 \%$ a grande y el 51\% salió. Por razones obvias se consideraron únicamente los años 1986 y 1987.

Fuente: Elaboración propia a partir de un panel de empresas encuestadas por el INE entre 1986 y 1997. La clasificación es la misma que en el Cuadro № 2. 
caído a la categoría de microempresa, el 37\% seguiría siendo pequeña, el 10\% sería mediana, sólo el 1\% grande y el 51\% habría muerto. El cuadro muestra claramente que la tasa de mortalidad de plantas pequeñas y medianas es considerablemente más alta que la de grandes empresas: $51 \%$ y $35 \%$ vs. $26 \%$. Más aún, apenas el $1 \%$ de las plantas pequeñas llega a ser grande.

Hecho 13. Muy pocas empresas pequeñas llegan a ser grandes.

Estas tasas de salida altas tienen varias implicancias. Por ejemplo, veremos más adelante, en la sección de financiamiento, que estas tasas de salida a diez años explican en gran medida por qué existe tan poco crédito a plazos largos respaldados por la mera expectativa de flujos: en el largo plazo una fracción considerable de las empresas ya no existe y no pagaría el crédito.

Es importante destacar que la alta tasa de salida de plantas manufactureras chilenas no es un problema coyuntural de las recesiones, sino que una regularidad que también se observa en períodos de auge. El Cuadro $\mathrm{N}^{\circ} 8$ muestra las tasas de salida de todas las plantas que entraron en 1980, 1981 y así sucesivamente. Si bien la tasa de salida fue particularmente alta durante la depresión de principios de los ochenta, (del orden del 40\%), las tasas de salida de plantas es considerable durante la más larga y fuerte expansión de la economía chilena entre 1986 y 1997, a pesar de que se trata del período más estable macroeconómicamente hablando de todo el siglo 20. En efecto, al cabo de un año la tasa de salida de plantas creadas entre 1986 y 1996 es mayor que 10\%. Aun en años de expansión más lenta (1990 y 1994) las tasas de salida no son apreciablemente distintas que en los años de mayor expansión. Las elevadas tasas de falla no se registran sólo durante el primer año de vida de las plantas sino que a través del tiempo. Se aprecia en el cuadro que después de cinco años la tasa de sobrevivencia no es superior al 70\%, y en la mayoría de los años es aún menor.

Hecho 14. Las altas tasas de salida de empresas en Chile no son consecuencia de la recesión sino de la dinámica industrial normal, aun durante los auges.

La alta tasa de fracasos ¿es un "problema" que justifique la intervención del Estado con programas de apoyo y fomento? Discutire- 


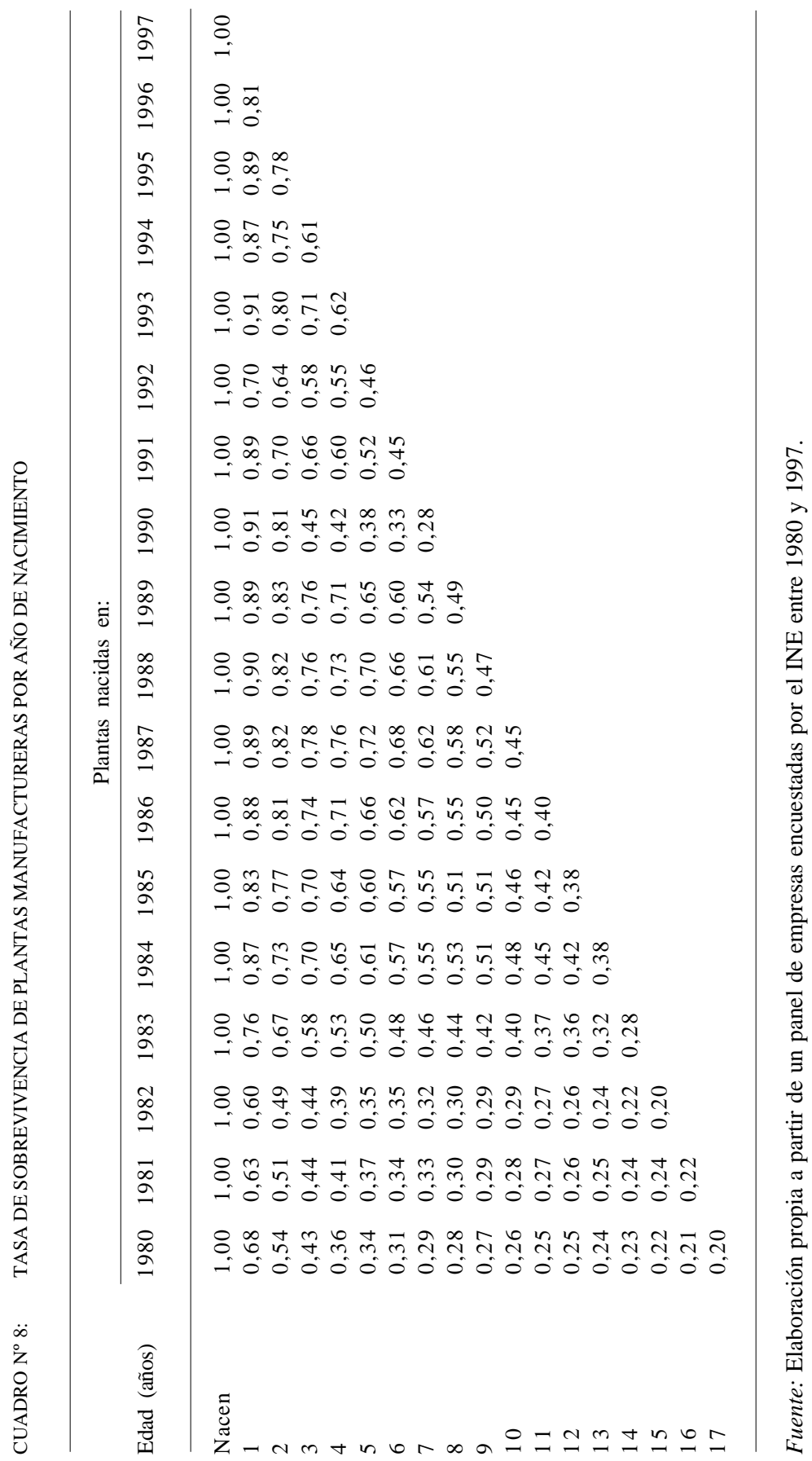


mos esto en detalle más adelante, pero nos apresuramos a indicar que los hechos revisados sugieren que la respuesta es "no". Las tasas elevadas de muerte de empresas no son características de la economía chilena sino de la dinámica industrial de todas las economías, independientemente de su nivel de desarrollo, y reflejan la experimentación que en todo momento forma parte del sistema económico. La escala reducida de las pyme hace que lo normal y esperable sea observar entre ellas una mayor tasa de nacimientos y muertes.

\section{ALGUNAS IMPLICANCIAS DE LA ECONOMÍA BÁSICA DE LAS PYME}

La economía básica de las pyme tiene una serie de implicancias, las que discutimos a continuación.

\subsection{Costos fijos y las pyme}

¿Cuándo van a exportar las pyme? Las estadísticas muestran que muy pocas pyme exportan directamente: por ejemplo, Álvarez et al. (1999) reportan que sólo el 1,6\% de las pequeñas empresas lo hace. Sin embargo, las pyme que exportan tienden a ser exitosas ${ }^{24}$. Por eso, muchas veces se propone estimular las exportaciones de las pyme con programas de fomento que les “enseñen” a hacerlo. ¿Por qué exportan tan poco las pyme, a pesar de que los mercados internacionales parecen ofrecer tantas oportunidades?

Parte del "problema" es que las estadísticas clasifican como “exportadoras” únicamente a las pyme que venden directamente al extranjero. Así por ejemplo, en algunas estadísticas los miles de productores agrícolas que producen fruta de exportación no aparecen exportando, a pesar de que casi todo lo que producen se vende en el extranjero a través de tradings de fruta. La causa de este problema es un simple error de medición: la medida apropiada es qué fracción del valor agregado exportado lo producen empresas medianas y pequeñas. Pero lo fundamental es que la mayoría de las pyme no debería exportar directamente porque en muchos casos exportar implica incurrir en costos fijos que lo hacen inviable.

${ }^{24}$ Casos fascinantes de pyme exportadoras exitosas se encuentran descritos en Fischer (2001b) y en Asimet (2001). 
Para comenzar, muchas veces se requieren inversiones indivisibles de gran tamaño. Por ejemplo, para exportar fruta se requiere estandarizar el producto, invertir en plantas de empaque, contenedores y, sobre todo, desarrollar logística sofisticada que sólo se justifica si se opera a escalas grandes. Lo eficiente es que los productores de fruta vendan su producción a empresas grandes que se especializan en exportarla ${ }^{25}$. Segundo, para comenzar a exportar se requiere descubrir y desarrollar el mercado externo. Hacerlo impone un costo fijo que sólo vale la pena si los volúmenes exportados son importantes. Tercero, en muchos rubros se requiere satisfacer una serie de estándares regulatorios para ingresar a los mercados externos, y cumplir con ellos es un costo fijo. Lo anterior implica que se deben dar condiciones muy concretas para que una pyme pueda exportar directamente ${ }^{26}$.

Hecho 15. Para que una pyme exporte directamente, el tamaño mínimo de producción y operación debe ser suficientemente pequeño, el producto debe servir a un nicho suficientemente diferenciado y el costo de abrir mercados no debe ser muy grande.

El Recuadro $\mathrm{N}^{\circ} 4$ muestra el caso de una pyme exportadora que han sido exitosa explotando nichos de mercado.

Las pyme exportadoras y el nuevo proteccionismo. El proteccionismo ha sido tradicionalmente cuestión de aranceles altos. Sin embargo, desde hace un tiempo los acuerdos multilaterales han reducido sistemáticamente los aranceles en todo el mundo, y esto ha estimulado la emergencia del así llamado "nuevo proteccionismo", que consiste en imponer barreras no arancelarias al comercio, tales como medidas

${ }^{25}$ Es interesante preguntarse por qué las grandes empresas exportadoras no tienen sus propios campos productores de fruta. La respuesta es que a la empresa grande le conviene externalizar la producción mediante relaciones más permanentes. Primero, no existen indivisibilidades importantes en producción. Segundo, la producción de fruta de exportación requiere de gran atención al detalle, y los incentivos son más fuertes cuando el dueño del predio es quien asume la pérdida si la producción no satisface los requerimientos del exportador. Tercero, la calidad de la fruta es observable (si el agricultor trae fruta del tamaño equivocado o de maduración inapropiada, la partida se rechaza).

${ }^{26}$ En otras palabras, nuevamente la categoría "pyme” es inadecuada, porque incluye en el mismo grupo a empresas que no pueden exportar directamente y a empresas que sí tienen las condiciones. 


\section{RECUADRO No ${ }^{\circ}$ 4: UNA PYME EXPORTADORA ENCUENTRA SU NICHO}

[Extractado de Carmona (2001)] [C]on Drillco, desde el inicio supimos que teníamos que exportar, porque el mercado de nuestros productos, que son martillos y brocas de perforación con aire comprimido utilizados en minería, pozos de agua, canteras, etc., es limitado en Chile [...]. Con eso en mente, empezamos a [preguntarnos] dónde. En nuestro caso, la respuesta fue buscar el nicho más poderoso posible, que tuviera la mayor concentración de estos productos, donde los esfuerzos que íbamos a hacer fueran los más productivos. Y analizamos que el mercado más fuerte para nuestros productos era Estados Unidos. Por lo tanto, el año 1991 empezamos con las gestiones para exportar a los Estados Unidos.

Estábamos confiados, pensábamos que éramos fuertes, que teníamos un producto bueno y precios buenos. Pero al llegar allá nos encontramos con que en nuestro negocio el mercado es uno de los más duros en todo el mundo. No solamente la exigencia técnica del producto es muy alta, sino que además el cliente es muy duro, tanto como la roca. Sin embargo, nuestra arma era algo que habíamos aprendido en Chile, que nos había llevado a ser líderes en nuestro mercado y que era lo que nosotros llamábamos la "intimidad con el cliente”. La experiencia de Drillco es una clásica experiencia que surge de la sustitución de importaciones. Nosotros fuimos la primera y, hasta el día de hoy, la única empresa chilena que fabrica estos productos, en competencia directa con todas las empresas líderes del mundo, de modo que estábamos expuestos desde el inicio.

En este escenario, para poder diferenciarnos de la competencia, acuñábamos el concepto de la intimidad con el cliente, que no es otra cosa que estar muy cerca del cliente, realmente escucharlo y adaptarse a lo que quiere. Pues bien, con esa misma arma competitiva, salimos al mercado norteamericano, básicamente a escuchar y aprender. [...]

Hoy día, cerca del $57 \%$ de nuestra facturación son exportaciones y, considerando unidades físicas, estamos exportando casi el 70\% de nuestra producción, pues los precios son menores afuera. Con ello, se refleja que nuestra empresa es definitivamente exportadora. [...] Con respecto a nuestros productos, tenemos martillos, brocas y otros accesorios, todos elementos altamente tecnificados, no solamente en su fabricación, sino que también en diseño $\mathrm{y}$, además, son productos que requieren servicio. [...] Dado que nuestro producto es técnico y requiere servicio, hay que estar pegado al cliente, porque no es posible exportar esto por container, como es el caso de la uva u otros commodities chilenos. Eso nos llevó a tomar la decisión de estar muy cerca del cliente, por ello abrimos una oficina y contratamos a un norteamericano, buscando el factor comodidad, porque para la cultura norteamericana es muy importante entenderse con sus iguales, no con latinoamericanos. De este modo, los clientes compran un producto que está nacionalizado norteamericano y lo compran a otro norteamericano, que realiza la labor comercial basado en Utah. Junto con eso, pusimos nuestro personal técnico chileno, que va detrás del personal comercial, combinación que ha sido muy importante para nosotros. 
antidumping, estándares de calidad mínima (v. g. ISO 9000), regulaciones fitosanitarias, normas medioambientales o regulaciones laborales ${ }^{27}$.

Barreras de este tipo aumentan los costos de exportar y son utilizadas por las empresas locales para protegerse de la competencia. Pero desde el punto de vista de las pyme que exportan directamente, estas normas son aún más dañinas que los aranceles, porque en la mayoría de los casos se necesita incurrir en costos fijos para cumplirlas. Estos costos fijos son variados e incluyen, entre otros, la adecuación de los procesos de producción para ajustarse a los estándares y normas que varían de un país a otro, trámites engorrosos para conseguir las autorizaciones respectivas o la contratación de asesores locales que entienden cómo operan las reglas. Adicionalmente, como lo han notado Fischer y Serra (2000), varios de estos mecanismos proteccionistas son "contingentes", en el sentido que operan a pedido de un productor local que intenta protegerse de la competencia. Esto aumenta el riesgo que afrontan las empresas que exportan, particularmente si, como en el caso de las pyme, un envío dado tiende a ser grande como fracción de su producción.

En algunos casos los problemas causados por barreras paraarancelarias pueden mitigarse mediante acciones coordinadas de un grupo de empresas enfrentadas a un problema común (véase la discusión sobre asociatividad más abajo). Por ejemplo, para defenderse de las medidas antidumping impuestas por los Estados Unidos los productores de salmón contrataron en conjunto asesoría legal y lobby. Sin embargo, esto es menos factible cuando se trata de las pyme de nicho, porque la diferenciación de productos tiende a disminuir naturalmente el número de firmas que enfrentan cada problema.

¿Cuándo funciona la asociatividad? Sustitutos, complementos y costos de transacción. Si el problema de las pyme son los costos fijos, ¿por qué no asociarse para compartirlos? Esta idea subyace en varios programas de fomento de la "asociatividad" que intentan estimular a empresas pequeñas y medianas para que se asocien y compartan costos fijos. ¿Qué sugiere la economía básica de las pyme sobre la asociatividad?

Es conveniente partir notando que la asociatividad no es una panacea. En muchos casos no funciona porque los costos de transac2001a).

${ }^{27}$ Para un completo análisis del nuevo proteccionismo véase Fischer (1997 y 
ción y coordinación entre los socios son altos. Por ejemplo, durante un tiempo se formaron varias cooperativas de farmacias independientes para comprar volúmenes más grandes de medicamentos y conseguir descuentos. Sin embargo, la mayoría fracasó porque era muy difícil observar el descuento obtenido por quien negociaba con los proveedores $^{28}$. La consolidación del mercado de las farmacias ha ocurrido de manera distinta, a través de cadenas que compran volúmenes grandes y que no enfrentan el problema de repartirse las ganancias por descuentos. Otro ejemplo clásico de costos de transacción ocurre cuando grupos de productores distintos venden con la misma marca, sin que un tercero verifique la calidad de lo que produce cada uno. El problema es que si la calidad no es fácilmente observable y es posible reducir costos ofreciendo peores productos o servicios, cada uno de los socios tiene incentivos para hacerlo porque el perjuicio se reparte entre varios. Pero, obviamente, en ese caso el acuerdo fracasa.

Más generalmente, y como lo muestra una amplia literatura, el problema fundamental de compartir activos o costos fijos es que la propiedad común suele ser ineficiente porque es difícil determinar ya sea los beneficios que saca cada socio o bien cuál es el aporte sustantivo que cada uno hace ${ }^{29}$. Como lo discutimos más arriba, no es fácil coordinar actividades y es más difícil aún cuando se comparten costos o activos. De ahí que no sea casual que existan empresas distintas haciendo cosas similares, aun cuando mirado desde afuera pudiera parecer que eso les impide compartir costos fijos.

Hecho 16. La asociatividad no siempre es conveniente porque los costos de transacción pueden ser altos. Los costos de coordinar actividades son generalmente mayores cuando se comparten activos o costos.

Lo anterior no implica que siempre sea inapropiado compartir activos o costos sino que, nuevamente, se tienen que dar circunstancias particulares para que sea conveniente hacerlo. Grosso modo, tres

${ }^{28}$ Según se cuenta, el socio encargado de tratar con los proveedores solía apoderarse de gran parte del descuento facturando parte de la compra a su propia farmacia.

${ }^{29}$ Muchas veces, el compartir activos o costos fijos implica actividades conjuntas o en equipo. La referencia clásica que estudia las dificultades que conllevan las actividades conjuntas es Alchian y Demsetz (1972). 
son los tipos de asociatividad: entre empresas que producen bienes sustitutos o similares; entre empresas que producen complementos; o empresas que producen bienes no relacionados pero que podrían compartir el costo de un insumo o un activo: por ejemplo, dos empresas de rubros distintos podrían ocupar al mismo contador.

Este último tipo de asociaciones es infrecuente por una razón bastante simple: si muchas empresas de rubros no relacionados demandan bienes o servicios similares, el mercado será suficientemente grande y es más eficiente que los produzca un tercero independiente. Por ejemplo, las oficinas de contadores independientes que les prestan servicios a varias empresas que operan en rubros distintos. En esos casos, el costo "fijo" será distribuido entre distintos usuarios a través del mercado.

Hecho 17. Compartir costos o activos comunes es innecesario e inconveniente cuando el mercado es suficientemente grande. Para que sea conveniente es condición necesaria que el activo o costo fijo se deba a actividades específicas a un grupo pequeño de firmas.

Una implicancia del hecho 17 es que la asociatividad es valiosa sólo cuando el costo fijo a compartir se deba a una actividad específica de un grupo pequeño de empresas. Por el contrario, si la actividad no es específica, es muy probable que el bien o servicio se pueda comprar en un mercado.

Las asociaciones entre empresas que producen sustitutos presentan oportunidades para compartir costos fijos porque venden en mercados similares y ocupan insumos parecidos. Cuando se trata de empresas pequeñas que producen bienes estandarizados en mercados grandes es muy probable que se desarrollen asociaciones entre productores para compartir costos fijos, porque en ese caso la rivalidad entre empresas no es intensa. Por ejemplo, éste es el caso clásico de la agricultura, donde la rivalidad entre productores es casi nula, pues ninguno afecta el precio de los productos. En esos casos, lo más probable es que se compartan costos fijos a través de organizaciones gremiales (véase la discusión específica a continuación).

Sin embargo, la asociatividad entre productores de sustitutos es más problemática cuando se trata de empresas que venden en nichos o mercados muy pequeños, sobre todo cuando no tienen perspectivas de 
crecer. En esos casos, lo que uno gane generalmente lo pierde el otro. Por ejemplo, una de las críticas que se les suele hacer a las pyme es que "se gestionan mal" (véase la discusión en la sección siguiente) y la sugerencia es que deberían asociarse para contratar consultorías de gestión o, incluso, a un gerente común. Sin embargo, es muy improbable que compartan el mismo gerente empresas dedicadas al mismo rubro porque eso implicaría compartir información sobre, por ejemplo, clientes, costos o métodos de producción.

Es más probable que la asociatividad resulte cuando se trata de compartir costos fijos para expandir el mercado. Esto puede ocurrir cuando se trata de empresas que producen bienes o servicios similares en mercados o nichos con perspectivas de crecer, pero sobre todo cuando producen bienes complementarios. El caso de Vitroquímica S. A., una empresa que produce recubrimientos vítreos de alta temperatura que se ocupan para revestir bienes durables tales como cocinas, lavadoras o pisos cerámicos, es muy ilustrativo. Según su gerente general, Carlos Lizana:

“[...] dentro de nuestra estrategia de internacionalización, fue muy importante el habernos juntado con diferentes empresas chilenas, cuya naturaleza de productos es totalmente diferente, pero que tenían como factor común al cliente final: el fabricante de cocinas a nivel sudamericano. Trabajamos en conjunto Vitroquímica en el caso de los esmaltes de enlozado; Vidrios Del'Orto, que provee los vidrios para las puertas de cocina; Técnica Industrial y Comercial, que provee bisagras para las puertas de cocina; Cemco, que produce válvulas para el gas; Termometalúrgica, que provee de los quemadores. Coordinamos con este grupo una serie de actividades, para llegar a todos los fabricantes de cocinas latinoamericanos. (Lizana, 2001)

Asociatividad a través de asociaciones gremiales. Las asociaciones gremiales son instancias naturales de asociatividad y presentan varias ventajas que las tornan potencialmente eficientes para coordinar actividades que beneficien a un grupo de empresas. Los proyectos asociativos sólo son económicamente interesantes cuando implican compartir algún activo o algún costo en algún grado indivisible. Identificar las oportunidades de asociación que sean económicamente valiosas requiere conocer los problemas de la industria. Obviamente, los miembros de 
la industria son quienes mejor las conocen, por lo que las asociaciones gremiales tienen ventajas a la hora de identificar programas asociativos. Un ejemplo de proyecto asociativo exitoso es el desarrollado conjuntamente por la Confederación de Empleadores Suecos y la Federación de Industrias Suecas para establecer un sistema contable estándar para las pyme, el que se describe con más detalle en el Recuadro $\mathrm{N}^{\circ}$ 5. La participación de los empresarios permitió identificar desde el principio los requerimientos de las empresas e ir introduciendo mejoras paulatinas para hacer el sistema contable más útil.

\section{RECUADRO N ${ }^{\circ}$ : \\ ASOCIATIVIDAD A TRAVÉS DE ASOCIACIONES GREMIALES}

[Traducido de Johansson y Samuelson (1998)] En Suecia, a partir de los años sesenta, varias asociaciones han estado comprometidas con el desarrollo de mejores prácticas de administración en pequeñas y medianas empresas. Uno de los esfuerzos pioneros fue el realizado por la Confederación de Empleadores de Suecia, que promovió el diseño de un material de autoevaluación de empresas llamado "Cuidando a tu compañía”. Basados en esta experiencia y en encuestas de este material, pronto se hizo evidente un área donde compañías deficientes podrían considerarlo como un estándar aceptable: contabilidad y control administrativo.

La Confederación y la Federación de Industrias suecas iniciaron un gran proyecto en el desarrollo de modelos estándar en estos campos. El principal resultado de este proyecto fue un manual estándar de contabilidad: el manual BAS. La primera edición de este manual fue lanzada en 1976 y en un breve lapso se transformó en el estándar comúnmente usado en Suecia, no sólo por pequeñas y medianas empresas, sino también por grandes compañías. Aún es común su uso debido a que se ha ido adaptando a los nuevos esquemas de contabilidad exigidos por la ley. El manual BAS también se adaptó para su uso en agencias públicas y fue traducido a varios idiomas.

El manual BAS inicialmente sólo abarcaba la contabilidad financiera. No obstante se reconoció que, para cumplir con un desempeño efectivo y eficiente de las empresas, se hacía necesario agregar el área de responsabilidad administrativa. En la primera publicación del manual BAS se incluyeron algunas amplias sugerencias respecto a cómo se podía diseñar la responsabilidad administrativa y relacionarla con la contabilidad financiera. Estas sugerencias fueron, posteriormente, incorporadas en modelos más detallados (1982) y sus usos, en algunos casos, se dieron a conocer en otro libro (1983). 
Muchos proyectos asociativos están destinados a desarrollar capacidad de gestión, entrenar trabajadores, contratar consultores y recopilar información sobre las últimas tecnologías específicas para un determinado sector productivo que sirvan para fomentar programas de innovación. Los beneficios derivados de este tipo de actividades suelen diferir entre las empresas que se asocian, por lo que la participación de cada una de ellas en el financiamiento suele ser un aspecto conflictivo de la asociatividad. Sin embargo, la asociación gremial coordina este tipo de actividades y distintos proyectos de esta naturaleza ya están en desarrollo; lo que le interesa a una empresa son los beneficios y los costos promedio que le significan. El menor grado de conflicto entre las empresas asociadas disminuye los costos de transacción y torna a los programas asociativos más rentables. Por ejemplo, la Cámara Nacional de Comercio desarrolla una serie de programas que son de utilidad para sus asociados. Por medio de EAN-Chile administra estándares para el comercio electrónico, implementa un código de autorregulación para el comercio electrónico a través de CARe, ofrece servicios de certificación a través de ONCe, arbitra conflictos virtuales en su programa SINGOLPe y promueve la confianza de los consumidores en el comercio electrónico a través de CONFIARe.

Es menos probable que los programas asociativos sean inútiles cuando los impulsa una asociación gremial. A los directivos de la asociación gremial les va bien si entregan servicios valiosos a sus asociados, es decir se benefician si crean valor entre sus asociados. Por lo tanto, tienen mejores incentivos para identificar programas valiosos y contratar los prestadores de servicios calificados.

Hecho 18. Las asociaciones gremiales pueden jugar un papel importante en los proyectos asociativos, ya que pueden conocer mejor los problemas de la industria, disminuyen los costos de transacción y tienen incentivos para seleccionar proyectos valiosos.

¿Cuándo innovan las pyme? Álvarez et al. (1999) sostienen que en Chile las empresas pequeñas innovan poco en productos y procesos. ¿Por qué innovan poco las pyme?

Una de las principales razones es que el costo de innovar en productos y procesos es, en general, un costo fijo y hundido. Para que la innovación sea rentable se requiere que la escala de producción sea suficientemente grande de manera de prorratear su costo entre un 
mayor número de unidades. De hecho, como lo plantean Galbraith (1956) y Scherer (1980), las firmas pequeñas no van a innovar en industrias en las que existen grandes economías de escala. En estas industrias las firmas que están en mejor posición de explotar las ganancias de la innovación son las de mayor tamaño. Lo mismo ocurre en industrias intensivas en publicidad, en las que existen economías de escala al desarrollar actividades promocionales que facilitan la penetración de mercado de nuevos productos. En estos casos son las empresas grandes las que están en una mejor posición relativa que las más pequeñas para innovar (Comanor [1967] y Scherer [1980]). Por lo tanto, lo natural será que en este tipo de industrias las pyme no innoven mucho. Por eso, la innovación en empresas pequeñas se da más bien cuando producen para nichos de mercado en los que no hay empresas que estén produciendo a gran escala y la competencia es menos intensa. El Recuadro $\mathrm{N}^{\circ} 6$ muestra el caso de Hiload, una empresa chilena mediana que fue capaz de innovar aplicando tecnologías sofisticadas pero que no requerían gran escala.

Las oportunidades de innovación de las pyme, sin embargo, son mayores en industrias cuyos productos están en una etapa temprana de su ciclo de vida. En las etapas de introducción y crecimiento los productos no están estandarizados, el diseño del producto cambia mucho y la innovación requiere más que nada de mano de obra calificada en vez de activos físicos indivisibles (Pavitt y Wald [1971]). Esto explica por qué las pyme no innovan mucho. Como lo muestran Alarcón y Stumpo (2000), en Chile las pyme tienden a especializarse en sectores "maduros" tradicionales tales como textiles, prendas, cuero, muebles, productos metálicos y otras manufacturas.

En resumen, la decisión de innovar para una pyme está determinada por cuestiones tecnológicas, el ciclo de vida de los productos y la manera en que compiten las empresas. Por lo tanto, la mayoría de las pyme opera en mercados en los que innovar no es económicamente conveniente. Una política destinada a inducir innovaciones entre las pyme, aun en sectores en los cuales esto no es económicamente razonable, es inconveniente. La política de incentivos a la innovación debería considerar más bien el carácter de bien público que pudiera tener una innovación, y por lo tanto subsidiarla o facilitarla en la medida en que genere externalidades, independientemente del tamaño de la empresa que innova. Este carácter general es precisamente el que tiene el 


\section{RECUADRO N ${ }^{\circ}$ 6: UNA EMPRESA MEDIANA INNOVA Y COMPITE CON CATERPILLAR}

[Extractado de Fischer (2001b)] [A principios de los noventa] Dicsa (Distribuidores Cummins SA), una gran empresa familiar (1.000 empleados), era un distribuidor de equipos para la minería y contaba con un importante departamento de mantención. [...] Hasta ese momento, las tolvas de los camiones mineros eran fabricadas en el extranjero con aceros estándar. El uso obligaba a proteger la tolva con un revestimiento fabricado con el mismo acero, el que normalmente debía ser cambiado por lo menos una vez al año. En su búsqueda por encontrar un mercado para aceros de alta calidad, [Cristián] Feuereisen, gerente de la división de desarrollo de nuevos negocios, se dio cuenta de que, si se usaban en las tolvas, disminuirían su peso, reduciendo los costos de operación y al mismo tiempo alargarían su vida útil.

La división de nuevos negocios era bastante exitosa, de modo que Feuereisen solicitó a sus empleadores que le concedieran un año de permiso y financiamiento para desarrollar la idea de una tolva liviana, fabricada en acero de alta calidad, y sin revestimiento. [...] Una vez construido el prototipo, fue instalado en un camión de la mina La Candelaria, una gran mina chilena de propiedad de Phelps Dodge, a fin de probar el concepto. Al cabo de algunos meses la tolva se trizó, pero afortunadamente el tipo de fractura no representaba un error en el concepto básico. Una vez reparada, la tolva funcionó durante más de un año antes de fallar. Para entonces, Phelps Dodge ya estaba interesado en el proyecto y una segunda versión mejorada de la tolva funcionó bien.

Entretanto, en 1996-97, Komatsu ingresó al área de equipos para la minería (Komatsu Mining Systems), en la cual dominaba Caterpillar. También adquirió Dicsa, salvo la división de tolvas, la que se separó de la compañía y se convirtió en Hiload, perteneciente a Feuereisen y a los dueños originales de Dicsa. [...] En 1999 se llevó a cabo una prueba internacional en la cual compitieron tolvas livianas de Komatsu y Caterpillar junto al modelo de Hiload en Chino, una importante mina estadounidense perteneciente a Phelps Dodge. El diseño chileno pronto tuvo una falla, la que fue fácilmente reparada a distancia desde Chile, mientras que los otros diseños fracasaron catastróficamente al poco tiempo.

[...] A pesar de que la inversión en planta de Hiload es de poca magnitud, cerca de US\$ 2 millones, la tecnología es muy avanzada y combina en forma interesante equipos digitales de corte de acero en condiciones de baja temperatura y tecnología sofisticada de soldadura con procedimientos manuales en otras etapas del proceso. Sin embargo, la producción potencial alcanza a dos tercios de la producción de Caterpillar. Este caso muestra, además, que las nuevas tecnologías permiten el desarrollo de equipos complejos en países como Chile, siempre y cuando la escala de producción sea lo suficientemente baja, o suficientemente específica como para que los métodos de producción en cadena no sean apropiados. Los nuevos equipos hacen que no sea imprescindible tener demasiado personal especializado para crear maquinaria e implementos de buena calidad. En la industria minera gran parte de la maquinaria tiene estas características, ya que son unidades que deben ser adaptadas a las necesidades del cliente. Existe por lo tanto potencial para desarrollar industrias de este tipo en Chile. 
Fondo Nacional de Desarrollo Tecnológico y Productivo (Fontec) de Corfo, que no discrimina por el tamaño de la empresa.

Hecho 19. Las pyme innovan poco porque generalmente para hacerlo se requiere invertir en costos fijos y hundidos considerables.

\subsection{La dinámica de las pyme}

El mundo de las empresas es muy cambiante. En ocasiones, sectores completos en que dominaban las pyme son transformados por un puñado de empresas más grandes. Y, por otro lado, el tipo de pyme va cambiando a medida que el país se desarrolla. A continuación exploramos algunas implicancias de la economía básica en la dinámica de las pyme.

¿Cuándo y cuánto puede crecer una pyme? Muchas empresas que nacieron pequeñas llegaron a ser grandes compañías. Por ejemplo, en Chile, la empresa de arriendo de videos Errol's nació pequeña y terminó como una empresa grande que luego se vendió a la multinacional Blockbuster. A otra escala y nivel, la empresa de correos y encomiendas Federal Express también nació como una pyme que operaba regionalmente en los Estados Unidos y hoy es una empresa grande con operaciones a nivel mundial. Más aún, como vimos precedentemente, las firmas que sobreviven tienden a crecer más rápido cuanto más chicas son. Quizás “éxitos empresariales” de este tipo motivan el entusiasmo por políticas que ayuden a las pyme a crecer. Sin embargo, ¿es razonable esperar que todas las pyme crezcan? ¿Cuándo puede crecer una pyme? ¿Y hasta qué tamaño?

Para entender mejor bajo qué circunstancias crecen las pyme conviene examinar lo que tienen en común Errol's y Federal Express, que crecieron exitosamente hasta transformarse (guardando las proporciones) en empresas grandes. Lo hicieron porque en esos negocios el tamaño era ventajoso. En el caso del arriendo de videos los mayores volúmenes de operación permiten aprovechar economías de escala estocásticas y reducir la inversión en películas para un mismo nivel de servicio; en el caso de Federal Express, una flota más grande permite coordinar mejor la logística y alcanzar a un mismo costo mejores estándares de oportunidad y seguridad en las entregas. Es decir, en 
estas empresas la escala mínima eficiente de las operaciones nunca fue pequeña. En algún momento fueron pyme porque se encontraban en transición hacia su tamaño de operación eficiente. Estas empresas nacen pequeñas ya que requieren experimentar cuando se trata de una industria naciente, o bien han ocurrido innovaciones tecnológicas que abren espacios para desarrollar nuevos productos y servicios. El alto riesgo inherente de aprovechar estas oportunidades hace más conveniente experimentar con escalas pequeñas y expandirse una vez que se conoce mejor el negocio.

Hecho 20. Los "éxitos empresariales" de pyme que llegan a ser grandes empresas ocurren en actividades tales que el tamaño de operación eficiente es grande.

Este hecho sugiere que sería equivocado pensar que la receta del éxito consiste en estimular a que todas las pyme crezcan —una política que lo intente sería un desperdicio de recursos—. La primera razón se desprende de una de las regularidades que vimos más arriba, a saber: que en la mayoría de los mercados hay mucha entrada y ésta ocurre a escalas considerablemente menores que la de las firmas ya establecidas. Esta regularidad implica que es natural esperar que algunas empresas que nacen pyme crezcan; pero al mismo tiempo la otra cara de la moneda es que muchas más mueran. Más aún, como lo reporta Geroski (1995, p. 424), aun las empresas que son exitosas y crecen tienden a demorarse más de una década en alcanzar tamaños de operación eficientes. Así, las pyme que crecen y se transforman en empresas grandes lo hacen porque por alguna razón fueron exitosas después de largo tiempo en sectores donde la escala eficiente de operación es considerable, y no porque crecer garantice el éxito. Y las empresas que logran crecer son muy pocas. Los datos que presentamos en la sección anterior sugieren que muy pocas empresas hacen la transición de empresa pequeña o mediana a grande.

Hecho 21. La tasa de sobrevivencia de los entrantes es baja y los que sobreviven tardan más de una década en alcanzar el tamaño de la firma establecida promedio.

La segunda razón es que el tamaño eficiente de operación no es considerable en aquellos sectores donde deberían prevalecer las pyme. 
En esos sectores expandir la escala y crecer puede significar mayores costos por el deterioro en la calidad de la gestión y las pérdidas de coordinación que comienzan a ocurrir al interior de la empresa. En estos casos una pyme que crece no sobrevive, ya que no es capaz de competir con empresas más pequeñas que son más eficientes en la producción. Por ejemplo, un restaurante que ofrece un menú sofisticado difícilmente podría mantener su calidad si se expande a una cadena, ya que el chef probablemente no podrá supervisar adecuadamente la operación.

Hecho 22. La calidad de la gestión se deteriora cuando una empresa crece más allá de su tamaño eficiente. La empresa enfrenta entonces problemas de coordinación que ponen en riesgo su existencia.

Las pyme y el ciclo económico. Otra regularidad observada en el segmento de las pyme es que su participación es procíclica. Alarcón y Stumpo (2000) muestran que la participación de las pyme aumenta en el total de las ventas de un sector cuando la economía crece y disminuye cuando ésta se contrae ${ }^{30}$. También está la idea de que las pyme son más vulnerables que las empresas de mayor tamaño. Cuando cae la actividad económica desaparecen proporcionalmente más pyme. Surge, por lo tanto, la pregunta ¿existen características propias de las pyme que den cuenta de esta regularidad? La respuesta es que sí, y la razón estriba nuevamente en las características de las inversiones que realizan las empresas en sectores en que existen muchas pyme.

Como ya lo hemos dicho, las pyme son económicamente viables si operan en sectores en los cuales no se den inversiones indivisibles y que suelen ser hundidas, pues así los costos de entrada y salida son relativamente bajos y dan cuenta, al menos parcialmente, de la evolución procíclica de las pyme. Un ejemplo que ilustra bien este tipo de industrias es el de la construcción. Dado que crear una empresa constructora no requiere de grandes inversiones (prácticamente todos los insumos se pueden arrendar), los costos de entrar al mercado cuando la economía experimenta un ciclo expansivo y abandonarla cuando se contrae la demanda son muy bajos. Por lo tanto, no es sorprendente ver que cuando la economía crece se incremente fuertemente el núme-

\footnotetext{
${ }^{30}$ Mills y Schumann (1985) reportan que las empresas pequeñas representan una fracción mayor de la actividad durante expansiones.
} 
ro de empresas constructoras y que este disminuya en épocas recesivas.

Por contraposición, en sectores en los que existen importantes indivisibilidades y el costo de salida es alto, frente a un escenario macroeconómico adverso las empresas minimizan sus pérdidas ajustando su producción a la espera de mejores tiempos. Las empresas de estos sectores suelen no ser pyme y su comportamiento es menos volátil ${ }^{31}$.

Hecho 23. El nacimiento y desaparición de las pyme es procíclico, ya que son económicamente viables en sectores donde los costos de entrada y salida son relativamente bajos.

Desarrollo económico y estructura industrial. En ocasiones se sostiene que el acelerado desarrollo de la economía chilena durante los últimos quince años perjudicó a las pyme, porque junto con las microempresas perdieron importancia relativa en el total (véase, por ejemplo, a Alarcón y Stumpo [2000, p. 16]). Las “ganadoras”, en tanto, fueron las empresas grandes, que crecieron más rápido que el promedio. El Cuadro $\mathrm{N}^{\circ} 9$ muestra que la participación de empresas grandes (plantas que emplean 100 o más trabajadores) aumentó durante los pasados veinte años en la industria manufacturera de poco más de $11 \%$ en 1980 a casi $20 \%$ en 1997. ¿Cómo deberían evolucionar la estructura industrial y el tamaño de las empresas a medida que el país crece? La Figura $\mathrm{N}^{\circ}$ 2, que proviene del estudio de Snodgrass y Biggs (1996), muestra que a medida que el ingreso per cápita de un país aumenta, el tamaño de las empresas también.

¿Qué explica el patrón anterior? La consecuencia más obvia del desarrollo económico es que aumenta el tamaño de los mercados locales, y esto tiende a favorecer a las tecnologías de producción de mayor escala. Además, en algunos casos la preferencia por mayor calidad implica un desplazamiento de la demanda desde bienes más baratos (de menor calidad) producidos a escalas más bien pequeñas hacia bienes de consumo masivo (de mayor calidad) producidos en plantas grandes

${ }^{31}$ El hecho de que en Estados Unidos la tasa de destrucción bruta de empleo sea menor en plantas de mayor edad, tal como lo reportan Davis et al. (1996, p. 76), es una evidencia indirecta de la menor volatilidad en sectores donde las inversiones son específicas y de largo plazo. 
CUADRO No 9: $\quad$ DISTRIBUCIÓN DE TAMAÑOS DE PLANTA (1980-1997)

\begin{tabular}{llllllllllll}
\hline \multicolumn{10}{c}{ Número de trabajadores } \\
\cline { 2 - 11 } & $10-19$ & $20-29$ & $30-39$ & $40-49$ & $50-59$ & $60-69$ & $70-79$ & $80-89$ & $90-99$ & $\geq 100$ \\
\hline 1980 & 42,05 & 21,16 & 9,31 & 4,18 & 4,43 & 2,64 & 2,24 & 1,73 & 1,09 & 11,17 \\
1981 & 41,89 & 19,70 & 9,56 & 4,99 & 4,11 & 3,08 & 2,03 & 1,68 & 1,31 & 11,64 \\
1982 & 44,56 & 20,05 & 8,81 & 4,84 & 3,88 & 2,79 & 2,07 & 1,45 & 1,43 & 10,12 \\
1983 & 42,57 & 20,83 & 9,18 & 4,83 & 4,14 & 2,47 & 1,97 & 1,90 & 1,31 & 10,80 \\
1984 & 39,17 & 20,35 & 9,71 & 6,51 & 3,77 & 2,63 & 2,49 & 1,83 & 1,62 & 11,92 \\
1985 & 35,96 & 19,85 & 10,80 & 6,51 & 4,62 & 3,14 & 2,47 & 2,03 & 1,59 & 13,04 \\
1986 & 32,12 & 20,75 & 10,67 & 6,72 & 4,62 & 3,43 & 2,72 & 2,14 & 1,74 & 15,08 \\
1987 & 32,11 & 19,47 & 10,56 & 6,83 & 4,95 & 3,13 & 3,02 & 2,01 & 1,97 & 15,94 \\
1988 & 28,01 & 20,05 & 11,23 & 7,00 & 5,07 & 3,62 & 3,02 & 2,42 & 2,00 & 17,56 \\
1989 & 26,26 & 19,81 & 10,92 & 7,37 & 5,41 & 3,77 & 2,56 & 2,52 & 1,92 & 19,46 \\
1990 & 27,04 & 18,21 & 11,65 & 7,02 & 5,65 & 3,97 & 3,08 & 2,18 & 1,98 & 19,21 \\
1991 & 25,48 & 19,12 & 11,96 & 7,33 & 5,42 & 4,09 & 3,11 & 2,39 & 1,81 & 19,29 \\
1992 & 26,44 & 18,38 & 11,59 & 7,76 & 4,78 & 4,05 & 3,14 & 2,39 & 2,39 & 19,08 \\
1993 & 26,32 & 18,41 & 11,40 & 7,58 & 4,98 & 4,17 & 3,13 & 2,50 & 1,82 & 19,69 \\
1994 & 26,43 & 19,07 & 11,08 & 7,12 & 4,82 & 4,31 & 3,21 & 2,13 & 1,71 & 20,13 \\
1995 & 26,35 & 18,54 & 11,19 & 7,16 & 5,34 & 3,93 & 2,76 & 2,19 & 2,17 & 20,36 \\
1996 & 28,76 & 19,17 & 10,94 & 6,70 & 4,70 & 3,75 & 2,93 & 2,03 & 2,01 & 19,01 \\
1997 & 29,25 & 19,37 & 10,19 & 6,81 & 4,52 & 3,82 & 3,17 & 1,97 & 1,95 & 18,97 \\
& & & & & & & & & & \\
\hline
\end{tabular}

Fuente: Elaboración propia a partir de un panel de empresas encuestadas por el INE entre 1980 y 1997.

que aprovechan las economías de escala en producción y distribución asociadas con la estandarización. Esto ha ocurrido en Chile, por ejemplo, con muchos productos de consumo masivo tales como los alimentos envasados, la ropa o los vinos. Todo esto implica que la distribución de tamaños de empresas debería desplazarse hacia la derecha, aumentando el tamaño promedio de las firmas a medida que aumenta el ingreso.

Al mismo tiempo, los países más ricos tienen considerablemente más capital físico y humano por persona que los más pobres. Por esta razón el tamaño promedio de las firmas tiende a ser mayor. ¿Por qué? Por un lado, la mayor abundancia relativa de capital físico promueve la aplicación de técnicas de alto costo, las que muy frecuentemente vienen asociadas a tamaños eficientes de plantas mayores, en parte porque las tecnologías intensivas en mano de obra son casi por naturaleza 


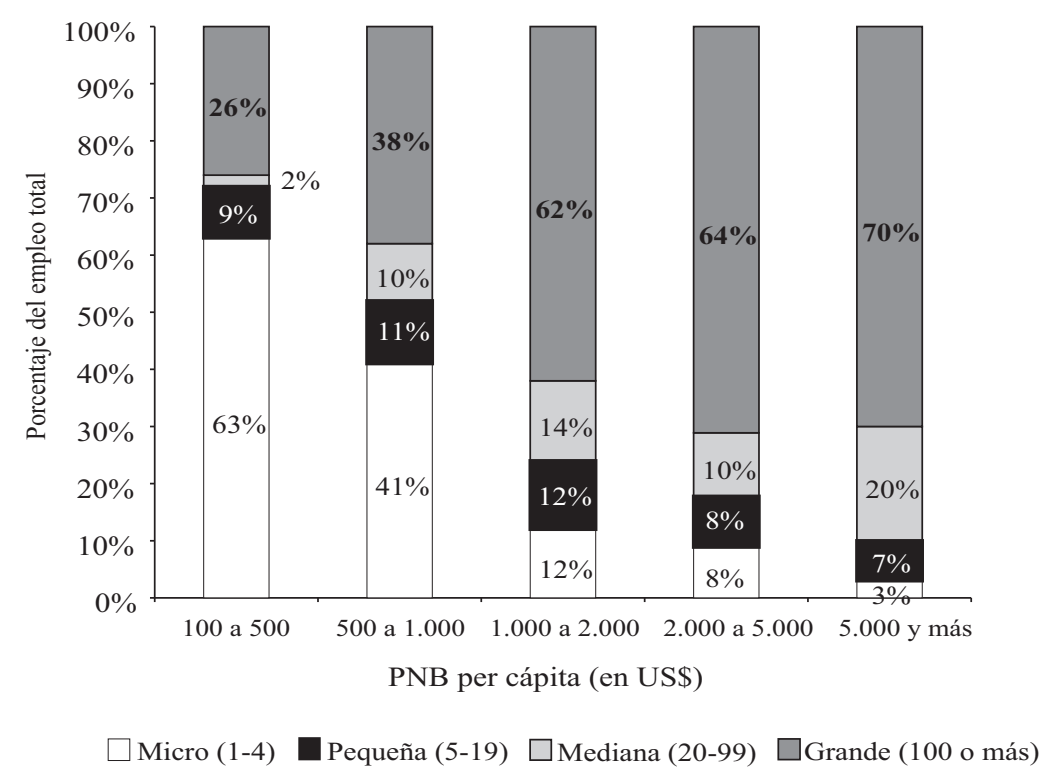

Fuente: Snodgrass y Biggs (1996)

divisibles. Por el otro, la mayor abundancia de capital físico y humano aumenta los salarios y parte de los microempresarios (o trabajadores por cuenta propia) prefieren emplearse en empresas. Más capital humano también implica ingresos por hora mayores, aun si se trata de empresarios individuales; si, por ejemplo, la categoría "microempresa" se sigue definiendo con el mismo nivel de ventas, la fracción de empleados por cuenta propia que sobrepasen el umbral será mayor y esto hará caer el número medido de microempresas.

Hecho 24. A medida que el país se desarrolla, el tamaño de las empresas va aumentando. Esto es consecuencia de la acumulación de factores - capital humano y físico-que es inherente al desarrollo económico.

Sin embargo, sería equivocado pensar que las pequeñas y medianas empresas desaparecerán a medida que Chile se desarrolle, principalmente porque la evidencia lo desmiente de manera palmaria —en las economías desarrolladas abundan pequeñas y medianas empresas-. El 
hecho básico es que el desarrollo económico no implica que el tamaño eficiente de planta en todas las actividades deba crecer a escalas que hagan económicamente inviables a las pequeñas y medianas empresas. Más aún, como vimos más arriba, el desarrollo económico estimula la demanda de variedad y de diferenciación horizontal de productos, nichos que son aprovechados por las pyme cuando la escala eficiente es suficientemente pequeña. De modo similar, algunos bienes o servicios diferenciados verticalmente y de muy alta calidad son producidos por empresas pequeñas — por ejemplo, los restaurantes sofisticados, los hoteles exclusivos, las galerías de arte o las empresas de servicios personales-.

También sería un error afirmar que el crecimiento "perjudica a las pyme”. La pregunta relevante es si acaso perjudica a los trabajadores y empresarios que viven de ellas ${ }^{32}$. Adicionalmente, como veremos más abajo, gran parte del crecimiento de la productividad se debe al proceso de reemplazo de empresas menos eficientes por otras más eficientes. La única manera de que los salarios y los ingresos crezcan es que la economía sea más productiva y esto ocurre en gran medida por el reemplazo de empresas y plantas.

\section{La desaparición de las pyme: cambio tecnológico y ajuste industrial.}

Es frecuente escuchar que en algunos sectores las empresas grandes "están matando" a las chicas. Por ejemplo, en los últimos años se han visto reestructuraciones bastante violentas en sectores tales como los abarrotes y supermercados, las farmacias, las tiendas de arriendo de videos o las ferreterías, cuando muchas empresas pequeñas o medianas han sido reemplazadas por cadenas de tiendas. ¿Se trata esto de una tendencia global hacia la desaparición de las pyme?

La respuesta es no. Parte de la dinámica industrial consiste en cambios tecnológicos que aumentan la escala eficiente de operación ${ }^{33}$. Por ejemplo, en los casos comentados el cambio tecnológico detrás de la reestructuración del sector es el manejo centralizado de inventarios, que permite aprovechar las así llamadas “economías de escala estocás-

${ }^{32}$ Claramente, el empleo no cae, porque, si bien las empresas grandes son intensivas en capital, cuando el capital es más abundante también hay más empresas grandes.

${ }^{33}$ La idea de que la tecnología de una industria es superada por una innovación que disminuye el costo de producción pero requiere de mayor escala ha sido desarrollada por Jovanovic y MacDonald (1994). 
ticas": al manejarse los inventarios en línea, se disminuyen fuertemente las necesidades de mantener inventarios de reserva para garantizar un nivel dado de seguridad de abastecimiento. Los cambios tecnológicos que aumentan la escala eficiente de operación posibilitan que algunas empresas crezcan (v. g. Santa Isabel en los supermercados, Fasa en farmacias, Home Center en ferreterías) o entren grandes (v. g. Carrefour o Home Depot) y salgan las empresas más pequeñas.

En todo caso, sería un error pensar que el cambio tecnológico sesga la estructura industrial en contra de las pequeñas y medianas empresas. Muchas veces ocurre que la innovación tecnológica disminuye la escala de eficiencia de operación. Así lo muestran, por ejemplo, el caso de la empresa productora de tolvas (véase el Recuadro $N^{\circ} 6$ ); las bebidas gaseosas, donde la introducción de los envases de pete permitió disminuir considerablemente la escala eficiente de planta; $y$, por supuesto, las empresas puntocom que venden servicios (véase, por ejemplo, Cubillos [2001]).

Conectividad y la revolución tecnológica. Lo central de la revolución tecnológica en las comunicaciones y la informática es que los costos de captar, procesar y transmitir datos e información de todo tipo han caído dramáticamente y seguirán haciéndolo. ¿Qué implican estos cambios para las pequeñas y medianas empresas?

Como se puede apreciar con más detalle en el Recuadro $\mathrm{N}^{\circ} 7$, las nuevas tecnologías afectan y disminuyen tanto el costo de las comunicaciones internas de la empresa como el de las comunicaciones externas. Por un lado, cuando cae el costo de las transacciones internas es factible administrar organizaciones más grandes. Esto debería desplazar la distribución de tamaños de empresas hacia la derecha. Los casos citados en la subsección precedente (los supermercados, las farmacias y las ferreterías) son ejemplos en que la disminución de los costos de comunicación internos permitieron manejar más eficientemente los inventarios. Estos bajos costos más el hecho de que las compras en volúmenes más grandes permiten acceder a mayores descuentos por las economías de escala inherentes a las partidas más grandes, impulsan drásticos aumentos del tamaño de las empresas.

Pero, por otro lado, las comunicaciones externas más baratas tienden a favorecer la externalización de las actividades. Primero, será más factible controlar la calidad del proceso de producción y distribu- 


\section{RECUADRO N N $^{\circ}$ : LAS ETAPAS DE LA CONECTIVIDAD}

[Extractado de Díaz (2001)] “[...] si bien no se puede dar una receta de a dónde llegar, sí se puede decir desde dónde partir. [...] Lo primero son los sistemas internos. [...] Respecto de Internet, la conexión básica es lo que prácticamente todos ya tienen y que a un costo de 40 ó 50 dólares mensuales, permite un retorno inmediato de varias decenas o centenas de veces ese costo. [...] La herramienta de e-mail, que es la aplicación internet más usada y el acceso web, que permite contar con una cantidad gigantesca de información gratis, más que justifican ese costo. La segunda posibilidad [...] es el sitio web corporativo, en la cual la empresa básicamente ha trasladado sus memorias, sus folletos y sus catálogos [...]. Esto también tiene hoy día un costo que puede ser bajísimo, de hecho, en EE.UU. ya hay empresas que lo ofrecen en forma gratuita y en Chile se puede realizar por 30 ó 40 dólares al mes. Ahora, este costo, comparado con el de imprimir y enviar un folleto a alguien, que deber ser dos o tres dólares, muestra un poco la diferencia de costos que existe entre Internet y el mundo tradicional. [...]

La tercera etapa [e]s cuando queremos realizar un intercambio formal y estructurado de información, lo cual requiere un sitio que llamamos web dinámico. Eso permite, por ejemplo, que un cliente pueda comprar, [...]. Puede que la orden de compra se finiquite finalmente por papel y por fax, pero de todas maneras se ha disminuido el costo de todo ese proceso para ambas partes, en forma realmente impresionante. [...] Dicha etapa no es nada trivial, porque exige tener una relación estrecha con los sistemas internos, los cuales a veces no tienen la calidad de información, ni la disponibilidad, ni la infraestructura necesaria, la cual tiene que estar 24 x 7, es decir, 24 horas por siete días a la semana arriba [...].

Una cuarta fase es mirar hacia atrás, hacia los proveedores. Aquí, la parte más trivial, es el reverso de la medalla de la anterior, en la que algunos de mis proveedores tienen sitios con los cuales se puede transar. Probablemente, lo primero será usarlo para los insumos indirectos, como artículos de oficina, computadoras, equipos de aire acondicionado y cosas por el estilo. Porque en esos insumos, generalmente yo no tengo una relación largo plazo con el proveedor y puedo ganar mucho por una mejor negociación, ya sea juntando los requerimientos de toda la empresa o quizás, hasta juntándose con otras empresas, para negociar un paquete aún más grande de com- 
pra. También algunos servicios indirectos, como por ejemplo los viajes, son los pasos inmediatos que yo implementaría en cualquiera empresa en la relación hacia atrás con los proveedores.

Sin embargo, hay otra faceta que no es tan obvia. Así como los proveedores interactúan con sus empresas clientes para darles acceso a sus sistemas, también pueden hacerlo para ofrecer servicios que antes ellas realizaban internamente. Creo que esta es una tendencia más fuerte, porque al existir la posibilidad de comunicarse rápido, existe también la posibilidad de coordinación con una empresa externa, para hacer cosas que antes no se podían externalizar. Y mientras más pequeña la empresa más interactivo es esto, porque aparece una forma de tener un servicio de calidad, cuando no se tiene la posibilidad de contratarlo y generarlo internamente, por ejemplo, en cosas como el manejo de personal, desde la contratación hasta el pago de remuneraciones, en logística de almacenamiento, distribución, empaquetamiento, etc.

Una quinta forma posible [...] es la integración con un sitio externo de comercio electrónico, o market place, de los cuales hay muchos tipos. Hay algunos de alcance local y otros internacional, según el origen de las empresas [...]. Hay portales horizontales, en el sentido que promueven elementos que se usan en diferentes industrias, como por ejemplo, suministros de oficina, o en el tema financiero, que sirven para buscar un mejor crédito, o en logística, para contactarse con un proveedor de transporte o de almacenamiento. Y hay también portales verticales, que son aquellos orientados a una industria específica, en los que, típicamente, se mantienen catálogos de productos conjuntos y que automatiza[n] la búsqueda y selección de esos productos.

Por último, hay portales que se llaman públicos, que son típicamente hechos por alguien independiente, que junta muchos proveedores con muchos compradores, y hay portales privados, aunque no son tan privados porque no tendría sentido, que son privados en el sentido de que su propiedad y a veces su gestión, está en torno a un grupo de empresas o consorcio de empresas. Por ejemplo, las empresas automovilísticas americanas partieron con un portal orientado exclusivamente a los insumos de la industria automotriz, donde se daba el servicio de cotizar. Hay otros que establecen catálogos de productos, que permiten licitar, proveer servicios anexos, como logística, financiamiento o alternativas de pago, para complementar el proceso de transacciones del portal.” 
ción sin necesidad de integrar verticalmente las actividades dentro de una sola empresa más grande, porque se pueden coordinar electrónicamente los canales de proveedores o distribuidores. En estos casos es muy probable que las empresas más grandes estén dispuestas a pagar el costo en que se debe incurrir para que las empresas más pequeñas adopten nueva tecnología, porque se benefician de los excedentes que se crean por la mayor eficiencia.

La segunda razón es que las comunicaciones externas más baratas hacen factibles a empresas que, en esencia, se dedican a ahorrarles costos fijos a muchas otras coordinando y consolidando actividades. Por ejemplo, la empresa SOS Logística ofrece servicios de abastecimiento, almacenaje y distribución de bienes y actúa como agente de los clientes ante los proveedores. A través de internet y una red local, clientes y proveedores se conectan con un sistema de transacciones continuo, el cual proporciona información en línea sobre los productos, disponibilidad, precios, seguimiento de solicitudes de reposición, órdenes de compra, pedidos y reclamos. SOS estimula las relaciones de largo plazo con proveedores, acordando con ellos presupuestos anuales de consumo revisados mensualmente, lo que permite programar mejor la producción. Al disminuir los costos de acceder a varios clientes simultáneamente, se aumentan los volúmenes de cada orden. Y los servicios de bodegaje, handling, embalaje, permiten que, en realidad, muchos proveedores pequeños compartan costos fijos a través de SOS Logística.

La caída de los costos de comunicación es particularmente relevante para reducir los costos de inventarios, tanto de empresas grandes como de las más pequeñas, porque la coordinación de actividades reduce la incertidumbre y las necesidades de mantener unidades de reserva. Por ejemplo, calzados Guante S. A. modificó radicalmente sus procesos logísticos cuando conectó en línea a sus tiendas en 1998 y luego a otros clientes minoristas importantes. Según su gerente general, esto le permitió coordinar la producción y las ventas disminuyendo su ciclo de producción de 20 a 8 días, su stock de inventarios de producto de cuatro a 1,5 meses y su tasa de entregas atrasadas de $30 \%$ a $7 \% 34$. Algo similar ocurre con las empresas de servicios. Éstas pueden disminuir los tiempos ociosos de sus empleados si coordinan mejor sus

${ }^{34}$ Véase Halcartegaray (2001). 
actividades. Si bien no se trata de una pyme, es ilustrativo considerar el caso de Metrogas. Uno de los problemas que enfrentó cuando instaló el gas natural en Santiago fue cómo minimizar el tiempo ocioso de las cuadrillas de trabajo. Solucionó su problema logístico centralizando las decisiones en una sola unidad que manejaba un programa de optimización y le indicaba por radio a cada cuadrilla a qué lugar de la ciudad debía dirigirse.

\section{LOS PROBLEMAS DE LAS PYME}

\subsection{Introducción: ¿Cuándo hay un "problema”?}

Gran parte del análisis y las propuestas de política pública parten de la premisa de que existen fallas de mercado que limitan el acceso de las pyme a los mercados financieros y a una mejor gestión. La dificultad para acceder a estos recursos limita su desarrollo y no les permite aprovechar las economías de escala y ser más competitivas frente a las empresas de mayor tamaño. Esta visión es tan generalizada y compartida que conviene reflexionar sobre dos preguntas para entender mejor los "problemas” de las pyme. Primero, ¿que significa que existan "fallas de mercado” en el contexto de las pyme? Segundo, ¿cuáles son sus consecuencias para las pyme y para el país?

Cuando los economistas afirman que existe una "falla de mercado” están pensando en situaciones en las que la asignación de los recursos en los mercados no genera el máximo valor que podría lograrse. En este sentido el mercado fracasa en asignar los recursos en actividades y usos en que su potencial de crear valor es mayor. En el ámbito de las pyme esto significaría que en los mercados financieros y de capital humano existen distorsiones que obstaculizan que estas empresas puedan financiarse y contar con una calidad de gestión adecuada, recursos que terminan destinándose a otros usos que contribuyen en menor medida al bienestar.

El financiamiento insuficiente resultaría en que existen menos pyme que las que debería haber. El argumento es que muchas pyme que podrían invertir en proyectos económicamente rentables no lo pueden hacer y se pierden valiosas oportunidades de crecimiento. Actividades que podrían desarrollar las pyme de manera más eficiente terminan siendo realizadas por empresas más grandes a un mayor 
costo, lo que encarece la producción. Muchas pyme, siendo económicamente viables, no sobrevivirían una recesión porque no serían capaces de financiar una caída transitoria de sus ventas y desaparecerían así negocios rentables que dejarían de contribuir al desarrollo del país. Por último, la falta de financiamiento haría que muchas pyme no sean capaces de crecer y su negocio termine siendo arrebatado por las empresas más grandes. Por otra parte, la deficiente gestión de las pyme, que se reflejaría en su baja productividad, también resultaría en una mala utilización de los recursos. Ello hipotecaría gravemente las posibilidades de desarrollo del país considerando la gran cantidad de pyme que existen y la cantidad de personas que emplean.

En lo que sigue analizamos si estos supuestos "problemas" de las pyme existen y si realmente pueden asociarse a fallas de mercado.

\subsection{Financiamiento para las pyme: ¿poco y caro?}

No es una exageración afirmar que la mayoría acepta como un hecho palmario que las pyme tienen acceso inadecuado y caro al crédito y esto es ineficiente porque muchos proyectos rentables no se ejecutan —en otras palabras, existiría una "falla de mercado" que impide financiar muchos proyectos buenos que podrían ejecutar las pyme- En esta sección sostendremos que la historia es algo más complicada. Para comenzar, no hay evidencia de que en Chile las pyme reciban menos financiamiento que las empresas grandes. Y si bien es razonable pensar que hay proyectos buenos que nunca reciben financiamiento, la dinámica de las pyme que revisamos en la sección 2.2 sugiere que existe otro problema similarmente importante: muchas veces quienes tienen ideas no saben que son malas y el costo de experimentar es más bajo cuando es otro quien pone el capital. Por eso, cuando se evalúa la performance del sistema financiero no se puede considerar únicamente cuántos proyectos "buenos" se rechazan sino, más importante aún, cuántos proyectos malos reciben financiamiento. En esa dimensión, el sistema financiero chileno parece hacerlo bien, y esto explica por qué las tasas de incumplimiento son bajas.

En la primera parte de la sección discutiremos por qué el problema de la selección — separar a los proyectos rentables de aquellos que fracasarán - implica que muchos proyectos y empresas no recibirán financiamiento si el sistema financiero funciona adecuadamente. Los 
conceptos básicos son riesgo y "asimetrías de información” —el deudor conoce mejor sus características que el intermediario que le presta-. Presentaremos evidencia de que las asimetrías de información son un hecho en todos los países, independientemente de cuán desarrollado sea su mercado de capitales, y examinaremos sus implicancias para el financiamiento de las pyme. Más aún, las altas tasas de fracaso de empresas a cinco o diez años sugieren que no existe crédito de largo plazo sin garantías porque éste sería muy caro. En la segunda parte de la sección examinaremos la situación en Chile. Mostraremos que no hay evidencia que sugiera que las pyme son discriminadas en el mercado del crédito. En la tercera parte evaluamos los programas de rescate y apoyo financiero a pyme financiados por el Estado. Por último, proponemos mejoras que aumentarían la competencia y la información en el mercado del crédito y que beneficiarían a todas las empresas pero particularmente a las más pequeñas.

\subsubsection{Incentivos y el mercado del crédito: riesgo y asimetrías de información}

Finalmente, se suele justificar el diagnóstico de que el mercado del crédito es imperfecto y discrimina a las pyme con argumentos tales como que el retorno social de la inversión en las pyme sería mayor que el retorno privado debido al desempleo, las carteras de los bancos estarían sólo parcialmente diversificadas o la mayoría de las pyme tienen garantías insuficientes para respaldar los créditos. Todo esto se traduce en que las pyme pagan tasas más altas que los deudores grandes y tienen peor acceso al crédito. A continuación mostramos por qué es razonable esperar que las pyme enfrenten condiciones que aparecen como peores que las que enfrentan las empresas grandes pero que obedecen a que las pyme son más caras de financiar: su costo administrativo es mayor, son más riesgosas y la información que son capaces de proveer es peor.

Costos fijos. Los costos administrativos y operacionales son en gran medida independientes del monto del crédito. Por lo anterior, mientras menor sea la cuantía de un crédito, mayor será, proporcionalmente hablando, el costo por este concepto. No hay muchos estudios sistemáticos sobre costos administrativos por tamaño de deudor en 
Chile, pero la evidencia presentada por Basch (1995) sugiere que el costo total de prestarles a las pyme es mayor. Como se aprecia en el Cuadro $\mathrm{N}^{0} 10$, los costos administrativos como porcentaje del crédito son alrededor de tres puntos más para pyme $(3,7 \%$ vs. $1 \%$ en la primera institución; 5,7\% vs. 0,3\% en la institución 2).

Los costos fijos crean economías de escala a nivel de cada deudor (pero no a nivel de mercado). Una consecuencia directa es el encarecimiento relativo de los créditos concedidos a las pyme. Otra consecuencia clara, que para muchos puede parecer cierto tipo de discriminación, es el surgimiento de dos tipos de empresas que se distinguen por la clase de atención que reciben en el banco. Foxley (1999) distingue entre "empresas que reciben atención personalizada” y “empresas que reciben atención al mayoreo”.

Hecho 25. Una parte importante de los costos administrativos de prestar es fija. Luego, este costo fijo debería reflejarse en una tasa de interés más alta pagada por las empresas más pequeñas.

Riesgo de no pago. Una parte importante de los costos de un banco son los créditos que se pierden total o parcialmente. Para que un banco sea viable y rentable los ingresos por intereses de aquellos deudores que pagan deben compensar las pérdidas de intereses y capital por créditos que no se repagan. La evidencia indica que, en general, las pyme tienen tasas de incumplimiento mayores que las empresas grandes. Por ejemplo, como se aprecia en el Cuadro $\mathrm{N}^{0} 11$, la tasa de deudas vencidas de créditos a empresas pequeñas es considerablemen-

CUADRO N 10: COSTOS DE TRANSACCIÓN POR TAMAÑO DE EMPRESA

(Como porcentaje del préstamo)

\begin{tabular}{llllll}
\hline & \multicolumn{2}{c}{ Institución 1} & & \multicolumn{2}{c}{ Institución 2} \\
\cline { 6 - 6 } \cline { 5 - 6 } & Grande & Pyme & & Grande & Pyme \\
\hline Costos administrativos & 1,0 & 3,7 & & 0,3 & 5,7 \\
Riesgo de pérdida & 2,8 & 4,2 & & 2,0 & 3,6 \\
Total & 3,8 & 7,9 & & 2,3 & 9,3 \\
\hline
\end{tabular}

Nota: Los costos administrativos son costos de evaluación, otorgamiento y recuperación del crédito. El riesgo de pérdida son las reservas por el riesgo de no pago.

Fuente: Basch (1995, Cuadro $\mathrm{N}^{\circ}$ 3.18). 
CUADRO N ${ }^{\circ}$ 11: DEUDA BANCARIA VENCIDA POR TAMAÑO DE EMPRESA

\begin{tabular}{|c|c|c|c|c|c|}
\hline & Micro & Pequeña & Mediana & Pyme & Grande \\
\hline \multicolumn{6}{|l|}{1994} \\
\hline Deuda vigente (millones UF) & 77.185 & 103.471 & 89.837 & 193.308 & 392.542 \\
\hline Deuda vencida (millones UF) & 1.923 & 2.792 & 626 & 3.418 & 1.518 \\
\hline$\%$ de créditos vencidos* & $2,43 \%$ & $2,63 \%$ & $0,69 \%$ & $1,74 \%$ & $0,39 \%$ \\
\hline \multicolumn{6}{|l|}{1997} \\
\hline Deuda vigente (millones UF) & 92.195 & 151.872 & 112.006 & 263.878 & 509.255 \\
\hline Deuda vencida (millones UF) & 3.206 & 2.347 & 771 & 3.118 & 2.073 \\
\hline$\%$ de créditos vencidos & $3,36 \%$ & $1,52 \%$ & $0,68 \%$ & $1,17 \%$ & $0,41 \%$ \\
\hline \multicolumn{6}{|l|}{1998} \\
\hline Deuda vigente (millones UF) & 90.672 & 154.680 & 115.327 & 156.678 & 533.669 \\
\hline Deuda vencida (millones UF) & 3.311 & 4.394 & 2.180 & 6.392 & 5.379 \\
\hline$\%$ de créditos vencidos & $3,52 \%$ & $2,76 \%$ & $1,86 \%$ & $3,92 \%$ & $1,00 \%$ \\
\hline \multicolumn{6}{|l|}{1999} \\
\hline Deuda vigente (millones UF) & 85.550 & 141.935 & 108.314 & 250.249 & 527.448 \\
\hline Deuda vencida (millones UF) & 3.846 & 6.094 & 3.324 & 9.418 & 4.494 \\
\hline$\%$ de créditos vencidos & $4,30 \%$ & $4,12 \%$ & $2,98 \%$ & $3,63 \%$ & $0,84 \%$ \\
\hline
\end{tabular}

* El porcentaje de créditos vencidos corresponde a razón de la deuda vencida sobre la deuda total.

Fuente: Román (2000, Cuadros Nos 6, 6-A y 9).

te mayor que las de empresas grandes (2,63\% vs. 0,39\% en $1994 \mathrm{y}$ $4,12 \%$ vs. $0,84 \%$ en 1999$)$. De esto se sigue inmediatamente la siguiente consecuencia:

Hecho 26. Las pyme fracasan más que las empresas grandes; luego, la tasa de interés que pagan debería ser mayor.

El hecho 26 tiene una implicancia importante. La fuente primaria del riesgo es la incertidumbre de si a la empresa le irá bien o no, riesgo que nunca se puede eliminar. Como vimos, el riesgo de fracaso es más alto a medida que decrece el tamaño de la empresa. Por lo tanto, las pyme pagarían tasas de interés más altas aun si el banco contara con la misma información que el deudor.

El hecho 26 también permite identificar la razón primaria de por qué es muy difícil que se entregue crédito a largo plazo respaldado meramente con la expectativa de flujos. Como vimos en la sección 2, la 
tasa de fracasos de empresas es alta, y al cabo de incluso cinco años una fracción importante sale y desaparece — vale decir, no genera flujo alguno al momento en que debería pagar el crédito-. Si existiera crédito a, digamos, diez años, aquellos que pagan de vuelta deberían compensarle al banco las pérdidas por prestarles a las empresas que desaparecen.

Hecho 27. La tasa de fracaso de pequeñas y medianas empresas observada implica que el costo del financiamiento de largo plazo sería mucho más alto que una serie de créditos de corto plazo renovables si la situación de la empresa lo justifica.

Asimetrías de información: ¿qué son? El mayor riesgo inherente a las pyme es un segundo problema: las asimetrías de información. Se da una asimetría de información cuando una de las partes que transa conoce con mayor precisión la información relevante para valorar el bien o servicio. El ejemplo clásico debido a Akerlof (1970) son los autos usados: quien vende conoce el estado del auto y su valor con mucho mayor precisión. Pero el problema también se presenta cuando se trata de prestarle plata a una empresa. En particular, existen dos fuentes principales de asimetrías de información entre un prestamista y una pyme. En primer lugar, como vimos en la sección 2.2, en todo momento las firmas rentables conviven con firmas que van a fracasar y salir en poco tiempo más y sus dueños tienen mejor información que los financistas sobre sus probabilidades de sobrevivencia. En segundo lugar, las firmas pequeñas generan peor información que las grandes, en parte porque los requerimientos legales son menos exigentes, pero sobre todo porque generar información es, en gran medida, un costo fijo. Por eso, las empresas más pequeñas no suelen tener estados contables auditados que reflejen confiablemente su situación.

Selección adversa y daño moral. La información asimétrica genera varios problemas, los que se pueden clasificar en dos categorías, selección adversa y el daño moral (moral hazard) ${ }^{35}$. La selección adversa

${ }^{35}$ Moral hazard es una expresión técnica que viene de la literatura de los seguros y que denota el hecho de que cuando alguien contrata un seguro contra un tipo de siniestro generalmente modifica su comportamiento y la probabilidad del siniestro aumenta. Por ejemplo, cuando uno asegura su auto contra robo se preocupa menos dónde estacionarlo. 
ocurre porque hay deudores cuya probabilidad de éxito es menor que la de otros. Por ejemplo, algunos empresarios son gestores más capaces que otros y, por ende, la probabilidad de que sobrevivan es mayor. Sin embargo, a priori el banco no siempre puede discriminar quién es quién. Los malos deudores (los incompetentes, flojos o deshonestos) no son inofensivos, sino que perjudican a los buenos (los competentes, diligentes y honestos) porque las tasas de interés que pagan estos últimos deben, además, compensar las pérdidas que generan los que fracasan. Pero, además, Akerlof (1970) y luego Stiglitz y Weiss (1981) mostraron que cuando la proporción de malos deudores es suficientemente grande, no es posible distinguir entre ellos y todos enfrentan la misma tasa de interés y el mercado podría dejar de funcionar. ¿Por qué?

Como vimos, a medida que aumenta la proporción de deudores cuya probabilidad de fracaso es alta, la tasa de interés que pagan los exitosos debe aumentar. Por esta razón, si se tiene un proyecto bueno, progresivamente se va haciendo peor negocio endeudarse ${ }^{36}$. En otras palabras, cuando aumenta la tasa de interés las buenas empresas eligen salir del mercado — de ahí el término "selección adversa”- Stiglitz y Weiss (1981) mostraron que en algún momento al banco no le conviene seguir subiendo la tasa de interés porque sólo las empresas con alta probabilidad de fracasar estarían dispuestas a endeudarse y en ese caso el crédito se raciona (vale decir, no todos los que quieren endeudarse consiguen hacerlo). Más aún, cuando el problema de selección adversa es suficientemente severo y la proporción de malos deudores es suficientemente alta, la probabilidad de repago es tan baja que tampoco vale la pena prestar; en palabras de Akerlof (1970), el mercado desaparece.

El problema creado por la selección adversa no es "teórico" en el sentido peyorativo del término. La serie de estudios editados por Pagano (2001) muestra que el principal obstáculo para que surja un mercado del crédito eficiente en países en desarrollo — vale decir, uno que financie proyectos rentables y descarte los inconvenientes - son las trabas legales que impiden descartar deudores y disminuir las tasas de incumplimiento. Por ejemplo, gran parte de la razón de por qué no existe una industria de capital de riesgo en Chile se debe a que aún no se ha

${ }^{36}$ Por ejemplo, a medida que aumenta la tasa de interés, al buen gestor se le hace más rentable postergar su proyecto y financiarlo con utilidades retenidas. 
desarrollado la capacidad técnica suficiente para descartar una proporción suficientemente alta de malos proyectos. Similarmente, las tasas de fracaso de microempresas son considerablemente más altas que las de las pyme y las empresas grandes. Por lo tanto, no es muy sorprendente que muchos tipos de microempresas no tengan acceso a crédito.

Ahora bien, se desprende de la discusión anterior que la mayor parte del trabajo de los intermediarios financieros no consiste en seleccionar buenos proyectos sino en descartar los malos. Por otro lado, la sección 2.2 mostró que las tasas de falla y salida de empresas son elevadas en Chile, pero también en el resto del mundo. Por eso podemos establecer el siguiente hecho:

Hecho 28. Si el sistema financiero funciona bien y selecciona mayoritariamente buenos proyectos, muchas firmas, sobre todo pequeñas, no recibirán crédito. La selección estricta favorece a las buenas empresas porque les disminuye el costo de fondos.

El hecho 28 es muy importante porque va en contra de la creencia bastante generalizada de que un mercado de capitales eficiente financia a la mayoría de los empresarios que llegan a pedir financiamiento. Al respecto, es interesante notar qué ocurre en los Estados Unidos, país que cuenta con el mercado de capitales más desarrollado del mundo. Berger y Udell (1998) reportan que sólo la mitad de las firmas pequeñas mantiene créditos con el sistema bancario. Por otro lado, Silver (1996) y Fenn et al. (1995, p. 30) indican que los capitalistas de riesgo (bajo todo punto de vista considerados exitosos) rechazan 99 de cada 100 proyectos que evalúan (véase la discusión sobre capital de riesgo más abajo).

El segundo problema que causa la información asimétrica es el daño moral. Éste ocurre porque los incentivos cambian cuando una empresa se endeuda. La razón fundamental es que si a la empresa le va mal, comparte las pérdidas con el banco; por el contrario, si le va bien, se queda con gran parte de las utilidades. Una amplia literatura originada en el trabajo de Stiglitz y Weiss (1981) muestra que el riesgo que la empresa elige tomar aumenta y los estímulos a ser diligente y trabajar duro decaen a medida que el deudor disminuye su compromiso de capital propio, lo que disminuye la probabilidad de repago. Las reglas de regulación prudencial a las que están sujetos los bancos y que 
apuntan a controlar el riesgo tienen exactamente la misma motivación. Si existe un seguro estatal explícito o implícito para los depósitos, los dueños del banco tienen incentivos para tomar más riesgo del conveniente. Esto se traduce en que los proyectos y empresas financiados son más riesgosos y de peor calidad.

Mecanismos que mitigan las asimetrías de información. La selección adversa y el daño moral motivan una serie de mecanismos que usan los intermediarios financieros para mitigar sus consecuencias. Estos mecanismos son diversos, pero en todos los casos su objetivo es facilitar la creación de información o bien alinear los incentivos del deudor con el interés del prestamista ${ }^{37}$. Es importante notar desde ya que varios de estos mecanismos implican restricciones al acceso de crédito — $\mathrm{v}$.g. límites máximos de endeudamiento, requerimientos de garantías, registro centralizado del historial crediticio, plazos cortos, etc.- y frecuentemente son citadas como indicación de que el mercado del crédito no funciona bien. Sin embargo, como veremos a continuación, éstas no son fallas de mercado sino precisamente respuestas apropiadas a los problemas causados por la información asimétrica. Más aún, si bien el efecto directo es que restringen el acceso de algunas empresas al crédito, la consecuencia es que aumentan el acceso de los buenos deudores y disminuyen la tasa de interés que éstos tienen que pagar.

La respuesta más obvia a la selección adversa es que el financista se informe - v.g., que visite las instalaciones de la empresa, converse con los administradores, estudie sus estados financieros-, precisamente lo que hacen intermediarios financieros tales como bancos, empresas de factoring o capitalistas de riesgo. Hay evidencia bastante amplia de que en los países desarrollados, particularmente en los Estados Unidos, los bancos adquieren información privada de sus deudores, aun si se trata de empresas grandes (las que, se supone, generan mejor información pública). Una serie de estudios hechos para los Estados Unidos ha encontrado que el precio de la acción de una empresa aumenta cuando se anuncia que ha cerrado un acuerdo de crédito con un banco, pero cae cuando la firma repaga créditos emitiendo deuda no intermediada (véase, por ejemplo, a James [1987], Lummer y McConnell [1989], Shockley y Thakor [1987]).

\footnotetext{
${ }^{37}$ Para un tratamiento más detallado se puede consultar a Freixas y Rochet
} (1997). 
Sin embargo, como se dijo, los estados financieros de las empresas pequeñas no son muy informativos. A lo anterior se suma que evaluar una empresa implica incurrir en un costo fijo, así que prestarles a las empresas más pequeñas es proporcionalmente más caro. Por último, el mismo hecho de que las empresas más pequeñas tengan tasas de fracaso más altas implica que una parte importante del costo de prestarles sea indirecto: para encontrar un buen deudor es necesario evaluar a varios malos deudores y prestarles equivocadamente a un $\operatorname{par}^{38}$. La tasa de interés que paga el buen deudor debiera reflejar esos costos indirectos de seleccionarlo, pero una vez que el buen deudor muestra que su riesgo es más bajo, éste tiene incentivos para cambiarse de banco en busca de una tasa de interés más baja ${ }^{39}$.

Se puede hacer poco contra el hecho de que el costo por unidad prestada a una empresa pequeña sea más alto que el de una grande, más allá de eliminar las regulaciones que le ponen tope a la tasa de interés que se puede cobrar (véase la propuesta en la sección 4.2.4). Por contraste, algunos argumentos justifican un subsidio cuyo objeto sea mejorar la información contable de las empresas y, tal vez, la certificación de empresas pequeñas. La razón es que el desarrollo de estados contables estandarizados y la información sobre la calidad del deudor son en gran medida bienes públicos y por ello los incentivos privados para generar esa información no son los más adecuados. Más aún, el solo hecho de tener un historial crediticio limpio facilita acceder a otras fuentes de financiamiento, en desmedro de la institución que invirtió en la relación de largo plazo que creó ese historial. En la sección 4.2.4 discutimos algunas propuestas concretas.

Hecho 29. Es posible que se justifique subsidiar el desarrollo de mecanismos que mejoren la información sobre las pyme y disminuyan el costo de informarse.

El segundo mecanismo que mitiga la selección adversa es la información sobre el historial crediticio del deudor y su nivel agregado de endeudamiento. Japelli y Pagano (1993 y 2001) muestran que cuan-

${ }^{38}$ Conversaciones con ejecutivos bancarios sugieren que este costo indirecto o de selección es la principal razón de por qué gran parte de las microempresas no son atractivas para los bancos.

${ }^{39}$ Este problema lo analizan en detalle Anand y Galetovic (2000) y Petersen y Rajan (1995). 
do los prestamistas comparten información la calidad de las empresas que piden crédito es mayor y la tasa de interés que pagan es menor. En Chile existe un mecanismo efectivo de información crediticia compartida —el Dicom — que les permite a los bancos conocer el historial de cumplimiento del deudor; además, la Superintendencia de Bancos acopia información sobre el nivel de endeudamiento y de incumplimiento de cada deudor al sistema bancario, el que está disponible para todos los bancos ${ }^{40}$.

Hecho 30. Las centrales de información crediticia que acumulan información sobre el incumplimiento pasado del deudor y de su nivel de endeudamiento aumentan el acceso y disponibilidad de crédito.

El tercer mecanismo que los bancos usan para mitigar la selección adversa es obligar al deudor a que comprometa garantías o aportes de capital propio. Se suele afirmar que cuando se exigen garantías se restringe el acceso al crédito y esto es perjudicial. Sin embargo, estas garantías son necesarias para alinear los incentivos del deudor con los intereses del prestamista. Cuando aquél compromete garantías arriesga su capital en el negocio y por ende tiene incentivos para pedir crédito sólo si estima que su empresa generará flujos suficientes para repagarlo. La literatura muestra que las garantías mitigan la selección adversa y por medio de restringir el financiamiento de malos proyectos mejoran el acceso al crédito a los buenos deudores — sin garantías la selección adversa sería tan severa que la cantidad de crédito disponible sería mucho menor- ${ }^{41}$. En todos los países del mundo los bancos exigen garantías y Chile no es la excepción. Fuentes y Maquieira (2001) muestran que en Chile poco más del 60\% de los créditos otorgados por bancos a empresas está respaldado por colateral u otro tipo de garantías ${ }^{42}$. Es ilustrativo compararlo con lo que ocurre en los Estados Unidos. Berger y Udell (1998) reportan que el 92\% de las deudas bancarias de empresas pequeñas tiene algún tipo de garantía y

\footnotetext{
${ }^{40}$ Para más detalles sobre Dicom véase Fuentes y Maquieira (1999). Es interesante destacar que el Dicom sólo registra información sobre incumplimiento. Los bancos y las casas comerciales guardan celosamente la información sobre buenos deudores y las veces que han respondido apropiadamente.

${ }^{41}$ Véase, por ejemplo, Stiglitz y Weiss (1981, 1986), Bester (1985), Chan y Kanatas (1985) y Besanko y Thakor (1987a, b)

${ }^{42}$ Esta cifra no distinguen por tamaño de deudor.
} 
el 54\%, colateral. Más aún, alrededor del 40\% de los créditos a empresas pequeñas (y cerca del $60 \%$ de los dólares prestados) se garantizan con el patrimonio personal de los dueños (Ang et al. [1995] y Avery et al. [1998]). Por último, y como lo propone Larraín (2001), tal vez sería conveniente acelerar el otorgamiento de título ejecutivo a las facturas, lo que mejoraría su calidad como garantías. Esto no es menor. Berger y Udell (1995) documentan que en los Estados Unidos las empresas pequeñas utilizan mayoritariamente los inventarios y cuentas por cobrar para garantizar líneas de crédito bancarias.

Hecho 31. Los registros de crédito, las garantías y el compromiso de capital propio son necesarios para alinear los incentivos del deudor con el interés del prestamista y mitigan las consecuencias de la selección adversa y el daño moral.

Algunos de estos mecanismos descritos también mitigan el daño moral. Por ejemplo, cuando existen registros precisos de incumplimiento o bien el deudor compromete garantías y capital propio, los incentivos para ser diligente, no incurrir en riesgos excesivos y trabajar duro son más fuertes porque el costo del incumplimiento es mayor. Además, uno de los estímulos más fuertes para pagar una deuda es la perspectiva de poder endeudarse en el futuro. Pero existen dos mecanismos adicionales para mitigar el daño moral.

El primero consiste en establecer relaciones de largo plazo con el deudor. Una amplia literatura indica que éstas mejoran la calidad del monitoreo del comportamiento del deudor, porque el banco o financista adquiere información privada de la firma. Por ejemplo, a medida que la relación se desarrolla el banco conoce mejor los flujos de caja de la firma, quiénes son sus clientes, o la frecuencia con que ejecuta distintos tipos de operaciones ${ }^{43}$. Aunque existe la posibilidad de que las relaciones de largo plazo le otorguen poder de mercado al banco (lo que se conoce como “monopolio de información”), la evidencia de países desarrollados indica que las firmas pequeñas se benefician con ellas porque pagan tasas de interés menores ${ }^{44}$, se les exige menos

${ }^{43}$ Reseñas de la literatura se encuentran en Berger (1999), Boot (2000) y Ongena y Smith (2000).

${ }^{44}$ Berger y Udell (1995), Degryse y Van Cayseele (2000), Harhoff y Körting (1998), Scott y Dunkelberg (1999). 
colateral $^{45}$, dependen menos del crédito de proveedores ${ }^{46}$ y se pueden endeudar más fácilmente ${ }^{47}$.

Sin embargo, la información que el financista adquiere a medida que se desarrolla la relación de largo plazo no sería muy útil si no pudiera retirar los fondos prestados apenas se dé cuenta de que el deudor está tomando más riesgo que el deseable, trabajando menos intensamente que lo conveniente o desviando los fondos para otros usos. Por eso, la posibilidad de retirar el crédito apenas el comportamiento del deudor cambia en la dirección incorrecta es muy importante para mitigar el daño moral y alinear los incentivos del deudor con los intereses del financista. Esto se logra cuando el plazo nominal de los créditos es corto y se van renovando siempre y cuando el comportamiento del deudor sea satisfactorio. Berger y Udell (1998) argumentan que la posibilidad de caducar el crédito en un plazo breve sustituye a las cláusulas contractuales que restringen el comportamiento del deudor. Estas cláusulas son más efectivas cuando se trata de sociedades anónimas abiertas, pero sería muy difícil hacerlas cumplir cuando la empresa es chica porque la calidad de la información que generan no es muy buena. De esta forma, los plazos cortos mejoran el acceso al crédito de las pyme.

Hecho 32. El crédito a plazos cortos permite monitorear mejor al deudor. Las relaciones de largo plazo entre el banco y el deudor transforman al crédito de corto plazo en financiamiento de plazo más largo.

En este sentido, se suele afirmar que las pyme no tienen acceso a financiamiento de largo plazo y que el Estado debiera suplir esta supuesta falla de mercado. La realidad, sin embargo, es distinta. La supuesta inexistencia de crédito de largo plazo se debe, muy probablemente, a la necesidad de controlar el daño moral. En efecto, tal como en países más desarrollados, en Chile existe crédito de largo plazo para financiar activos que se dan en garantía, por ejemplo bienes raíces o vehículos, pero no contra flujos futuros ${ }^{48}$. Pero sería a todas luces (1999).

${ }^{45}$ Berger y Udell (1995), Degryse y Van Cayseele (2000), Scott y Dunkelberg

${ }^{46}$ Petersen y Rajan (1994 y 1995).

${ }^{47}$ Cole (1998), Elsas y Krahnen (1998), Maschauer y Weber (2000), Scott y Dunkelberg (1999).

${ }^{48}$ Es interesante notar, por ejemplo, que los microempresarios taxistas tienen acceso bastante expedito al crédito. 
imprudente prestarles a las pyme a plazos largos sin más garantías que los flujos futuros esperados, por la sencilla razón de que los plazos largos atraerían a una proporción muy grande de empresas que fracasarán y, como vimos, eso motiva que las que tienen éxito deban pagar tasas más altas para compensar las pérdidas.

Es interesante notar que en los Estados Unidos más del 50\% de los créditos otorgados por las instituciones financieras a empresas pequeñas son líneas de crédito (véase a Berger y Udell [1998]). El resto es para financiar activos, generalmente prendados contra el crédito (hipotecas, equipos, vehículos y bienes de capital). Más aún, si se toma el epítome del financiamiento de largo plazo contra flujos, el capital de riesgo, se comprueba que las empresas nunca reciben todo el financiamiento de una vez, sino que se les va entregando a medida que el proyecto cumple etapas - el capitalista de riesgo siempre se reserva el derecho de dejar de financiar el proyecto (véase, por ejemplo, Gompers y Lerner [2000])—.

La información asimétrica es un hecho, no una falla de mercado. ¿Qué tan efectivos son estos mecanismos que usan los bancos para mitigar los problemas que causan las asimetrías de información en Chile? Una manera de averiguar qué tan lejos puede llegar un sistema financiero en mitigar las asimetrías de información y calibrar si lo que observamos en Chile sugiere grandes imperfecciones de mercado, es observar la estructura del financiamiento de las empresas en países donde la calidad de la información sobre ellas es mejor y los mercados financieros son más desarrollados. Como lo demuestran, entre otros, Myers (1984), Myers y Majluf (1984) y Nachman y Noe (1994), el patrón de financiamiento esperable si las asimetrías de información son importantes es que las empresas se financien primero con utilidades retenidas y aporte de los dueños, luego con deuda bancaria y por último con acciones y bonos vendidos en mercados de oferta pública. La razón es que el costo de los fondos propios es menor habida consideración que la selección adversa y el daño moral aumentan la tasa de interés exigida por financistas externos.

El Cuadro $\mathrm{N}^{0} 12$ muestra que en la mayoría de los países desarrollados las utilidades retenidas son la principal fuente de financiamiento del flujo de la inversión de las empresas (de todos los tamaños), seguidas luego por el crédito bancario y de proveedores. Más aún, en 
CUADRO No 12: $\quad$ FINANCIAMIENTO BRUTO PROMEDIO 1970-1985

(Empresas no financieras, en \%)

\begin{tabular}{|c|c|c|c|c|c|c|c|}
\hline & Canadá & Finlandia & Francia & Alemania & Japón & $\begin{array}{l}\text { Reino } \\
\text { Unido }\end{array}$ & $\begin{array}{l}\text { Estados } \\
\text { Unidos }\end{array}$ \\
\hline Utilidades retenidas & 52,2 & 42,1 & 44,1 & 55,2 & 33,7 & 72,0 & 66,9 \\
\hline Obligaciones de corto plazo & 1,4 & 2,5 & 0,0 & 0,0 & n.a. & 2,3 & 1,4 \\
\hline Transferencias de capital & 0,0 & 0,1 & 0,1 & 1,4 & 5,7 & 0,0 & 2,9 \\
\hline Préstamos bancarios & 12,8 & 27,2 & 41,5 & 21,1 & 40,7 & 21,4 & 23,1 \\
\hline Crédito comercial & 8,6 & 17,2 & 4,7 & 2,2 & 18,3 & 2,8 & 8,4 \\
\hline Bonos & 6,1 & 1,8 & 2,3 & 0,7 & 3,1 & 0,8 & 9,7 \\
\hline Acciones & 11,9 & 5,6 & 10,6 & 2,1 & 3,5 & 4,9 & 0,8 \\
\hline Otros & 4,1 & 6,9 & 0,0 & 11,9 & 0,7 & 2,2 & $-6,1$ \\
\hline Ajustes & 0,8 & $-3,5$ & $-4,7$ & 0,0 & n.d. & $-9,4$ & $-4,1$ \\
\hline Total & 97,9 & 99,9 & 98,6 & 94,6 & 105,7 & 99,9 & 100,1 \\
\hline
\end{tabular}

Fuente: Mayer (1990, Cuadro 12.3).

los Estados Unidos, que tiene un mercado de capitales óptimo, más del $65 \%$ del financiamiento del flujo de nueva inversión proviene de fondos propios y, contrariamente a lo que podría pensarse, las emisiones de bonos y acciones son mucho menos importantes ${ }^{49}$. Si se trata de empresas pequeñas, Berger y Udell (1998, Cuadro $\mathrm{N}^{\circ} 1$ ) muestran que en los Estados Unidos alrededor del 50\% de los activos (es decir, el stock) se financia con capital propio. Del $50 \%$ financiado con deuda sólo la mitad es aporte de los bancos y otras instituciones financieras (26,5\% del total del financiamiento) y una fracción significativa es crédito de proveedores y otras empresas ( $17 \%$ del total del financiamiento).

Hecho 33. En países desarrollados gran parte del financiamiento del flujo de inversión de las empresas proviene de las utilidades que retienen. Esto es consistente con la presencia de asimetrías de información, aun si se trata de mercados desarrollados, y es independiente del tamaño de las firmas.

Todo lo anterior lleva a concluir lo siguiente: años cuarenta.

${ }^{49}$ Taggart (1985) muestra que en los Estados Unidos esto ha sido así desde los 
Hecho 34. La información asimétrica es una característica fundamental de los intercambios en el mercado financiero; no es una falla de mercado susceptible de ser eliminada con subsidios. En contadas ocasiones hay regulaciones que pueden ayudar a mitigar las consecuencias de la información asimétrica, pero no pueden eliminarla.

Hecho 35. Se suele afirmar que los requerimientos de garantías, los registros centralizados de historial crediticio y la inexistencia de crédito de mediano y largo plazo son señales de que hay fallas de mercado y perjudican a las pyme. Sin embargo, en realidad son mecanismos para mitigar la selección adversa y el daño moral. Estos mecanismos hacen posible un mercado del crédito y que éste asigne los fondos a buenos deudores la mayoría de las veces.

\subsubsection{Financiamiento de las pyme en Chile}

Se suele afirmar que las pyme reciben muy poco crédito en Chile, que se las discrimina porque pagan tasas de interés más altas que las empresas grandes y que hacen falta intermediarios dedicados a pyme — por ejemplo, los capitalistas de riesgo—. A continuación examinamos esos argumentos.

Crédito a las pyme: ¿poco y caro? El Cuadro $\mathrm{N}^{\circ} 13$ muestra la distribución del crédito bancario por tamaño de empresas. A diciembre de 1998, la deuda de las pyme alcanzaba a UF 277 millones (alrededor de \$US 8.200 millones). Dos cosas llaman la atención. Primero, la participación de las empresas pequeñas y medianas en el total de la deuda con bancos es más de 30\%, mayor que su participación en las ventas totales $(23,72 \%)$. Por lo mismo, la participación de las empresas grandes en la deuda total es cercana al $60 \%$, menor que su participación en las ventas (casi 72\%). Más aún, de acuerdo con el Ministerio de Economía, entre 1994 y 1998 el crédito a las pyme creció en más de $40 \%$, más que el de las empresas grandes (poco menos de 37\%). Así, no pareciera que las pyme tengan menos acceso al crédito bancario que las empresas grandes ni que exista un sesgo en contra de ellas. Tampoco parece que la banca no se interese por financiar empresas pequeñas y medianas; incluso las microempresas reciben más del 10\% del crédito total, lo que excede largamente su participación en las ventas $(4,4 \%)$. 
CUADRO No 13: DISTRIBUCIÓN DEL CRÉDITO BANCARIO

\begin{tabular}{lccccc}
\hline & $\begin{array}{c}(1) \\
\text { Crédito total } \\
\text { (millones de UF) } \\
(1998)\end{array}$ & $\begin{array}{c}\text { Participación } \\
\text { en el crédito } \\
(\%)(1998)\end{array}$ & $\begin{array}{c}\text { (3) } \\
\text { Participación } \\
\text { en las ventas } \\
\text { (\%) (1997) }\end{array}$ & $\begin{array}{c}(4) \\
(2) /(3)\end{array}$ & $\begin{array}{c}\text { (5) } \\
\text { Crecimiento } \\
\text { del crédito (\%) } \\
(1994-1998)\end{array}$ \\
\hline Micro & 93,9 & 10,33 & 4,40 & 2,35 & 18,8 \\
Pequeña & 159,1 & 17,49 & 12,46 & 1,40 & 49,7 \\
$\begin{array}{l}\text { Mediana } \\
\text { Pyme }\end{array}$ & 117,5 & 12,92 & 11,26 & 1,15 & 29,9 \\
Grande & $\mathbf{2 7 6 , 6}$ & $\mathbf{3 0 , 4 1}$ & $\mathbf{2 3 , 7 2}$ & $\mathbf{1 , 2 8}$ & $\mathbf{4 0 , 6}$ \\
& 539,1 & 59,26 & 71,88 & 0,82 & 36,8 \\
\hline
\end{tabular}

Fuente: Columnas (1) y (3): Ministerio de Economía; columna (2) y (5): Corfo.

Por supuesto, se podría argumentar que si las pyme recibieran más crédito, su participación en las ventas aumentaría. Sin embargo, no parece haber argumentos de peso en el sentido de que una pyme debiera operar con razones deuda/ventas significativamente mayores que las de una empresa grande, menos aún si, como se aprecia en el Cuadro $\mathrm{N}^{\circ} 11$, la tasa de deudas vencidas de créditos a empresas pequeñas es considerablemente mayor que la de empresas grandes (2,63\% vs. 0,39\% en 1994 y 4,12\% vs. $0,84 \%$ en 1999). Como se vio más arriba, la evidencia presentada por Basch (1995) sugiere que el costo total por peso prestado es mayor si se trata de una pyme; junto con los costos por mayor riesgo, el costo de prestar a las pyme es considerablemente mayor.

Hecho 36. No existe evidencia de que en Chile las pyme reciban menos crédito que las empresas grandes. Además, es razonable esperar que las pyme paguen tasas de interés más altas porque sus costos administrativos y tasas de incumplimiento son más altos.

Es interesante notar que existe alguna evidencia de que el acceso al crédito de las pyme en Chile no es muy distinto que en los Estados Unidos. En efecto, recuérdese que Berger y Udel (1998) indican que sólo la mitad de las firmas pequeñas registran créditos con bancos u otra institución financiera. Por su parte, en su estudio sobre productividad de firmas pequeñas, Álvarez y Crespi (2001) reportan que el 
31,2\% de las microempresas encuestadas tenía algún tipo de crédito bancario, porcentaje que aumentaba a 48,6 para las firmas pequeñas y $60 \%$ para las medianas ${ }^{50}$.

Al mismo tiempo, pareciera que el menú de instrumentos financieros al que pueden acceder las pyme es bastante amplio. En efecto, a partir de las entrevistas realizadas a los ejecutivos de cuatro importantes bancos de la plaza (tres de los cuales tienen definidas políticas que le dan alta prioridad al mercado de las pyme o las microempresas) se comprueba que el menú es bastante completo. Las pyme pueden acceder a productos para facilitar la administración de flujos (v. g. cuentas corrientes, líneas de crédito); la administración de pagos (v.g. pago automático de remuneraciones, impuestos, proveedores, cotizaciones previsionales, cobranza de letras); el financiamiento de corto plazo (v. g. líneas para capital de trabajo, factoring); para financiar activos de largo plazo, siempre y cuando los activos financiados se puedan constituir en garantías (v.g. adquisición de terrenos, construcción, inversiones en activo fijo, leasing financiero ${ }^{51}$ ); para financiar operaciones de comercio exterior (v.g. informes de importación, cobranzas extranjeras, cartas de crédito, préstamos de pre y postembarque, descuento de letras de cartas de crédito, seguros de exportaciones, factoring internacional).

Hecho 37. En Chile la fracción de pyme con créditos bancarios es similar a la de Estados Unidos. Más generalmente, no existe evidencia de que las pyme tengan mal acceso al crédito.

Se suele citar la falta de crédito de largo plazo como evidencia de que el sistema financiero ofrece financiamiento inadecuado a las pyme. Sin embargo, el crédito de largo plazo existe en Chile, siempre y cuando sea para financiar activos que se pueden constituir fácilmente en garantías (v.g. terrenos y edificios), lo que coincide con la situación

50 Sobre al particular, véase también Foxley (1999, pp. 11 y ss.).

${ }^{51}$ Esta forma de financiamiento ha perdido parte importante de su atractivo, al punto que las compañías de leasing han sido progresivamente absorbidas por las instituciones bancarias matrices. Las razones: las ventajas tributarias casi no existen; la mayor rapidez de la depreciación económica de los bienes, por falta de mantención y obsolescencia técnica, reduce el valor como garantía del bien materia del leasing; los menores requerimientos de capital establecidos para una empresa de leasing respecto de un banco son compensados por un mayor costo de fondos. 
en mercados más desarrollados. Es cierto que las pyme no se pueden endeudar contra flujos de largo plazo, pero, como vimos, esto se debe a que su riesgo de desaparecer es muy alto y la renovación periódica del crédito es necesaria para alinear los incentivos del deudor con el interés del banco.

Por último, una razón adicional para pensar que en Chile el acceso al crédito de las pyme que vale la pena financiar (vale decir, aquellas que tienen buenas perspectivas de sobrevivir) no es malo, es que los bancos parecen ser, si se compara con otros países, particularmente exitosos en controlar el riesgo de no pago. El Cuadro $\mathrm{N}^{\circ} 14$ muestra que en Chile menos del 1\% de los créditos está vencido, lo que se compara muy favorablemente con otros países, tanto latinoamericanos como desarrollados. Como vimos, los buenos deudores se benefician cuando los bancos les prestan poco a malos deudores, porque les aumenta la disponibilidad de crédito y disminuye su costo. Se podría argumentar que los bancos en Chile, gracias a su excesiva prudencia, son muy exitosos en no prestar a malos deudores. Sin embargo, ya

CUADRO No 14: CRÉDITOS NO COBRADOS

\begin{tabular}{lcccc}
\hline & $\begin{array}{c}(1) \\
\text { Créditos no } \\
\text { cobrados / créditos } \\
\text { totales (\%) }\end{array}$ & $\begin{array}{c}\text { Número de } \\
\text { bancos } \\
\text { considerados } \\
\text { en la } \\
\text { estimación }\end{array}$ & $\begin{array}{c}\text { (3) } \\
\text { Reservas } \\
\text { de créditos } \\
\text { incobrables/ } \\
\text { créditos totales } \\
\text { (\%) }\end{array}$ & $\begin{array}{c}\text { Número } \\
\text { de bancos } \\
\text { considerados } \\
\text { en la } \\
\text { estimación }\end{array}$ \\
\hline Argentina & & n.d. & 3,79 & 97 \\
Brasil & n.d. & 94 & 3,63 & 95 \\
Chile & 6,31 & $\mathbf{2 9}$ & $\mathbf{0 , 3 4}$ & $\mathbf{3 1}$ \\
Colombia & $\mathbf{0 , 9 3}$ & 24 & 1,74 & 27 \\
México & 7,34 & 22 & 2,88 & 22 \\
Perú & 7,09 & 23 & 3,45 & 18 \\
Australia & 8,93 & 12 & 0,34 & 24 \\
Canadá & & 7 & 0,79 & 17 \\
Alemania & 3,70 & - & 0,60 & 1.596 \\
Italia & 2,34 & 235 & 1,74 & 250 \\
España & - & 19 & 0,98 & 163 \\
Suecia & 5,21 & 15 & 1,12 & 16 \\
Reino Unido & 4,74 & n.d. & 0,16 & 59 \\
EE. UU. & 7,02 & 495 & 0,56 & 497 \\
\hline
\end{tabular}

Fuente: Fuentes y Maquieira (2001, Cuadro $\mathrm{N}^{\circ}$ 6.2). 
vimos que no parece que se den sesgos en contra de prestarles a empresas pequeñas. Más aún, si los bancos prestasen "poco" eso se traduciría en indicadores de profundidad financiera significativamente más bajos que los de países con similar nivel de desarrollo ${ }^{52}$. De hecho, en una encuesta reciente realizada en 1999 por Lora et al. (2001) sólo el 23\% de los empresarios encuestados en Chile estimó que el financiamiento era un obstáculo para el crecimiento de las empresas ${ }^{53}$.

Hecho 38. En Chile el porcentaje de deudas no cobradas es muy bajo. Esto no se debe a que los bancos presten poco.

¿Perjudica a las pyme la regulación prudencial? Se suele afirmar que la regulación bancaria perjudica a las pyme porque los bancos tienen que hacer provisiones excesivas cuando le prestan a una pyme. Vale la pena destacar que la filosofía detrás del control de riesgo bancario en Chile es la regulación prudencial. Esta regulación se puede definir como aquella que pone énfasis en controlar el riesgo pero sin interferir en los precios de los productos y sin fijar límites cuantitativos o cualitativos a las captaciones o colocaciones o al tamaño del deudor.

Los principales componentes de la regulación prudencial son: la estimación del riesgo de la cartera; las provisiones que se deben realizar en base a dicha estimación; una relación deuda capital medida en función del riesgo de los activos y un límite máximo muy conservador de dicha deuda, y una regulación del portafolio que establece límites máximos a los descalces de plazos y monedas entre activos y pasivos. Se puede afirmar que la regulación prudencial chilena es una de las más modernas y que ha tenido muy buen desempeño desde 1986, cuando completó el grueso de su perfeccionamiento. Las normas prudenciales se pueden clasificar en dos categorías.

En primer lugar, las normas de clasificación de cartera. Mediante este procedimiento se estiman las pérdidas asociadas a la cartera de colocaciones — considerando la capacidad de pago de cada deudor y el monto de las garantías constituidas-, respecto de la totalidad de sus obligaciones con la institución acreedora. Las entidades financieras

${ }^{52}$ Los indicadores de profundidad financiera tradicionales son la razón entre obligaciones bancarias líquidas a PGB (M2/PGB) y la razón de obligaciones bancarias cuasi-líquidas a PGB ([M2 - M1]/PGB)

${ }^{53}$ Esto contrasta con el $45 \%$ en países de Europa Oriental, 37\% en América Latina y el $15 \%$ en los países desarrollados. 
deben clasificar los saldos de las colocaciones vigentes o vencidas, incluidos sus respectivos reajustes e intereses por cobrar, efectuadas a los 400 mayores deudores o al número necesario para alcanzar el 75\% de la cartera de créditos comerciales, prefiriendo el saldo mayor entre los dos. Se desprende de lo anterior que los bancos no están obligados por la regulación a clasificar los créditos a las pyme si no están dentro de los 400 créditos mayores o si suman menos de $25 \%$ de las colocaciones; la primera condición se cumple en la práctica siempre y la segunda obligaría sólo a los bancos donde excedan de tal porcentaje y sólo en el exceso. Más aún, las bases para clasificar son prudenciales. De acuerdo a la Superintendencia, los criterios para evaluar el riesgo de un crédito no se refieren al tamaño del deudor sino a sus características:

\begin{abstract}
En la evaluación del comportamiento del deudor se deberá considerar su historial financiero y crediticio, su conducta en el ámbito de los negocios y, en general, todos aquellos antecedentes orientados a tener un conocimiento integral del deudor.

Respecto de la capacidad de pago, su evaluación deberá estar basada en el análisis de las características de su endeudamiento global y en una estimación de los flujos de caja provenientes de la actividad comercial del deudor, incorporando para el efecto distintos escenarios en función de las variables de riesgo clave del negocio. Asimismo, deberán considerarse en forma explícita los posibles efectos de los riesgos financieros a que está expuesto el deudor y que pueden repercutir en su capacidad de pago, tanto en lo que concierne a los descalces en monedas, plazos y tasas de interés de su estructura de balance, como en lo que toca a sus operaciones fuera de balance, particularmente las efectuadas con derivados financieros.
\end{abstract}

(El Recuadro $\mathrm{N}^{\circ} 8$ detalla las cinco categorías de riesgo en que se clasifican los créditos.) Es posible, no obstante, que una gran proporción de las pyme obtenga clasificaciones que implican riesgo alto por debilidades o deficiencias en su información. A juicio de la Superintendencia:

La evaluación del riesgo crediticio se ve dificultada cuando los antecedentes financieros de los deudores, especialmente los balances, son poco confiables, no contienen suficiente 


\section{RECUADRo No 8: CATEgoríAs DE RIESGO}

La normativa ha definido cinco categorías de riesgo y la provisión mínima por pérdida esperada que se exige a los créditos en cada una de ellas. Dichas categorías y sus respectivas provisiones mínimas son:

- $\quad$ Categoría A: créditos de riesgo normal; sin provisión obligada.

- Categoría B: créditos de riesgo potencial inferiores al 5\%; provisión obligada $1 \%$.

- Categoría $\mathrm{B}^{-}$: créditos con pérdidas esperadas entre el 5\% y el $39 \%$ del total adeudado; provisión obligada $20 \%$.

- Categoría C: créditos con pérdidas esperadas entre el $40 \%$ y el $79 \%$; provisión obligada $60 \%$.

- Categoría D: créditos irrecuperables, pérdida esperada entre el $80 \%$ y el $100 \%$; provisión obligada $90 \%$.

detalle o están desactualizados. Las instituciones fiscalizadas deben hacer los máximos esfuerzos para convenir con sus prestatarios la entrega de antecedentes financieros correspondientes a ejercicios parciales, estableciendo una rutina permanente para ello y poniendo especial hincapié en la información sobre los flujos financieros. Asimismo, deben procurar que dichos estados sean auditados por personal profesional en la materia, aspecto al cual esta Superintendencia le otorga la mayor importancia. La heterogeneidad de la información financiera incluida en las carpetas de los deudores dificulta el análisis crediticio, por lo cual es imprescindible homogeneizar la presentación de dichos estados, los que sirven de base para la evaluación de la cartera.

Claramente, este problema no se soluciona relajando las normas de regulación prudencial.

En segundo lugar, la Superintendencia creó la categoría de créditos riesgosos en su origen,

[...] aquellos créditos en que la institución financiera, al momento de otorgarlos, hayan incurrido en un riesgo claramente superior al inherente a una operación estructurada en forma conservadora, aun cuando dicho riesgo no se manifieste en una pérdida evidente. 
La Superintendencia ahonda en la precisión de este criterio en los siguientes términos:

El escaso o nulo aporte del deudor en el financiamiento de un proyecto o negocio sin que su patrimonio tenga relación con la magnitud de la deuda asumida, la ausencia de garantías suficientes cuando se trata de créditos a largo plazo o la falta de información acerca del conglomerado económico al que pertenece el deudor, son algunas de las situaciones en que se está en presencia de prácticas que se alejan de lo prudente en materias crediticias.

El propósito de la Superintendencia fue "[...] evitar que, en un afán de crecimiento o de captación de nuevos mercados, las entidades fiscalizadas asuman riesgos más allá de los normales en los préstamos que otorguen". Los créditos considerados como riesgosos en su origen se incorporan a la medición del riesgo global de la cartera y, por ende, a la constitución de provisiones. Sin embargo, esta categoría de riesgo se aplica cuando el endeudamiento total del deudor es igual o superior al equivalente de 25.000 unidades de fomento. Vale decir, los créditos otorgados a las pyme pueden ser riesgosos en el origen y, sin embargo, no estar sujetos a provisiones por este motivo, porque éstas son obligatorias sólo cuando la deuda supera UF 25.000. Gran parte de los créditos a las pyme quedan fuera de esta clasificación por la simple razón de que las pyme son empresas chicas. En resumen:

Hecho 39. No existen normas prudenciales específicas para las pyme. La clasificación de riesgo del crédito se obtiene evaluando su probabilidad de recuperación, no el tamaño de la empresa. $Y$, en cualquier caso, la mayoría de las normas prudenciales busca limitar la exposición al riesgo de grandes deudores.

En el balance financiero de un banco las provisiones por riesgo de cartera ya sean voluntarias u obligatorias son consideradas como gasto para medir resultados. Pero desde el punto de vista tributario el criterio es más restringido. En efecto, el SII con la venia de la SBIF ha determinado que serán deducibles como gastos para efectos tributarios las provisiones que correspondan "sólo a créditos que se encuentren registrados en la cartera vencida de acuerdo con las instrucciones de esta Superintendencia, incluidos los intereses por cobrar vencidos y alcanzarán hasta el 
100\% de la parte o del total vencido del respectivo crédito, que no se encuentre amparado por garantías reales". Explícitamente, no se consideran las provisiones transitorias sobre créditos renegociados, las provisiones por créditos riesgosos en su origen ni la provisión especial por el uso de procedimientos deficientes de clasificación ${ }^{54}$.

El criterio restringido con que se tratan las provisiones para efectos tributarios castiga en mayor medida a las colocaciones más riesgosas. Por lo tanto, se puede considerar que esta normativa tiene un sesgo en contra de las colocaciones que se hagan a las pyme por ser éstas de mayor riesgo relativo.

Capital de riesgo. A veces se afirma que uno de los principales obstáculos al crecimiento de las pyme es que en Chile no existe capital de riesgo. Dentro del capital de riesgo se pueden distinguir dos subcategorías: el capital de riesgo "clásico", que corresponde a aportes realizados durante la etapa de proyecto o muy al inicio de la vida de la empresa, y el capital de desarrollo de empresas, que corresponde a aportes realizados principalmente para financiar expansiones, modernizaciones o reestructuraciones de empresas con cierta historia. Además, es conveniente notar que los capitalistas de riesgo son intermediarios financieros, vale decir, captan recursos de terceros y los invierten en empresas y proyectos con gran potencial de crecimiento ${ }^{55}$.

Es conveniente partir notando que en el mejor de los casos el capital de riesgo puede ser una fuente de financiamiento minoritario de las pyme. En efecto, Berger y Udell (1998, p. 619) indican que en los Estados Unidos el capital de riesgo representa menos del 2\% del financiamiento total de las empresas pequeñas y poco más del $3 \%$ del financiamiento de deuda (el Recuadro $\mathrm{N}^{\circ} 9$ detalla las fuentes de financiamiento de los fondos de capital de riesgo $)^{56}$. Sin embargo, es muy importante para un tipo reducido y especial de pyme, aquellas que tienen un potencial de crecimiento alto. De hecho, el 30\% de las empresas que se abren a la bolsa mediante una IPO (por initial public offering) es financiado con capital de riesgo.

${ }^{54}$ Art. $31 \mathrm{~N}^{\mathrm{o}}$ 4, Ley de Impuesto a la Renta, y Circular $\mathrm{N}^{\circ} 2.002-450$ del director del SII y de la SBIF.

${ }^{55}$ Para mayores detalles, véase Arrau (2001).

${ }^{56}$ Para comparar, el financiamiento de "ángeles" (individuos de gran patrimonio que financian aventuras empresariales) representa el 3,59\% del financiamiento total. 


\section{RECUADRO N 9: \\ LAS FUENTES DEL CAPITAL DE RIESGO}

(Basado en Arrau [2001].) Existen cuatro fuentes principales para la obtención del capital de riesgo de una empresa o proyecto:

- $\quad$ Patrimonio personal de los socios: es la fuente primaria de capital de riesgo. Sin embargo, en el caso de las pyme su potencial resulta extremadamente limitado, tanto por un problema de escasez relativa como por razones de diversificación (generalmente los empresarios no quieren "poner todos los huevos en la misma canasta”).

- Accionistas minoritarios personas naturales: este tipo de financiamiento no es relevante en el agregado, ya que los recursos manejados directamente por personas naturales es muy pequeño.

- Accionistas minoritarios institucionales: esta fuente es potencialmente importante por la magnitud de los recursos que manejan. Sin embargo, en la actualidad los inversionistas institucionales enfrentan grandes limitaciones para invertir sumas importantes en pyme, entre otras cosas porque la normativa les impide invertir directamente (los fondos sólo pueden comprar títulos transados en bolsa) y también porque sería ineficiente invertir un pequeño porcentaje de sus fondos en múltiples negocios que requieren gran monitoreo y que, por tanto, tienen elevados costos de administración.

- Fondos de inversión de capital de riesgo: estos fondos fueron precisamente pensados para canalizar el financiamiento de personas naturales e inversionistas institucionales a proyectos de alto riesgo. Sin embargo, hasta el momento su desempeño ha sido decepcionante, lo que queda en evidencia en el hecho de que al 31 de diciembre del 2000 manejaban aproximadamente US\$ 170 millones, de los cuales US\$ 90 millones estaban invertidos en renta fija y proyectos de infraestructura. De las 30 ó 40 empresas que se repartían los US\$ 80 millones restantes, sólo una de ellas tenía ventas de menos de US\$ 1 millón al año y no más de 20 registraban ventas inferiores a US\$ 10 millones anuales. Además, entre 1996 y 2000 el aporte de las AFP fue casi nulo, pues se redujo su participación en el financiamiento de los fondos desde 93\% en 1995 hasta 74\% a fines del 2000. Durante ese período la rentabilidad promedio de los fondos fue sólo de 3\%. 
Hecho 40. El capital de riesgo es una fuente menor de fondos para la generalidad de las pyme: menos del $2 \%$ del total del financiamiento total y algo más del 3\% del financiamiento de deuda. Sólo es apropiado para empresas con alto potencial de crecimiento y para estas empresas puede ser muy importante.

En Chile, el aporte de los fondos de capital de riesgo al financiamiento de las empresas ha sido insignificante, apenas US\$ 166 millones a marzo del 2001. ¿Qué explica este relativo fracaso? El punto de partida es reconocer que el capital de riesgo es una actividad muy difícil y compleja. En efecto, el problema de selección adversa y daño moral es doble. Por una parte, entre los aportantes al fondo y el administrador del fondo, quien tiene mejor información y, en vista de que arriesga el capital de otros, puede tener incentivos para tomar riesgo excesivo; por otra parte, entre el administrador del fondo y el gestor de la empresa receptora de los fondos: en este caso, el gestor posee información más precisa y muchas veces tendrá incentivos para la toma excesiva de riesgo, trabajar laxamente o, incluso, desviar los fondos a otros proyectos. A todo esto se suma que los retornos sólo se materializan después de largo tiempo y la tasa de fracasos es naturalmente muy alta: como ya vimos, en los Estados Unidos el 99\% de los proyectos evaluados por capitalistas de riesgo se rechazan; de los financiados, Sahlman (1990) muestra que casi el 65\% de los montos invertidos genera pérdidas o apenas recupera la inversión y estas pérdidas deben ser compensadas por los (literalmente) espectaculares retornos de un par de grandes éxitos. Para solucionar estos problemas se necesitan contratos muy complejos y sutiles que permitan monitorear adecuadamente tanto al capitalista de riesgo como a los empresarios, y también desarrollar una red de capitalistas de riesgo que tienen una reputación que guardar y deben cuidar mecanismos expeditos de salida a bolsa donde, de más está decirlo, se repiten los problemas de selección adversa.

Según Arrau (2001), se pueden distinguir dos intentos fallidos para desarrollar el capital de riesgo en Chile, el primero entre 1989 y 1995 originado por la Ley $\mathrm{N}^{0}$ 18.815; y el segundo entre 1995 y el 2000, con las leyes $\mathrm{N}^{\circ} 19.301$ y $\mathrm{N}^{\circ} 19.389$ que dieron lugar a los llamados fondos de desarrollo de empresas (FIDE). Estos intentos no fueron exitosos, entre otras razones, por la excesiva regulación, las fuertes restricciones a la gama de inversiones y a que el sistema de clasificación de riesgo de las cuotas del fondo impedía la inversión en 
sociedades cerradas y, por ende, en empresas en un estado embrionario. La causa última de los problemas habría estado en que los fondos de capital de riesgo fueron concebidos como instrumentos para los fondos de pensiones y esto llevó a la autoridad correspondiente a sobrerregularlos.

Recién se introdujeron dos modificaciones legales que probablemente facilitarán el desarrollo de una industria de capital de riesgo. En primer lugar, el artículo 7 número 29 de la Ley de Opas creó la figura de los fondos de inversión privados y de las administradoras de fondos de inversión (AFI). La principal novedad es que su funcionamiento queda regulado única y exclusivamente por lo estipulado en sus reglamentos internos, lo que les entrega gran flexibilidad para diseñar contratos que permitan lidiar con los problemas de selección adversa y daño moral ya descritos. En segundo lugar, se crea la llamada "Bolsa Emergente”. Por tres años y hasta el 2006 se eximen del impuesto a las ganancias de capital el mayor valor que resulte de la enajenación de acciones de empresas emergentes inscritas en estas bolsas, siempre y cuando la empresa cumpla algunos requisitos mínimos de desconcentración y dispersión.

Si bien estas modificaciones seguramente son pasos en la dirección correcta, es improbable que en cuestión de uno o dos años surja una industria de capital de riesgo desarrollada. Lo central aún falta: individuos que tengan los conocimientos suficientes de la economía y las industrias chilenas para seleccionar proyectos con gran potencial de crecimiento, familiaridad con contratos complejos que mitiguen eficazmente los problemas de incentivos largamente discutidos en este trabajo y capitalistas de riesgo con reputación de cautelar el interés de los terceros inversionistas al momento de invertir en los fondos. Como siempre, el desarrollo de la industria será gradual y tomará tiempo.

\subsubsection{Programas de financiamiento estatal para las pyme: una evaluación}

Hay una serie de programas de crédito que otorga la Corfo para aumentar el financiamiento en determinadas actividades ${ }^{57}$. Como se aprecia en el Cuadro $\mathrm{N}^{\circ}$ 15, entre 1990 y 2001 se realizaron 12.370

${ }^{57}$ Una descripción y evaluación detallada de los programas se encuentra en Cabrera et al. (2002). 
CUADRO N ${ }^{\circ}$ 15: COLOCACIONES DE CRÉDITOS CORFO ${ }^{1}$ (1990-2001)

\begin{tabular}{lccc}
\hline & $\begin{array}{c}(1) \\
\text { Número de } \\
\text { operaciones }\end{array}$ & $\begin{array}{c}(2) \\
\text { Monto total } \\
\text { (mm de US\$ } \\
\text { de 1999) }\end{array}$ & $\begin{array}{c}(3) \\
\text { Crédito } \\
\text { promedio } \\
\text { (US\$ de 1999) }\end{array}$ \\
\hline 1990 & 445 & 28,91 & 64.966 \\
1991 & 915 & 62,04 & 67.803 \\
1992 & 1.344 & 132,16 & 98.333 \\
1993 & 870 & 97,67 & 112.264 \\
1994 & 1.072 & 135,50 & 126.399 \\
1995 & 1.566 & 146,00 & 93.231 \\
1996 & 1.608 & 158,05 & 98.290 \\
1997 & 1.384 & 189,64 & 137.038 \\
1998 & 902 & 176,99 & 196.220 \\
1999 & 1.132 & 193,30 & 170.760 \\
2000 & 881 & 112,15 & 127.299 \\
$2000^{2}$ & 251 & 58,05 & 231.279 \\
Total & & & \\
\hline
\end{tabular}

Notas: (1) Incluye crédito a través de bancos y empresas de leasing. (2) Al 20 de noviembre de 2001.

Fuente: Corfo.

operaciones de crédito por casi 1.500 millones de dólares (vale decir, cada operación fue de alrededor de 120.000 dólares en promedio). El monto promedio anual de colocaciones fue US\$ 124 millones, equivalente al 2,1\% del crédito comercial total extendido durante el año 2000.

Los programas de financiamiento parten de la premisa de que existen imperfecciones de mercado que implicarían discriminación en contra de las pyme. Se pretende corregir estas fallas de mercado con cuatro tipos de programas ${ }^{58}$ :

- $\quad$ Programas de crédito: son créditos intermediados por bancos comerciales con tasas subsidiadas y restricciones de uso.

- $\quad$ Programas de cuasi-capital: son aportes directos de fondos Corfo a intermediarios financieros, con la obligación de que dichos fondos sean utilizados para financiar cierto tipo de proyectos.

${ }^{58}$ El Cuadro No 16 resume los programas vigentes hasta 1998. 
CUADRO No $16: \quad$ PROGRAMAS DE INTERMEDIACIÓN FINANCIERA ${ }^{1}$

(Al 31 de agosto de 1998)

\begin{tabular}{|c|c|c|c|c|}
\hline & $\begin{array}{l}(1) \\
\text { Fecha de } \\
\text { inicio }\end{array}$ & $\begin{array}{c}(2) \\
\text { Colocaciones } \\
\text { acumuladas } \\
\text { (mm de US\$) }\end{array}$ & $\begin{array}{l}\text { (3) } \\
\text { Número de } \\
\text { empresas }\end{array}$ & $\begin{array}{l}(4) \\
\text { Colocación } \\
\text { promedio } \\
\text { (US\$) }\end{array}$ \\
\hline BID bancos² & $6 / 1990$ & 230,26 & 245 & 939.837 \\
\hline Bancos, línea B11 & 4/1996 & 131,90 & 170 & 775.882 \\
\hline Alemania, línea B12 & $12 / 1994$ & 4,05 & 33 & 122.727 \\
\hline Exportadores, línea B22 & $4 / 1996$ & 14,46 & 14 & 1.032 .857 \\
\hline $\begin{array}{l}\text { Compradores extranjeros } \\
\text { de bienes de capital, línea B21 }\end{array}$ & $5 / 1992$ & 81,21 & $70^{3}$ & 1.160 .143 \\
\hline BID leasing & $6 / 1990$ & 807,60 & $8.210^{4}$ & 98.368 \\
\hline $\begin{array}{l}\text { Compradores nacionales } \\
\text { de bienes de capital vía leasing }\end{array}$ & 7/1995 & 47,55 & $771^{4}$ & 61.673 \\
\hline Bonos subordinados & 7/1997 & 17,21 & 1.362 & 12.636 \\
\hline Fondos de inversión (Fides) & $3 / 1998$ & 6,80 & - & - \\
\hline $\begin{array}{l}\text { Total acumulado } \\
\text { (1990-1998) } \\
\text { Cartera vigente } \\
\text { al 31-12-1997 }\end{array}$ & & $1.341,04$ & & \\
\hline
\end{tabular}

Notas: (1) No incluye crédito universitario, ni transferencias al fomento de innovación tecnológica (Fontec) y otras de tipo no crediticio. (2) Programa descontinuado. (3) Corresponde a 358 operaciones, varias de ellas realizadas por el mismo exportador. (4) Corresponde al número de contratos.

Fuente: Held (2000).

- $\quad$ Programas de garantías: son subsidios o garantías directas otorgadas por Corfo destinadas a sustituir la exigencia de garantías reales al momento de solicitar un crédito.

- $\quad$ Programas de rescate financiero: son un conjunto de medidas para reprogramar las deudas de empresas pequeñas supuestamente afectadas por la actual recesión (véase el Cuadro $\mathrm{N}^{\circ} 17$ ).

Casi todos los programas Corfo los intermedian bancos comerciales (el Recuadro $\mathrm{N}^{\circ} 10$ resume cómo funcionan los programas de crédito). Un aspecto fundamental es que, salvo cuando Corfo subsidia las garantías, el banco asume íntegramente el riesgo de no pago y 
CUADRO No 17: REPROGRAMACIÓN DE DEUDAS PYME

(2)

Recursos

posibles de

movilizar

(mm US\$)

Beneficiarios

Condiciones

\section{Deuda bancaria y acceso \\ a crédito}

Garantía de 30\% (40\% para deudas reestructuradas con capital de trabajo). Estado provee calces por US\$ 300 millones. BECh US\$ 200 millones.

Garantías de hasta el $40 \%$ para créditos de preembarque para exportadores.

Plan de negocios para que el Banco del Estado preste preferentemente a la pequeña empresa. 40 plataformas especializadas $y$ nuevos productos.

Ampliación en $50 \%$ del programa de subsidios a la intermediación financiera para bancarizar a microempresarios.

\section{Deuda previsional}

Se aprobó ley que permite la celebración de convenios de pago de deudas previsionales.

\section{Deuda tributaria}

Convenios de pago de tributos adeudados
1.000 Empresas que el año 2000 hayan vendido hasta $\$ 1.000$ mm (UF 60.000) 40.000 empresas.

200 Exportadores no tradicionales; ventas menores US\$ 10 millones. (800 empresas).

50.000 micro y pequeñas empresas.

1010.000 microempresas.

670250.000 empleadores.

280 Ventas netas de IVA menores que mm \$ 500 e independientes $1^{\text {a }}$ categoría. (80.000 empresas)
Máximo valor de crédito \$ $100 \mathrm{~mm}$. con plazos desde 30 meses hasta 6 años incluido un período de gracia mínimo de 6 meses.
Estos contratos se celebrarán una sola vez y posibilitarán cancelar la deuda en cuotas mensuales hasta en 18 meses.

Se condonan intereses y multas y pueden pactar a 12 meses el pago de deudas giradas entre el 1 de enero de 1998 y el 31 de enero de 2001.

Total

Fuente: Ministerio de Economía. 


\section{RECUADRO N ${ }^{\circ}$ 10: ¿CÓMO FUNCIONAN LOS CRÉDITOS CORFO?}

Se accede a las líneas de financiamiento Corfo a través del banco con que habitualmente opera la empresa o de cualquier banco comercial que opere en Chile. Además de lo anterior, en el caso de la línea B21 (Financiamiento al comprador extranjero de bienes durables y servicios de ingeniería chilenos), se puede operar directamente a través de los bancos extranjeros que tengan convenio de líneas de crédito con Corfo.

El banco comercial realiza el análisis financiero, de riesgo y de garantías del proyecto presentado por el inversionista. Si el análisis financiero es concluyente respecto de la factibilidad del proyecto, el banco presenta una solicitud de financiamiento a Corfo. Posteriormente, Corfo analiza la solicitud de acuerdo con la normativa e instructivo de cada una de las líneas de crédito (v.g. condiciones que deben cumplir las empresas de acuerdo con las pautas de las líneas de crédito, montos del crédito, moneda, inversiones elegibles). Si la inversión es elegible, Corfo desembolsa los fondos a nombre del banco comercial que presentó la solicitud, por lo que el banco comercial asume el riesgo de crédito asociado al financiamiento del proyecto.

En la actualidad Corfo otorga créditos a tasa fija, cuyo valor varía de acuerdo a los plazos, moneda y tipo de programa. Considerando la tasa base cobrada por Corfo, existen determinados programas que limitan el margen o el spread aplicado por los bancos comerciales.

asume la pérdida si presta mal. Esta característica se ha criticado porque los bancos tratan estos créditos como cualquier otro y exigen garantías, lo que supuestamente disminuye su atractivo y el acceso de las pyme. Sin embargo, por todo lo que hemos discutido anteriormente, se trata más bien de una virtud, porque de esta forma se mitigan las consecuencias de la selección adversa y el daño moral. La experiencia con programas de crédito subsidiado de la propia Corfo pre 1990, y de casi todos los programas de fomento que se han intentado en el resto del mundo, es con tasas de irrecuperabilidad sustantivas. Esto se debe fundamentalmente a que estos programas prestaban sin garantías y las pérdidas eran traspasadas al presupuesto del Estado ${ }^{59}$.

${ }^{59}$ Foxley (1998) estima que durante la década de los ochenta la Corfo perdió 555 millones de dólares por créditos irrecuperables. La desastrosa experiencia internacional con créditos de fomento es resumida por Hallberg (2000). Foxley (1999, p. 33) explica por qué las tasas de recuperabilidad son tan bajas cuando no se exigen garantías: "En varios países de América Latina, incluido Chile a fines de los ochenta, los fondos de garantía perdieron rápidamente su capital frente a presiones grupales de gremios u otros que consiguieron desvirtuar su naturaleza, utilizando los fondos para cubrir riesgos mal evaluados”. 
Hecho 41. Una virtud de los programas de financiamiento Corfo es que traspasan el riesgo de no pago al banco que presta los fondos.

Por lo mismo, pensamos que los programas que garantizan parte de los créditos (por ejemplo, el Fogape, los $\mathrm{Cubos}^{60}$; las garantías otorgadas por el Estado a las deudas reprogramadas por las pyme; y el sistema nacional de garantías para créditos a pyme propuesto por el Ministerio de Economía ${ }^{61}$ ) son inconvenientes porque no corrigen una falla de mercado. En efecto, el subsidio a las garantías parte de la premisa equivocada de que estas exigencias reflejan una falla de mercado. Sin embargo, una vez que se le presta atención a la información asimétrica, rápidamente se concluye que dichos programas se justificarían sólo si el Estado fuera mejor evaluador del riesgo de no pago que los propios bancos ${ }^{62}$. No existe evidencia alguna en favor de esta creencia y la evidencia en contrario es abundante. Por lo tanto, cuando el Estado garantiza créditos privados, en la práctica subsidia la toma de riesgos del banco y, además, exacerba los problemas causados por el daño moral y la selección adversa porque facilita que malos deudores obtengan crédito. Como hemos visto, esto perjudica a los buenos deudores.

Hecho 42. Los programas de subsidio de garantías son inconvenientes porque estimulan la selección adversa y el daño moral.

Excluyendo a los programas que otorgan garantías, el resto consiste fundamentalmente en subsidiar el costo del endeudamiento, ya sea a través de tasas menores o plazos más generosos. Nuevamente, esto se justificaría sólo si existieran fallas de mercado, tales como externalidades que hagan que el retorno social de los proyectos sea mayor que el privado, y estudios detallados que las hayan identificado y cuantificado. No tenemos noticia de estos estudios previos y la impresión general que nos formamos es que gran parte de los programas de financiamiento Corfo no mitiga fallas de mercado.

En efecto, el objetivo del principal programa de financiamiento, la línea B11, que representó el 61\% de los fondos prestados por Corfo en

${ }^{60}$ Fogape es el acrónimo de "Fondo de garantía para el pequeño empresario"; Cubos, de "Cupones de bonificación de primas de seguro de crédito”. Para descripciones detalladas, véase Cabrera et al. (2002).

${ }^{61}$ Véase Ministerio de Economía (2000).

${ }^{62}$ Lo que, por lo demás, cuestionaría la decisión de Corfo de intermediar a través de bancos comerciales. 
los últimos tres años, es muy amplio, a saber: financiar a largo plazo inversiones en activos fijos requeridos por empresas para el desarrollo productivo $^{63}$. La única falla de mercado que supuestamente mitiga este programa es la supuesta oferta insuficiente de crédito de largo plazo para las pyme. Sin embargo, como ya vimos, esto no es una falla de mercado sino consecuencia de la selección adversa y el daño moral. Más aún, el programa incluye a empresas con ventas anuales hasta UF 1.200.000 (aproximadamente US\$ 30 millones), muy por encima de las UF 100.000 que separa a las empresas medianas de las grandes. De esta forma, se les está prestando de manera subsidiada principalmente a empresas medianas y sobre todo grandes que no tienen mayores problemas de acceso a crédito cuando la calidad de los proyectos lo justifica.

Hay un par de programas específicos que favorecen actividades particulares. Por ejemplo, el crédito medioambiental (línea B14) les presta a largo plazo (tres a doce años) hasta un millón de dólares a empresas con ventas de a lo más UF 1.200 .000 para inversiones necesarias para cumplir con la normativa medioambiental. El programa de financiamiento para bienes de capital nacionales (línea A.2) subsidia a la industria nacional de estos bienes. Y la línea B.21 subsidia a empresas extranjeras que compran bienes de capital o durables fabricados en Chile o contratan servicios de ingeniería o consultoría chilenos. Sin embargo, salvo en el caso medioambiental, no existe evidencia alguna de que se den distorsiones en los mercados respectivos que ameriten subsidiar el acceso a crédito, mucho menos estudios que hayan identificado las supuestas fallas.

Hecho 43. La gran mayoría de los programas de financiamiento Corfo no corrige ni mitiga fallas de mercado. Más aún, en muchos casos se favorece a empresas grandes que tienen acceso expedito al financiamiento bancario.

Mención aparte merecen los programas de rescate de las pyme en problemas, iniciados el año pasado (el así llamado "Plan financiero pyme 2001” se resume en el Cuadro $\left.\mathrm{N}^{\circ} 17\right)^{64}$. El diagnóstico que

${ }^{63}$ Financia inversiones en maquinaria, instalaciones, construcciones, obras civiles, plantaciones, ganado, servicios de ingeniería y montaje, incluyendo capital de trabajo asociado, como asimismo inversiones requeridas para descontaminación y mejoramiento del medio ambiente —es decir, inversión en general—.

${ }^{64}$ Existe además un programa Corfo de reprogramación de pasivos de pequeñas empresas (línea B13). Sin embargo, los montos involucrados son muy pequeños (US\$ 4,4 millones en 2001). 
sustenta a estos programas es que la recesión debilitó financieramente a las pyme y que en su gran mayoría son viables si se les extiende el plazo para pagar. Eso se hizo con los impuestos adeudados, condonándose intereses y multas, y una ley aprobada recientemente extendió el plazo para pagar las deudas previsionales. El principal programa, sin embargo, consiste en subsidiar la reprogramación de deuda bancaria de las pyme. Este programa garantiza parte de la deuda reprogramada (30 ó 40\% según sea el caso) y alarga el plazo para pagar, que será entre 30 meses y seis años. Este programa supone que por algún motivo los bancos reprograman menos de lo conveniente.

El principal defecto del programa de reprogramación (y de las reprogramaciones en general) es que parte de la premisa equivocada de que gran parte de las pyme en problemas son viables en el mediano plazo. Como vimos, aun durante un auge el número de las pyme "en problemas" es significativo: por ejemplo, de acuerdo a la ENIA, el 15\% de las plantas industriales pyme que están operando saldrían en cualquier caso en los próximos dos años. Este porcentaje aumenta en recesiones, pero en su gran mayoría se trata de empresas que no son viables en el mediano plazo. Por lo tanto, mientras más "exitoso" sea un programa de reprogramación de deudas, en el sentido de llegar a un mayor número de pyme, mayor será la fracción del financiamiento que llegará a empresas que fracasarán en cualquier caso y a las que se les mantendrá vivas un tiempo más con el subsidio. Como se verá a continuación, esto tiene una serie de implicancias negativas para el empleo y el crecimiento. En lo que aquí nos interesa, esto sugiere que los programas de reprogramación son potencialmente una gran fuente de mal uso de recursos. El mal uso será mayor mientras más generosas sean las garantías estatales, mayor el plazo para pagar los créditos reprogramados y mayor el subsidio de las tasas.

Hecho 44. Las reprogramaciones de deudas subsidiadas por recursos públicos favorecen, en gran medida, a empresas que fracasarán en cualquier caso.

Dentro del "Plan financiero pyme 2001", 14.507 empresas habían reprogramado US\$ 337 millones al 24 de octubre del 2001. Sin embargo, según lo señalado por ejecutivos bancarios, el impacto del programa ha sido limitado porque las empresas viables ya habían sido 
reprogramadas por los bancos, mientras que el subsidio no es suficientemente generoso como para rescatar a empresas inviables. Si esta apreciación de los ejecutivos es correcta, se seguirían dos conclusiones. En primer lugar, y desde el punto de vista de la asignación de recursos, es afortunado que el programa no subsidie mayormente el rescate de empresas inviables. En gran medida esto se debería a que el riesgo de no pago sigue radicado en gran proporción en el banco que otorga el crédito, quien además es el mejor situado para evaluar si acaso la empresa es viable. En segundo lugar, el subsidio probablemente benefició a empresas que hubieran reprogramado en cualquier caso, pero de modo principal a los bancos. ¿Por qué? En vista de que es muy difícil que una empresa en problemas se cambie de banco, las condiciones que el banco le ofreció al deudor quizá no fueron muy distintas de las que le hubiera ofrecido de todas formas ${ }^{65}$.

En resumen, compartimos la opinión de Foxley (1999):

En general, en cuanto a medidas de política de "pequeña empresa” [es conveniente] evitar la distracción de recursos públicos en programas masivos de financiamiento y/o en subsidios, los que no parecerían necesarios dados los altos grados de penetración y competencia alcanzados por la banca en ese segmento de empresas en Chile.

\subsubsection{Algunas propuestas para mejorar el acceso a financiamiento de las pyme}

Competencia entre bancos y el impuesto de timbres y estampillas. Hay un par de regulaciones que, a nuestro juicio, podrían perfeccionarse para aumentar la competencia en el mercado bancario y que beneficiarían particularmente a las pyme.

Las relaciones de largo plazo implican costos fijos tanto para el banco como para las empresas y, por lo tanto, las empresas pequeñas tenderán a relacionarse con menos bancos, en muchos casos sólo con uno. Esto implica que es particularmente importante para las pyme que el mercado bancario sea lo más competitivo posible y que no existan regulaciones que encarezcan el cambio de banco.

${ }^{65}$ Es difícil cambiarse de banco al reprogramar porque los bancos alternativos no aceptarán a un deudor en problemas, amén de que el impuesto de timbres y estampillas es una barrera importante a la movilidad. 
La principal regulación que encarece el cambio de banco es el impuesto de timbres y estampillas, que se devenga mensualmente como una tasa de $0,1 \%$ sobre el monto del crédito, con tope máximo de $1,2 \%$. Este impuesto encarece el costo de los créditos. Por ejemplo, en el caso de un crédito a doce meses o menos, con una tasa de interés de $8 \%$ anual, el impuesto elevará la carga financiera en un $15 \%$. Pero, además, relaja la intensidad de la competencia entre bancos. En efecto, no basta que un banco de la competencia le ofrezca a un deudor una mejor tasa que su banco actual; el cambio se encarece porque, de hacerlo, se deberá pagar nuevamente el impuesto. Este mayor costo le permite al banco actual cobrar una tasa más alta ${ }^{66}$.

Hecho 45. El impuesto de timbres y estampillas tiene consecuencias anticompetitivas; las pyme son relativamente más perjudicadas.

Es interesante considerar las consecuencias de los cambios introducidos por la Ley de Mercado de Capitales a partir del $1^{\circ}$ de enero de este año, que aumentó el impuesto a 1,6\%, pero eliminó el requerimiento de pagarlo si se trata de una renovación del crédito. En apariencia el efecto para las empresas es ambiguo: pagan más por créditos nuevos pero menos por renovarlos. En la práctica, es muy probable que la modificación perjudique aún más a las empresas. Claramente lo hace el aumento de tasas, pero la exención a la renovación le permite al banco aumentar la tasa que cobra sin que el deudor se cambie. Por lo tanto, el aumento del impuesto perjudicará a los deudores tanto por créditos nuevos como por créditos antiguos. Creemos que la medida más sana sería eliminar el impuesto de timbres y estampillas.

Competencia y traslado de garantías. Un obstáculo adicional que relaja la competencia entre bancos es la dificultad de liberar las garantías cuando un deudor refinancia su deuda con otro banco. El efecto de esto es similar al del impuesto de timbres y estampillas. Alzar las garantías en un banco para constituirlas en favor de otro es caro, y el costo de cambiar de banco eleva los spreads. Creemos que sería conveniente estudiar cómo establecer un registro centralizado de garantías que le permita a un deudor cambiar su garantía de banco simplemente

${ }^{66}$ La demostración de cómo los costos de cambiarse relajan la competencia se debe a Klemperer (1987). 
cambiando el registro. Por ejemplo, una empresa puede constituir sus garantías a favor del registro centralizado y éste emitir un certificado endosando dicha garantía a un acreedor. Cambiar la garantía de un banco a otro sería sólo cuestión de cambiar el endoso de dicho certificado. Este sistema sería muy similar al de los almacenes generales (o warrants), que ya existe y opera fluidamente para prendas sobre materias primas, productos en proceso o terminados.

Intensidad de la competencia bancaria y pyme. Más generalmente, para las pyme es en extremo importante que la competencia entre los intermediarios financieros sea lo más intensa posible. En ese sentido, en los últimos años se ha discutido acaloradamente sobre cuán competitivo es el mercado bancario. Lamentablemente, no se han hecho estudios empíricos de la organización industrial de este sector que evalúe la intensidad de la competencia ${ }^{67}$. La evidencia sugiere que los spreads son más bajos en Chile que en el resto de Latinoamérica, pero más altos que en los países desarrollados. Tampoco hay estudios sistemáticos de cómo varían las tasas de interés con el tamaño de la empresa deudora ajustadas por el riesgo del deudor. Como se dijo, es natural esperar que las pyme paguen tasas más altas que las empresas grandes porque su probabilidad de no pago es mayor, pero existe evidencia circunstancial que sugiere que las empresas más pequeñas pagan tasas que parecen altas. Sea como fuere, es posible modificar un par de regulaciones además de las ya señaladas y esto seguramente aumentaría la intensidad de la competencia, que favorecería a todas las empresas, pero particularmente a las pyme ${ }^{68}$.

En primer lugar, es conveniente estudiar si se justifica mantener la exclusividad de los bancos en el negocio de la correduría de dinero. Actualmente sólo los bancos pueden captar dinero para prestarlo a terceros ${ }^{69}$. Probablemente es conveniente que se permita a otras empresas (v.g. compañías de factoring, casas comerciales, distribuidoras de maquinaria, equipos y vehículos, empresas que financian a productores agrícolas) emitir bonos y efectos de comercio (bonos de corto plazo) para financiar a sus clientes. Estas empresas suelen manejar

${ }^{67}$ Una excepción es Basch y Fuentes (1998), quienes analizan los determinantes de los spreads bancarios en Chile.

${ }^{68}$ Varias de las propuestas que siguen se deben a Fontaine (2002).

${ }^{69}$ Art. 39 de la Ley de Bancos. 
buena información sobre los deudores y, al facilitarles la captación de fondos, se estaría mejorando el acceso al crédito de las pyme que tratan con ellas y forzando a los bancos a competir más intensamente.

En segundo lugar, una serie de regulaciones impone costos fijos a los bancos y encarece la entrada al mercado y aumenta la escala mínima de operación. Como lo señala Fontaine (2002), muchas de estas restricciones se deben a la intención de regular conductas en vez de multar los comportamientos indebidos. Estas regulaciones inhiben a los bancos de nicho porque, por pequeños que sean, deben cumplir con los mismos costos regulatorios que los bancos grandes.

En tercer lugar, los bancos actualmente en el mercado tienen una serie de acuerdos que los ligan en red y que hacen casi imposible la entrada de un banco nuevo si éste no es admitido al club. En concreto, la banca controla la red única que conecta a los comercios con los bancos para permitir las operaciones de tarjetas de crédito (Transbank), una red casi exclusiva de cajeros automáticos (Redbanc) y una cámara de compensación de pagos electrónicos única (CCA). En estas condiciones, la entrada de bancos nuevos parece muy difícil. En efecto, un banco entrante que no sea admitido al club (y actualmente no hay ninguna obligación de hacerlo) tendría que duplicar las redes para ofrecer servicio similar al resto de los bancos. Una amplia literatura demuestra que la negativa de interconexión es una barrera a la entrada efectiva y por tanto anticompetitiva ${ }^{70}$. Por lo tanto, se justifica que se obligue a los bancos dueños del club a que acepten nuevos miembros en condiciones no discriminatorias - la interconexión debiera ser obligatoria - y esto seguramente sería dictaminado rápidamente por la Comisión Antimonopolios si examina los méritos del caso.

Credit scoring y centrales de información. Como vimos, la falta de buena información sobre las pyme contribuye a exacerbar los problemas de selección adversa y daño moral. Existe una herramienta técnica llamada credit scoring que, de adoptarse generalizadamente, permitiría mitigar estos problemas ${ }^{71}$.

El credit scoring consiste en reunir la mayor cantidad posible de información sobre los deudores y ordenarla de acuerdo a un conjunto de características o atributos de ellos de tal manera de poder realizar

\footnotetext{
${ }^{70}$ Véase, por ejemplo, Shy (2001), especialmente el capítulo 8.

${ }^{71}$ Esta sección está basada en el documento del IFC (2001).
} 
análisis estadístico de su riesgo. Esta forma de evaluar el riesgo es de antigua data especialmente en el crédito de consumo. Por otro lado, las centrales de información son organismos que construyen y administran un banco de información. Recurriendo a diversas fuentes forman bases de datos y sus correspondientes series históricas suficientemente grandes que permiten crear un banco de credit scoring.

Un modelo típico de credit scoring se construye a partir de una muestra importante y representativa de créditos. Esto permite construir una medida de cumplimiento de los créditos y determinar las características que mejor lo explican. El modelo resultante se puede aplicar luego para tomar decisiones. En el caso de las empresas pequeñas es conveniente, además, incorporar información sobre el dueño, puesto que en estos casos la decisión de crédito se asemeja a la de un crédito de consumo. De hecho, los estudios sugieren que el mejor predictor de la probabilidad de pago de estas empresas es la historia del crédito personal de su dueño. Así, los principales factores para medir el riesgo de crédito en una empresa pequeña típicamente son los años en el negocio, la historia crediticia del dueño y los activos financieros y deudas del dueño.

Un punto debatible es si los prestamistas deben dar información positiva, o sea informar sobre quiénes son sus buenos clientes. Darla es de beneficio de los consumidores pero perjudica los intereses comerciales de los financistas. En el sistema de información de los Estados Unidos la participación de los prestamistas es voluntaria, y el sistema es privado y competitivo.

Los detalles de la propuesta deben estudiarse con cuidado, pero proponemos revisar la legislación con el propósito de facilitar el desarrollo de centrales de información de crédito. En particular, se debería revisar la legislación en lo referente a la recolección y distribución de información detallada de crédito por parte de personas legalmente autorizadas para dicho objeto.

Cuentas financieras estandarizadas diseñadas para las pyme. Una manera adicional de mejorar la información es desarrollar cuentas financieras estandarizadas especialmente diseñadas para empresas pequeñas. Como ya se vio en el Recuadro $\mathrm{N}^{0} 5$, en Suecia se desarrolló con gran éxito un manual estándar de contabilidad (el manual BAS) que en un breve lapso se transformó en el estándar comúnmente usado en 
Suecia, no sólo por pequeñas y medianas empresas, sino también por grandes compañías. Las cuentas estandarizadas permitirían evaluar mejor a las pyme y hacerlas comparables y agrupables en categorías similares de riesgo y seguramente mejorarían el acceso al crédito de los buenos deudores.

La tasa máxima convencional. Como vimos, las pyme son deudores más caros por peso prestado y lo que corresponde es que paguen por ese costo más alto. Claramente, no se trata de una falla de mercado (no hay una distorsión sino un costo más alto) y un subsidio no se justifica. Sin embargo, en Chile la tasa de interés que se puede cobrar tiene un tope, la tasa máxima convencional, igual a 1,5 veces la tasa promedio del sistema financiero en cada categoría de crédito. Esta regulación tiene su origen en el intento de impedir la usura, pero su consecuencia es que margina automáticamente del mercado a las pyme cuyo costo de intermediación sea mayor, aunque existan bancos que estén interesadas en financiarlas. Este efecto se ve reforzado por la nueva ley de cobranza extrajudicial que limitó los cobros por cobranza de créditos impagos. Larraín (2000) estima que, combinando ambos efectos, se requeriría un incremento entre 1,5 y 2,0 puntos porcentuales sobre la actual tasa máxima que afecta a los tramos inferiores del crédito.

La cobranza extrajudicial tiene como propósito incrementar la recuperabilidad de los créditos y, con ello, disminuir el gasto de cartera de las instituciones financieras. Sin embargo, la nueva Ley de Cobranza establece que no se podrán cobrar por concepto de gastos de cobranza extrajudicial porcentajes mayores que los regulados. Según Larraín (2000), la consecuencia de los topes es que los honorarios de las empresas de cobranza resultan muy inferiores a los montos cargados hasta antes de la dictación de la ley. De esta forma, en el tramo de créditos de hasta UF 20, el nuevo tope llegaría a sólo 16,4\% de los cobros previos; en el tramo que va entre UF 20 y UF 50, el tope llegaría al 31\%; y, finalmente, en el tramo que va entre UF 50 y UF 100, el tope establecido llegaría al 53\%. Larraín (2000) estima que esto hará inviables las operaciones de cobranza en los tramos bajos de la escala crediticia. Esto agudizará la selección adversa y el daño moral e incrementará el riesgo de no pago de dichos tramos y, por ende, tenderá a excluirlos del proceso crediticio del sistema financiero (es decir, los “desbancarizará”). 
Creemos que ni la tasa máxima convencional ni los topes a las cobranzas se justifican y que sería conveniente eliminarlos.

Título ejecutivo de facturas. Estimamos que es necesario estudiar la posibilidad de otorgar a las facturas la categoría de título ejecutivo. Tal posibilidad mejoraría el acceso al financiamiento porque probablemente reforzaría el desarrollo de la industria del factoring y, además, permitiría el uso de las facturas como garantía crediticia, lo que incrementaría la base de garantías de las pyme.

Impuestos a las utilidades retenidas y el financiamiento de las pyme. La revisión de la literatura sobre financiamiento de las pyme indicó que la selección adversa y el daño moral implican que gran parte del financiamiento de las pyme debería provenir del patrimonio personal de los socios y de las utilidades retenidas por la empresa. Como se vio, éste es un patrón que se observa no sólo en Chile sino que también en los países desarrollados. Además, los mismos problemas implican que es sano que los bancos les exijan garantías a las empresas. Por eso, las utilidades retenidas también son importantes porque permiten que la empresa tenga más garantías.

Por estas razones estimamos que sería conveniente estudiar la posibilidad de que las pyme tributen sólo por las utilidades que reparten y no por las que retienen. Estamos conscientes de que esta medida podría facilitar la evasión y elusión de impuestos, pero, por otro lado, es muy probable que disminuya el costo de financiamiento de las pyme y por ello debería considerarse seriamente.

\section{3. ¿Productividad baja?}

Una preocupación frecuente es que las pyme serían menos eficientes y productivas de lo que deberían y, ciertamente, menos que las empresas grandes. Esto se debería a su incapacidad de aprovechar economías de escala, a los problemas que enfrentan para acceder al crédito para invertir y a la falta de recursos para contratar capital humano calificado. De ahí que se necesitarían programas de apoyo a las pyme para que mejoren su productividad. A continuación discutimos si las pyme tienen un problema apreciable de productividad. Comenzamos revisando una serie de trabajos que han estudiado la 
dispersión de productividad entre empresas, tanto en economías desarrolladas como en desarrollo; estos estudios encuentran sistemáticamente diferencias sustantivas de productividad entre empresas. Luego explicamos por qué no nos debería sorprender ver en todo momento pyme "ineficientes". Por último argumentamos que gran parte de las diferencias de productividad entre empresas es de la esencia del crecimiento económico, que en gran medida consiste en la experimentación y el reemplazo de empresas ineficientes por eficientes. Las políticas públicas que interfieren con este reemplazo (por ejemplo aquellas que apoyan a pyme ineficientes) retardan el crecimiento.

\subsection{1. ¿Deberíamos esperar diferencias de eficiencia entre empresas?}

Existe bastante evidencia de que las disparidades de eficiencia entre empresas en Chile son significativas ${ }^{72}$. Por ejemplo, Álvarez et al. (1999) encuentran que la eficiencia promedio de una planta manufacturera está entre 60 y $70 \%$ de los logros de las firmas más eficientes. Alvarez y Crespi (2002), quienes consideran una encuesta que no incluye firmas grandes, encuentran resultados similares: eficiencia promedio de $65 \%^{73}$. La gran heterogeneidad de los niveles de productividad también se da en las tasas de crecimiento. Con datos de la ENIA entre 1981 y 1992 Camhi et al. (1997, p. 201) reportan que, en promedio, el $45 \%$ de las plantas presenta cambios anuales de productividad media del trabajo de más de $20 \%$ y la dispersión de las tasas de cambio entre plantas es muy grande ${ }^{74}$.

Sin embargo, diferencias de esta magnitud no son infrecuentes. Para formarse una idea, Caves (1992) detectan que la eficiencia industrial promedio en cuatro países desarrollados (Japón, Estados Unidos, Australia y el Reino Unido) está entre 65 y $70 \%{ }^{75}$. Y Tybout (2000),

${ }^{72}$ En la discusión que sigue nos referimos a la eficiencia total de los factores.

${ }^{73}$ Alvarez y Crespi (2002) detectan que las firmas medianas son más eficientes que las pequeñas y las microempresas ( $84 \%$ en promedio vs. $67 \%$ y $62 \%$ ). Sin embargo, este resultado probablemente se debe a sesgo de selección. En efecto, las empresas se encuestaron en 1998 pero fueron seleccionadas entre empresas que eran pequeñas en 1996. En esos dos años algunas crecieron y se transformaron en medianas, y seguramente muchas lo hicieron precisamente por ser más eficientes.

${ }^{74}$ Véase la Figura No 2 en Camhi et al. (1997).

${ }^{75}$ Véase también Bartelsman y Doms (1997). 
quien reseña la evidencia para países en desarrollo, indica que, sorprendentemente, las diferencias de productividad entre empresas al interior de países en desarrollo no son muy distintas de las que se observan en países desarrollados.

Hecho 46. Es normal que existan diferencias apreciables de eficiencia entre empresas. Las diferencias que se observan en Chile son similares a las internacionales.

\subsection{2. ¿Por qué son más ineficientes las pyme?}

Es conveniente partir por lo que no es evidencia de que las pyme sean más ineficientes. Es frecuente que se compare la productividad media de la mano de obra entre empresas grandes y chicas, por ejemplo, aproximándola por las ventas por trabajador. No es muy sorprendente que las empresas más pequeñas aparezcan vendiendo menos por trabajador empleado. Esto no sólo porque las medidas de ventas no se corrigen por la evasión (las empresas pequeñas evaden más) sino, fundamentalmente, porque las pyme se desarrollan en aquellos sectores en los que el tamaño de planta eficiente no es muy grande y el capital por trabajador es menor $^{76}$. Sin embargo, hay otros motivos que explican por qué es razonable esperar mucha heterogeneidad entre las pyme y que su productividad sea a veces menor que la de empresas de mayor tamaño.

Para comenzar, recordemos que los hechos 8 y 11 indican que las empresas no entran grandes, sino que expanden su tamaño de planta una vez que han aprendido el negocio y esperan ser viables. Esto implica que las empresas más pequeñas y jóvenes deberían mostrar productividad menor que las más grandes. De hecho, hay evidencia de que en Chile las plantas que entran tienen productividades menores que las de plantas de más edad. Camhi et al. (1997, p. 210) reportan que en el sector manufacturero la productividad media del trabajo en plantas con al menos seis años de vida es $21 \%$ mayor que en las plantas con sólo un año de vida.

Estas diferencias de productividad se agudizan porque las empresas pequeñas y medianas fracasan y salen más (hechos 9 y 12). De

${ }^{76}$ Es abundante la evidencia de que el capital por trabajador aumenta con la escala mínima eficiente. Véase, por ejemplo, Caves y Pugel (1980). 
hecho, Camhi et al. (1997, p. 214) reportan que en Chile las plantas manufactureras que han salido de la industria tenían una productividad $35 \%$ menor que la de plantas que siguen operando. Es interesante notar, además, que la salida suele no ser instantánea. Las empresas que salen comienzan por perder parte de su negocio, caen las ventas, reducen su inversión y, en definitiva, se achican antes de abandonar la industria. De hecho, Liu (1993) encuentra que en Chile la productividad de las empresas que salen comienza a decaer varios años antes ${ }^{77}$. En definitiva, entre las pyme se observan muchas empresas que están saliendo porque su productividad es baja.

Existe, además, otra razón de por qué la productividad de las empresas que recién entran es menor que la de las empresas en régimen. Como ya se vio, Audretsch (1995a, cap. 6) encuentra que las empresas que recién entran sobreviven en parte porque pagan a sus factores menos que las empresas establecidas. Quien emprende una aventura empresarial está dispuesto a sacrificar parte de su retribución presente por lograr una mayor compensación futura si el proyecto tiene éxito. Lo mismo puede ocurrir con otros factores productivos, por ejemplo con los trabajadores o los dueños de activos físicos o financieros, que ven su baja retribución actual como una inversión necesaria para alcanzar retornos mejores en el tiempo. Sin embargo, esto es sólo temporal. Recordemos que el hecho 9 indica que las firmas que sobreviven crecen más rápido. Por eso, a medida que pasa el tiempo, o bien la empresa logra alcanzar niveles de productividad adecuados para sobrevivir y crecer hasta su tamaño de planta eficiente o bien desaparece. De hecho, Camhi et al. (1997, p. 210) reportan que en el sector manufacturero chileno la productividad de las empresas que logran sobrevivir hasta el segundo año crece en promedio 4,5 puntos porcentuales más que la productividad promedio de las plantas maduras (seis años o más), y en las plantas que sobreviven dos o tres años la productividad crece 3,8 puntos porcentuales más que la de aquellas que llevan cuatro o cinco años (Camhi et al. [1997, pp. 210 y 211]). Como lo indican estos autores, estas diferencias son muy grandes, en vista de que la tasa de crecimiento anual promedio de la productividad en manufactura durante el período que consideran fue 2,1\%. Evidencia similar

${ }^{77}$ A diferencia de Camhi et al. (1997), Liu (1993) mide la productividad total de los factores. 
encontró Liu (1993), en un estudio que cubre un período más corto e incluye una gran recesión (1979-1986). La productividad media es mayor en aquellas plantas que sobreviven y entran que en las que salen. $\mathrm{Y}$, consistente con el resto de la evidencia, la productividad de las plantas que entran y sobreviven crece más rápido que la de plantas establecidas.

Todo lo anterior nos lleva a concluir que la menor productividad de las pyme en gran medida es consecuencia de la dinámica habitual de las industrias.

Hecho 47. Si se las compara con empresas grandes, en la categoría pyme estarán sobrerrepresentadas las empresas nuevas, las que fracasan y las que exhiben tasas de crecimiento de la productividad alta pero niveles de productividad más bajos porque se están acercando a la norma eficiente. Por eso, es razonable esperar que en cada momento la productividad observada de las pyme sea más baja.

\subsubsection{Las diferencias de productividad son parte importante del crecimiento económico}

Una lectura posible de la evidencia citada es que se debería intervenir con políticas de "apoyo" para estimular la eficiencia de las pyme relativamente más ineficientes y, eventualmente, disminuir su tasa de fracaso. Al menos son dos las razones de peso que sugieren que esta lectura de la evidencia es equivocada.

La primera razón es simplemente práctica: los programas de apoyo enfrentan exactamente el mismo problema de selección que los intermediarios financieros: distinguir a las buenas empresas de las que no lo son. Hemos explicado latamente durante este trabajo que es normal que existan empresas no viables porque esto forma parte de la dinámica de las industrias. Lo que le conviene al país es apoyar a las "buenas" pyme, que son las menos y difíciles de identificar. Sin embargo, casi por definición, los programas de apoyo masivo a las pyme, ya sea para reprogramarles deudas que las mantengan funcionando, o para estimularlas a ser más eficientes, terminarán financiando en gran medida empresas que no son viables en el largo plazo. Más aún, las instituciones públicas enfrentan limitaciones fundamentales para dar los incentivos adecuados para que el proceso de selección sea eficiente. 
Para que los incentivos sean "adecuados" la selección debe hacerla quien al mismo tiempo se beneficie directamente con los excedentes creados y asuma el costo de equivocarse. Pero la naturaleza de las instituciones públicas no permite (porque sería inconveniente) que la remuneración del que toma las decisiones de prestar y fomentar dependa de los excedentes creados ni tampoco que asuma las pérdidas de financiar proyectos y empresas equivocadas - el costo de los errores lo asume el tesoro público-. Por lo tanto, su tasa de fracasos tenderá a ser considerablemente más alta que la de intermediarios privados.

Pero la razón más importante y de fondo es que las políticas de estímulo masivo son dañinas para el crecimiento de la productividad, el empleo, los salarios y el desarrollo económico porque retardan, pero no evitan, la salida de las empresas poco productivas. En efecto, la evidencia indica que una parte muy importante de las mejoras de la productividad, independientemente de si se trata de una economía desarrollada o no, proviene de la experimentación con nuevas ideas, muchas de las cuales resultan ser malas. En la práctica, esta experimentación implica invertir en activos cuyo valor de reventa es muy bajo si el proyecto fracasa. Por eso, una parte muy importante de las mejoras de la productividad proviene de reasignaciones de recursos — capital físico y humano y trabajadores - motivadas por la apertura y cierre de empresas. Como lo destacan Caballero y Hammour (2001), la reasignación de recursos desde empresas menos eficientes a las más eficientes es parte fundamental del crecimiento de la productividad agregada de la economía ${ }^{78}$. La reasignación aumenta la productividad porque las empresas que entran y sobreviven son más productivas que las que salen.

Los estudios muestran que inicialmente la productividad de los que entran es sólo un poco mayor que la de los que salen. Pero esto esconde que la mayoría de los que entran fracasan a poco andar precisamente por no ser suficientemente eficientes (véase por ejemplo Roberts y Tiebout [1997] y Camhi et al. [1997]). Con el tiempo, las plantas y empresas que sobreviven tienden a ser significativamente más eficientes que las que salen y esto arrastra el crecimiento de la productividad. Por ejemplo, Foster et al. (2000) encuentran que en los Estados Unidos la reasignación de factores fue responsable del 52\% del

${ }^{78}$ Caballero y Hammour (2001) también destacan el hecho bien documentado de que gran parte de las reasignaciones son dentro del mismo sector: empresas que producen $X$ reemplazan a otras empresas que producen $X$. 
crecimiento de la productividad manufacturera entre 1977 y 1987; de ese crecimiento por reasignación, la mitad ocurrió por entrada y salida de plantas. Para Chile, Liu (1993, p. 235) reporta que entre 1982 y 1986 una fracción significativa de los aumentos de productividad en la manufactura ocurrió por el reemplazo de plantas ineficientes por otras más eficientes. Similarmente, Aw et al. (2001) reportan que en Taiwán la salida de plantas y su reemplazo por otras más eficientes es una fuente muy importante del crecimiento de la productividad; en algunas industrias y períodos es responsable de la mitad del crecimiento.

En definitiva, los programas de apoyo masivo a las pyme disminuyen el crecimiento de la productividad porque retardan la salida de empresas poco productivas que no fueron capaces de competir con otras empresas que hacen lo mismo pero más eficientemente. Más aún, al usar fondos que podrían haberse asignado a las empresas más productivas y competir favorecidas por subsidios, probablemente retardan el crecimiento de las empresas de mayor potencial. Por eso es hasta cierto punto paradójico que se justifiquen estos programas por la supuesta importancia de la pyme como fuente de empleo. Como es sabido, la única manera de aumentar sostenidamente los salarios reales es mediante mejoras de la productividad. Las políticas de apoyo generalizado a pyme tendrán precisamente el efecto contrario ${ }^{79}$.

En este sentido, es interesante examinar algunas de las políticas propuestas por el Estatuto para el Fomento y Desarrollo de la Pequeña Empresa. El Estatuto propone, entre otras cosas, que el Estado garantice deudas de empresas pequeñas para créditos de corto, mediano y largo plazo que les permitan iniciar nuevos negocios, financiar inversiones o su capital de trabajo; para exportadores que desarrollen proyectos que impliquen transferencia o aplicación de innovaciones tecnológicas; para pequeños negocios que experimentaron pérdidas por desastres naturales; para desarrollar la acción crediticia de entidades financieras no bancarias que participen en el otorgamiento de créditos de corto, mediano y largo plazo; y para desarrollar un sistema de fondos y programas especiales para promover la innovación y el desarrollo productivo. En ninguno de estos casos se considera que el problema central es seleccionar a las, comparativamente pocas, pyme que lo harán bien y evitar que los recursos lleguen al resto. Estas políticas,

${ }^{79}$ Véase Hopenhayn y Rogerson (1993) para un análisis formal que demuestra esta conclusión. 
por lo tanto, retardarán el crecimiento de la productividad agregada de la economía y estimularán la creación de empleos inestables. Y, por lo mismo, harán que en el largo plazo los salarios reales crezcan más lento.

\section{4. ¿Se gestionan mal las pyme?}

La sección anterior mostró que es normal observar diferencias de productividad apreciables entre las empresas de un mismo país, pero ¿qué explica las diferencias de productividad promedio tan grandes entre las pyme chilenas y las de países desarrollados? Una de las ideas generalizadas es que la fragilidad de las pyme en Chile y su supuesto escaso potencial de desarrollo radica en que se gestionan mal. Dos razones pueden estar detrás de este problema. Por un lado, una falta generalizada de capacidad de gestión que afecta de manera particular a las pyme. Por el otro, que la capacidad de gestión disponible, que podría ser más valiosa en las pyme, es utilizada por otras empresas; o sea, sería ineficiente esta asignación cuando está orientada, por ejemplo, a empresas más grandes. Sin embargo, a continuación veremos que ninguna de las dos hipótesis es plausible.

\subsubsection{El determinante de la capacidad de gestión: la disponibilidad de capital humano}

Cualquier análisis de la gestión de las pyme debe partir reconociendo el siguiente hecho:

Hecho 48. El determinante fundamental de la peor gestión de las empresas en Chile en general y de las pyme en particular es la escasez relativa de capital humano.

Por ejemplo, Bravo y Contreras (2001, pp. 69 a 72) concluyen que las competencias básicas de la población adulta chilena son muy limitadas e inferiores a las de países de mayor nivel de desarrollo. El problema es que no resulta fácil revertir esta condición en el corto plazo. Tal como ocurre en cualquier país, la capacidad de gestión existente está determinada por la educación formal, entrenamiento y 
experiencia acumulada, por lo que es el resultado de un proceso de inversión en capital humano que se acumula en el tiempo y que no es fácil incrementar en el corto plazo.

Dada esta escasez relativa, la capacidad de gestión se concentra en mayor medida en empresas de mayor tamaño. Por ejemplo, Álvarez et al. (1999) encuentran que el número de técnicos y profesionales universitarios crece con el tamaño de la empresa, como también el nivel de calificación de los empresarios. Entre los microempresarios sólo el 28,3\% tiene educación universitaria completa, proporción que aumenta a $33,5 \%$ en el caso de las empresas pequeñas y llega a $46,4 \%$ en las empresas medianas. ¿ ¿Se justifica la intervención del Estado?

Para comenzar, no es muy sorprendente que la capacidad de gestión se concentre en empresas más grandes. Al margen de que la causalidad puede ser inversa (la empresa gestionada por alguien más preparado tiene más posibilidades de sobrevivir y crecer), el costo de la gestión suele ser fijo y afecta proporcionalmente más a los costos unitarios de producción de las pyme que a los de las empresas más grandes. Por eso es relativamente más conveniente para las empresas grandes contratar un gerente de mayor calificación, porque en esas empresas la escala de operación justifica separar la gestión del negocio de la administrativa. Sin embargo, podríamos pensar que una mejora en la gestión puede generar una expansión del negocio, es decir que contratar una mayor capacidad de gestión sea un proyecto rentable para las pyme. No obstante, las características de muchas pyme implica que esto no es necesariamente así.

\subsubsection{Gestión administrativa y gestión del negocio}

Recordemos que las pyme están en sectores en los cuales los tamaños eficientes de operación no son muy grandes y, en muchos casos, en los que existe la posibilidad de desarrollar negocios de nicho. La característica fundamental de la gestión en estos casos es el conocimiento del negocio, e implica que el empresario debe conocer y entender perfectamente los aspectos productivos de la empresa, ser capaz de diseñar sus productos para satisfacer las necesidades de sus clientes, buscar la manera de introducir mejoras en los productos y en los procesos o evaluar la calidad de las materias primas que utiliza. Así, los 
aspectos técnicos de la gestión del negocio son especialmente importantes en el caso de las pyme y gestionar bien va mucho más allá de ser eficiente en los aspectos administrativos, organizacionales y contables de la empresa. Es por eso que una de las bases del éxito de las empresas pequeñas suele ser el capital humano que forma parte de la persona del empresario. Una muestra de ello es que muchas pyme fracasan cuando el empresario fundador muere o se aleja del negocio.

De esta forma (y como se puede comprobar simplemente conversando con un número suficientemente grande de empresarios pequeños), la escasez de capacidad de gestión entre las pyme se explica en parte porque el empresario no puede dedicar mucho de su tiempo a las labores administrativas, ya que su conocimiento y experiencia es insustituible en la operación de la empresa. A esto se suma que su escala de producción no justifica económicamente contratar un gerente. Pero aun si pudiera pagar un gerente, eso puede no ser suficiente para mejorar la gestión. Lo que eventualmente podría comprar un empresario pequeño en el mercado es capacidad de gestión administrativa, es decir aquella capacidad de gestión de carácter general que permite mejorar los procesos administrativos, organizacionales y contables de la empresa. Pero es mucho más difícil contratar capacidad de gestión del negocio, porque es un conocimiento de carácter mucho más específico a la empresa y se adquiere fundamentalmente por medio de la experiencia.

Hecho 49. Cuando se habla de gestión de la pyme es necesario distinguir entre la gestión administrativa y la del negocio. La escala de producción de la mayoría de las pyme no justifica contratar a un gerente que se especialice en la gestión administrativa.

\subsubsection{Capacidad de gestión y la dinámica industrial}

Una razón adicional por la que no debería sorprendernos que la capacidad de gestión sea menor en las pyme son las regularidades observadas, que sugieren que esto es propio de la dinámica de las industrias. Como vimos, las empresas que recién ingresan al mercado suelen entrar pequeñas y entre ellas existe mucho aprendizaje todo el tiempo. Por lo general, el que está aprendiendo comete errores, es menos productivo y gestiona "mal". Además, en una primera etapa la 
gestión no es prioritaria. Es mucho más importante invertir el tiempo en conseguir clientes, asegurarse los proveedores y optimizar los aspectos técnicos de la producción.

Asimismo, parte del aprendizaje consiste en averiguar si el empresario sabe gestionar lo suficientemente bien como para competir. Los que tienen esta habilidad crecen y se desarrollan, los que no la tienen lo averiguan tardíamente en el proceso y salen del mercado. Por lo tanto, entre las pyme tenemos una mayor proporción de empresas con malos gestores que no sobrevivirán en las industrias, mientras que entre las empresas de mayor tamaño observamos una mayor proporción de empresas que crecieron precisamente por tener buenos gestores. Un ejemplo que ilustra es el de Cecinas Swan en Chile. Hacia fines de los ochenta Swan abrió una planta de cecinas en Chile, comenzando con una escala de producción pequeña con el objeto de aprender del mercado nacional. Su incursión no fue exitosa. La administración local no gozaba de la flexibilidad necesaria para reaccionar a los cambios que se producían en el mercado local, a diferencia de sus competidores que eran empresas locales de carácter familiar. Esto llevó a Swan a tomar la decisión de cerrar su planta y comercializar su marca a través de otro productor local que no tenía los problemas de gestión que le hicieron fracasar en el mercado local ${ }^{80}$.

¿Cómo desarrollar capacidad de gestión en las pyme? El capital humano y la capacidad de gestión se acumulan y por eso cabe preguntarse qué hacer para acelerarla. Para una pyme es difícil contratar capacidad de gestión específica a la empresa y la escala pequeña impone restricciones. Por eso tal vez lo más apropiado es desarrollar capacidad de gestión al interior de la empresa capacitando al empresario. La ventaja es que precisamente el empresario conoce su negocio y está en condiciones de darse cuenta dónde están las oportunidades de mejorar procesos y procedimientos, innovar en su tecnología o disminuir costos. Sin embargo, esta opción puede presentar dos inconvenientes: el empresario puede no querer capacitarse; o bien, el empresario puede no saber quién puede aportarle algo que le sirva.

La condición necesaria para la capacitación destinada a mejorar la gestión de la empresa es que el capacitador entienda los problemas

${ }^{80}$ El caso de Cecinas Swan es citado por Camhi et al. (1997, p. 207). 
de la empresa en concreto, es decir, que conozca los aspectos clave del negocio. Pero el empresario podría rehusar capacitarse si ello implica compartir conocimiento específico de su negocio, ya que ello podría significar una mayor competencia futura o perder su ventaja competitiva. Recordemos que, aunque pequeñas, muchas pyme explotan nichos, por lo que el conocimiento específico es valioso y fuente de rentas. Es la razón de que usualmente los empresarios pyme estén dispuestos a compartir su conocimiento del negocio con familiares directos (v.g. los hijos) pero no con terceros.

Aun cuando el empresario quiera capacitarse, es difícil seleccionar al consultor apropiado. El empresario sabe que le conviene mejorar su capacidad de gestión, pero no es claro que sea capaz de identificar qué tipo de consejo de gestión le puede ser útil, ni cuál consultor sería el indicado para ofrecerle esta capacitación. Tal como en el mercado financiero, en el de las consultorías hay selección adversa y daño moral - existen buenos consultores, capaces de agregar valor al negocio, y malos consultores, que difícilmente harán aportes relevantes-. El problema se resuelve haciendo coincidir los intereses del consultor con los de la empresa. Pero para que esto ocurra el beneficio del consultor debería atarse a los excedentes que crea su consultoría. Sin embargo, en la mayoría de los casos el consultor cobra por el servicio prestado, independientemente de los resultados.

Hecho 50. En el mercado de la consultoría existe selección adversa y daño moral. En ocasiones, seguramente estos problemas son suficientemente severos como para que el mercado apenas funcione, si acaso existe.

Estas razones dan cuenta de la evidencia casual de que las pyme mejor gestionadas son aquellas que se relacionan establemente con empresas de mayor tamaño. El desempeño de estas pyme no le es indiferente a la empresa más grande con la que se relacionan, puesto que cuando la pyme se gestiona mejor también gana la que contrata sus servicios. En ese caso existen incentivos claros para promover mejoras en la gestión. Por otra parte, los esfuerzos para mejorar la gestión en esta situación están claramente focalizados, ya que por lo general la empresa que compra servicios a una pyme conoce en detalle el negocio de su proveedor y sabe lo que ésta requiere. Por otra parte, el empresa- 
rio pyme no corre mucho riesgo de compartir información con su cliente, ya que hay una relación complementaria de largo plazo entre ambos.

Por la misma razón, las asociaciones gremiales pueden jugar un papel importante seleccionando consultores idóneos para desarrollar la capacitación en un sector determinado y servir de instrumento para que las empresas puedan compartir el costo que implican las asesorías en gestión. A las asociaciones gremiales les va bien cuando prestan un servicio valioso para sus asociados, por eso tienen incentivos para invertir seleccionando consultores y programas de capacitación que sean valiosos para sus miembros.

Lo anterior tiene claras implicancias para el diseño de programas públicos que pretendan mejorar la gestión de las pyme. Los programas de capacitación general en que los ingresos del capacitador están en función del número de cursos que vende tenderán a no ser muy útiles, y sobrevivirán sólo si existen subsidios que los financien. Es muy posible que muchas de las asesorías que se prestan en la actualidad no se contratarían sin un subsidio, no porque haya restricciones para financiarlas sino porque carecen de valor para las empresas.

Hecho 51. Un defecto del diseño de muchos programas de fomento de la capacitación es que remuneran a los consultores por curso dictado o asesoría prestada, no por los excedentes que éstos generen.

Perspectivas futuras de la gestión de las pyme. En conclusión, el problema fundamental en la gestión de las pyme no tiene que ver con una falla de mercado, sino con la escasez relativa de la capacidad de gestión que la hace relativamente cara. Es absurdo pretender en Chile estándares de gestión similares a los de países desarrollados, porque en esos países el capital humano es mucho más abundante. En otras palabras, si fuéramos capaces de gestionar como en los países desarrollados, ¡ya seríamos desarrollados! Sin embargo, uno debería esperar que en el futuro la gestión de las pyme mejore significativamente por el simple hecho de que la escolaridad y educación irán aumentando en el tiempo. La educación formal general incrementa la capacidad de entender problemas, de seguir adecuadamente instrucciones y ser metódico en el trabajo, habilidades que permitirán tener mejores gestores. Sin embargo, este proceso de acumulación requiere tiempo y, casi por definición, es gradual. 
Hecho 52. Casi por definición, el mejoramiento general de la capacidad de gestión no puede ser sino gradual.

Incrementar la capacidad de gestión en el corto plazo requeriría aumentar el acervo de capital humano discretamente. La única manera de hacerlo es por medio de una política de inmigración que atraiga personas calificadas a nuestro país sin discriminación de origen. Esta política puede ser deseable por muchas otras razones, pero lo es particularmente como medio barato de mejorar significativamente la calidad de la gestión en las pyme. Es sabido que en muchos países y a lo largo del tiempo, en general, los inmigrantes suelen tener un claro sesgo emprendedor. Esto, unido a un cierto nivel de calificación, generaría una base de pequeños empresarios con capacidad de gestión superior al promedio. Si se implementara una política como ésta, se debería esperar que se produzca una readecuación entre las pyme de los distintos sectores. Si los nuevos empresarios resultaran más eficientes que los establecidos, sería factible esperar la eventual salida de algunas empresas que hoy están operando. Sin embargo, este proceso de reemplazo de empresas menos eficientes por otras más eficientes resulta en ganancias netas para el país.

\author{
5. POLÍTICAS PÚBLICAS Y PYME: \\ FOMENTO NO FINANCIERO Y REGULACIÓN
}

Son dos los aspectos de la política pública que afectan más directamente a las pyme: los programas de fomento y la regulación. En la sección 3.2 ya se abordó el tema de los programas de fomento financieros y en esta sección nos centramos en los programas de fomento no financieros y las regulaciones que afectan de manera preferente a las pyme.

\title{
5.1. Programas de fomento no financieros
}

Las pyme han sido tradicionalmente beneficiarias de programas de fomento que, se argumenta, son necesarios para mitigar fallas de mercado, externalidades o disminuir costos de transacción. En esta sección examinamos los programas de fomento expresamente destinados a las pyme que pretenden corregir estos problemas: los Proyectos de Fomento (Profo), cuyo objetivo es fomentar la asociatividad de las 
pyme; el Programa de Desarrollo de Proveedores (PDP), cuyo propósito es facilitar el desarrollo de relaciones de largo plazo entre pyme y empresas grandes, y el Fondo de Asistencia Técnica (FAT), cuyo propósito es mejorar la capacidad empresarial de las pyme (el Recuadro $\mathrm{N}^{\circ} 11$ describe estos programas) ${ }^{81}$. El Cuadro $\mathrm{N}^{\circ} 18$ muestra que en 1999 estos programas beneficiaron a 10.967 empresas a las que se entregaron 24 millones de dólares ${ }^{82}$.

Tanto los Profos como los PDP fomentan la asociatividad. Se basan en la premisa de que existe algún costo fijo que se justifica si se juntan (o asocian) varias empresas, pero no si cada una lo asume por separado; pero algún costo de transacción impide que las empresas se pongan de acuerdo. El FAT, por contraste, es un programa que busca enseñarles a las pyme a gestionar mejor. En los tres casos la motivación del programa no parece tener mucho que ver con externalidades sino con costos de transacción y mera transferencia de conocimiento. Por lo tanto, se trata de proyectos cuyos beneficios son principalmente privados, no externos. Esto tiene una implicancia muy importante, a saber: que en su mayoría se trata de proyectos que deberían hacerse sólo si el valor creado para la empresa beneficiada es mayor que el costo del proyecto.

El problema del diseño. Los programas de fomento deberían diseñarse a partir del hecho de que sólo un porcentaje pequeño de las pyme es económicamente viable. Por lo tanto, un programa de fomento será exitoso sólo si su diseño resuelve el problema de la selección que hemos visto repetidamente en este trabajo. En efecto, muchas pyme fracasarán por falta de un buen proyecto empresarial, porque no sobrevivirán a la competencia, o bien morirán por la falta de capacidad empresarial de sus gestores. En estos casos, su fracaso nada tiene que ver con que los costos de asociarse sean altos, o que la empresa no pueda apropiarse de la totalidad de los beneficios que generan sus

${ }^{81}$ La Corfo ejecuta una serie de programas de fomento adicionales destinados a corregir fallas de mercado (v.g. los Fontec, fomento de exportaciones, etc.) pero que no están destinados para pyme. Siendo así, quedan fuera del ámbito de este trabajo.

${ }^{82}$ En estricto rigor se trata de 14.871 empresas-programas, ya que la contabilización de las empresas participantes que realiza Corfo es a nivel de cada programa. Así, existen empresas que participan en más de un programa y se cuentan más de una vez. Nótese que, a diferencia de los programas de financiamiento, en este caso los recursos no se devuelven, por lo que los US\$ 24 millones son transferencias netas. 


\section{RECUADRo No ${ }^{\circ}$ 11: Programas DE FOMENTO PARA LAS PYME}

La Corfo desarrolla distintos programas de fomento que pretenden estimular la asociatividad entre las pyme, desarrollar su gestión empresarial y fortalecer sus relaciones con las grandes empresas.

Los Profo. Este programa pretende mejorar la competitividad de las pyme cofinanciando la asociación entre distintas empresas pequeñas y medianas. Las empresas desarrollan un proyecto compartido que les permita resolver problemas de gestión y comercialización, que por su naturaleza o magnitud se pueden abordar de mejor forma de manera conjunta. El desarrollo de un Profo contempla una primera etapa de preparación. En ella se diagnostica el potencial de al menos cinco empresas para desarrollar un proyecto que les permita solucionar problemas comunes. La segunda etapa consiste en desarrollar el proyecto con el fin de incorporar a la operación de las empresas las mejoras de gestión, de los procesos productivos o de la comercialización. La Corfo financia hasta un $80 \%$ del costo de la primera etapa. Durante la segunda etapa, Corfo cofinancia el $70 \%$ del costo del proyecto durante el primer año y va disminuyendo su participación anual en $10 \%$ cada año siguiente hasta el cuarto año.

Programa de Desarrollo de Proveedores (PDP). Este programa financia acciones sistemáticas desarrolladas por empresas grandes destinadas a fortalecer su relación con pyme proveedoras de insumos o servicios. Las empresas grandes pueden optar a este programa si quieren capacitar a sus proveedores, apoyar su certificación o mejorar sus técnicas de producción. Al igual que en el caso de los Profo, existe una etapa de diagnóstico en que Corfo financia hasta un 60\% del costo total, y una etapa de ejecución en que el financiamiento público es de $60 \%$ el primer año y de $50 \%$ los próximos tres años. Tanto la empresa grande como la pyme participan en el financiamiento, aunque esta última en menor medida.

Fondo de Asistencia Técnica (FAT). El FAT es un programa para mejorar la capacidad empresarial de las pyme. El programa financia consultorías especializadas en técnicas de gestión, operación o introducción de nuevas tecnologías en los procesos, con el objeto de mejorar la competitividad de la pyme. Estas consultorías pueden realizarse a una empresa individual o bien a un conjunto de al menos tres empresas que sean sectorial o técnicamente afines. Al igual que en los demás programas, existe una etapa de diagnóstico, en la que Corfo financia UF 17 (o UF 5 por empresa si se trata de una asesoría colectiva), y una etapa de ejecución de la asesoría en la que Corfo financia hasta el 50\% del costo. 
CUADRO No ${ }^{\circ}$ 18: PROGRAMAS E INSTRUMENTOS CORFO PARA PYME

\begin{tabular}{|c|c|c|c|c|}
\hline \multirow[b]{2}{*}{ Instrumentos } & \multicolumn{2}{|c|}{1998} & \multicolumn{2}{|c|}{1999} \\
\hline & $\begin{array}{l}\text { Número de } \\
\text { empresas }\end{array}$ & $\begin{array}{l}\text { Aporte Corfo } \\
\text { (miles de US\$ } \\
\text { de 1999) }\end{array}$ & $\begin{array}{l}\text { Número de } \\
\text { empresas }\end{array}$ & $\begin{array}{c}\text { Aporte Corfo } \\
\text { (miles de US\$ } \\
\text { de 1999) }\end{array}$ \\
\hline $\begin{array}{l}\text { Proyectos de Fomento } \\
\text { (Profo) }\end{array}$ & 2.912 & $8.866(39,4 \%)$ & 3.628 & $10.746(44,7 \%)$ \\
\hline $\begin{array}{l}\text { Fondo de Asistencia } \\
\text { Técnica (FAT) }\end{array}$ & 4.450 & 13.402 (59,5\%) & 5.274 & 12.127 (50,5\%) \\
\hline $\begin{array}{l}\text { Programa Desarrollo } \\
\text { de Proveedores (PDP) }\end{array}$ & 1.296 & $243(1,1 \%)$ & 2.065 & $1.165(4,8 \%)$ \\
\hline Total & 8.658 & $22.511(100 \%)$ & 10.967 & $24.038(100 \%)$ \\
\hline
\end{tabular}

Fuente: Corfo.

programas de capacitación o sus mejoras en los procesos productivos y comerciales. Por ello, los programas de fomento deben diseñarse para mitigar la selección adversa, atraer a las empresas que tienen buenos proyectos y descartar al resto. Ciertamente, el número de subsidios entregados no puede ser la medida del éxito relativo del programa.

El segundo aspecto esencial es que se cuente con mecanismos que aseguren que la inversión de fondos públicos sea socialmente rentable. Esto implica que, además de financiar pyme viables, los beneficios del proyecto financiado deben superar el costo alternativo de los recursos utilizados. Por eso es indispensable que la rentabilidad social de cada programa se evalúe periódica e independientemente.

Hecho 53. Un desafío primario para los programas de fomento es seleccionar adecuadamente a las pyme que son económicamente viables. Una vez seleccionadas, se deben financiar sólo aquellos proyectos que, siendo socialmente rentables, no se harían sin el subsidio.

La regla de oro para garantizar que los proyectos seleccionados sean rentables en promedio es que la remuneración del que los financie o promueva dependa fundamentalmente del valor creado por el proyecto. Desafortunadamente, la naturaleza de las instituciones públicas no 
permite que la remuneración del que toma las decisiones de prestar y fomentar dependa de los excedentes creados ni tampoco que asuma las pérdidas de financiar proyectos y empresas equivocadas - el costo de los errores lo asume el tesoro público—- A este problema en alguna medida estructural se le suma que los mecanismos de selección contemplados en los programas analizados son débiles.

Para comenzar, los proyectos que se financian son promovidos por consultores independientes (también conocidos como agentes), que sirven de intermediarios entre la Corfo y las empresas beneficiarias. Estos consultores no son remunerados en función del éxito del proyecto, sino que reciben un pago por identificar una demanda por fomento, realizar el contacto con Corfo y elaborar un diagnóstico. Vale decir, sus ingresos y utilidades dependen del número de proyectos iniciados, no de la rentabilidad que alcance finalmente el proyecto.

Por ejemplo, en el caso de los Profo, la Corfo le paga al consultor UF 80 por empresa para realizar un diagnóstico sobre la viabilidad y la pertinencia de un proyecto asociativo. Si el proyecto es financiado, el agente recibe un pago adicional para cubrir los costos que implican supervisar y controlar el proyecto; el esquema es muy similar para los PDP. En el caso de los FAT, los agentes reciben un pago de suma alzada por presentar un acuerdo con un empresario para realizar un diagnóstico que permita determinar las necesidades de asesorías. El estímulo, entonces, es maximizar el número de proyectos aprobados, sin preocuparse mucho del valor que éstos generen. De hecho, una evaluación de los Profo agrícolas detectó como problema que a los proyectos financiados les faltaba claridad en cuanto a sus objetivos, lo que refleja en parte el problema de calidad de los mismos (Agraria, 1999, p. 19). En el mismo sentido, Álvarez et al. (1999, p. 23) encuentran que las empresas que participan en estos programas tienen una baja valoración por la asociatividad como un instrumento de crecimiento y mejoramiento de la competitividad.

Hecho 54. Los consultores que intermedian los proyectos de fomento Corfo ganan por el número de proyectos iniciados, no por el valor que éstos generen.

Se podría argumentar que la participación de empresas alinea los incentivos de los consultores, porque éstas no deberían estar interesadas en perder el tiempo y además se les exige cofinanciamiento. En 
principio, ninguna empresa estaría dispuesta a invertir sus recursos en un programa de fomento si sabe que con alta probabilidad se verá forzada a dejar la industria, o si el proyecto en cuestión no le genera un beneficio mayor que el valor de su aporte. Sin embargo, la Corfo financia gran parte de los costos del proyecto y en cualquier caso es muy difícil asegurarse que el cofinanciamiento efectivamente ocurra, porque el consultor y las empresas pueden coludirse para repartirse el subsidio e inflar el costo total del proyecto. De hecho, Held (2000) indica que el Subsidio de Asistencia Financiera se discontinuó precisamente por este problema.

La dificultad para seleccionar buenos proyectos se exacerba porque la aprobación final del proyecto depende de los directores regionales y de los miembros de los comités de asignación zonales. Éstos conocen de manera mucho más imprecisa la viabilidad económica de una empresa que sus gestores. Así, la aprobación de financiamiento descansa mayoritariamente en la evaluación del consultor, que cobra solamente si el proyecto se aprueba, y del empresario beneficiado por el proyecto. Por otra parte, las presiones políticas desde los gobiernos regionales, parlamentarios y otras autoridades para que se aprueben iniciativas que no tienen los atributos requeridos para ser exitosos, y el que los directores regionales perciban que la evaluación de su desempeño está ligada al número de proyectos de fomento desarrollados, también son causas de que el proceso de selección sea aun menos selectivo (Agraria, 1999, p. 41).

Asegurar que los programas de fomento financien proyectos rentables de pyme económicamente viables exige respetar una regla de oro: a los consultores se les debe remunerar por medio de la participación de los excedentes que crean con el proyecto que promueven y desarrollan, y no directamente por el servicio que prestan. Si así fuera, los consultores tratarían de seleccionar pyme viables y proyectos que generen valor ${ }^{83}$.

Hechos 55. Para mejorar la selección de proyectos rentables entre pyme económicamente viables los intermediarios de los progra-

${ }^{83}$ Se podría argumentar que esto no es posible si gran parte de los beneficios del proyecto consiste en externalidades. Sin embargo, como veremos más abajo, los Profo y los PDP son programas para disminuir costos de transacción, en tanto que los FAT benefician fundamentalmente a las empresas beneficiarias de la consultoría de gestión. 
mas de fomento deben remunerarse en función del excedente que crean entre los beneficiarios.

El segundo defecto del diseño de los programas de fomento es que los criterios de selección son muy generales. Por el contrario, lo adecuado es que se apunte a focalizar los subsidios en grupos con mayor probabilidad de éxito. Por ejemplo, la evaluación de los Profo debería considerar que los programas asociativos con mayor posibilidad de éxito son aquellos en que los empresarios desarrollan actividades complementarias, o bien que comparten un mercado común pero que está creciendo, ya que en estos casos existen objetivos comunes y no compiten intensamente entre ellos. Por el contrario, un Profo entre empresas que compiten en un mercado de bajo crecimiento es receta segura de fracaso. De hecho, la falta de objetivos comunes y los problemas para mantener cohesionados a los grupos que desarrollan Profo identificados en el sector agrícola por Agraria (1999, pp. 10 y 30) muestran la importancia de mejorar los criterios de selección. Lo mismo ocurre cuando el objetivo es financiar un proyecto que pretenda apoyar la exportación. Por ejemplo, no tiene sentido financiar el esfuerzo de una empresa pequeña en un mercado de commodities, en el que la escala es la gran ventaja competitiva, pero probablemente sí el de una empresa que produce para un mercado externo de nicho. Desarrollar criterios de selección simples pero basados en los principios económicos identificados en la sección 2 y en la subsección 3.1 disminuiría el costo del fomento, mejoraría su eficacia y aumentaría su eficiencia.

Hecho 56. Criterios de selección basados en los principios económicos que determinan el beneficio de una asociación mejorarían la efectividad y la eficiencia de los programas de fomento.

¿Se justifica cofinanciar? La importancia de evaluar. Además de los problemas de diseño, existe otro más fundamental: nada nos asegura que los programas de fomento que estamos analizando subsidien principalmente aquellas actividades que podrían necesitarlo. La raíz del problema es que en los tres casos se subsidian proyectos cuyos beneficios, si existen, son fundamentalmente privados. Para entender el punto, consideremos el programa Profo. Como se dijo, su justificación es que hay algún costo fijo en el que es rentable incurrir si se asocian 
varias empresas, pero no si cada una incurre en él por separado; pero algún costo de transacción impide que las empresas se pongan de acuerdo. Sin embargo, si el problema es el costo de transacción, lo que corresponde es a lo más subsidiar los gastos para mitigarlos o bien facilitar la asociación de empresas directamente. Por el contrario, el costo fijo crea valor para las empresas que se asocian, entonces las mismas empresas deberían estar dispuestas a pagarlo y la Corfo no debería cofinanciar. De esta forma, la Corfo se aseguraría de que se ejecutaran proyectos que creen valor, al tiempo que evitaría que los costos de organizarse y actuar colectivamente frustren proyectos asociativos. Por lo mismo, las empresas sólo contratarían a un consultor si estiman que éste afectivamente sabe cómo ejecutar un proyecto asociativo que cree valor. De igual manera, si los programas de capacitación empresarial crean valor para las empresas que los emprenden, y el problema radica sólo en el costo de transacción necesario para seleccionar a un consultor capacitado, bastaría que Corfo generase la información requerida para una selección correcta, por ejemplo, a través de certificar consultores.

Hecho 57. No se justifica que la Corfo cofinancie los proyectos asociativos (Profo y PDP) ni aquellos que mejoran la gestión de las pyme (FAT). La Corfo se debería limitar a reducir costos de transacción.

$¿$ Es plausible pensar que las externalidades generadas por estos proyectos justifican el cofinanciamiento de Corfo? No hay estudios que presenten evidencia de que estos proyectos generen externalidades lo suficientemente grandes que justifiquen los montos destinados a subsidiar estas actividades entre las pyme. Pero aun si generasen externalidades, los porcentajes de cofinanciamiento parecen muy grandes: entre el $80 \%$ y el 50\% del costo de los Profo, entre el 60\% y el 50\% de los PDP y el $50 \%$ de las consultorías en los FAT. Por eso, nos parece que es muy probable que la generosidad del subsidio esté promoviendo proyectos que generan poco valor a las empresas beneficiarias y que éstas los contraten sólo porque les cuesta poco y porque los consultores se benefician intermediándolos. De haber tenido que asumir el costo completo, es muy probable que la mayoría de los proyectos no se hubiera ejecutado. Lo más probable es que en estos casos los recursos invertidos tengan un retorno muy por debajo de su costo alternativo. 
Hecho 58. Los elevados montos necesarios para sostener programas de fomento sugieren que muchas de las actividades desarrolladas son poco valiosas para las pyme o bien que sólo se trata de la transferencia de una renta.

Los recursos utilizados en programas de fomento son considerables y tienen un costo alternativo, por lo que es indispensable evaluar su rentabilidad social. Sin embargo, se han hecho muy pocas evaluaciones y las que existen no permiten determinar la rentabilidad social de los mismos. Hay una evaluación de los Profo agropecuarios desarrollada por Agraria (1999). Sin embargo, esta estimación es más bien cualitativa y no los evalúa económicamente. Por otro lado, Benavente y Crespi (2000) realizaron una evaluación económica de los Profo y concluyen que la tasa interna de retorno es del orden del 21\%. Pero la metodología utilizada adolece sesgo de selección económico que sugiere que la TIR obtenida sobrestima la verdadera ${ }^{84}$.

Hecho 59. A pesar de los montos invertidos en programas de fomento, no se han hecho evaluaciones que permitan determinar su rentabilidad social.

En conclusión, nos parece indispensable que a la brevedad se evalúe independientemente la rentabilidad social de los programas de fomento no financieros que favorecen a las pyme.

\subsection{Regulaciones y las pyme}

Una de las quejas habituales de los pequeños y medianos empresarios (y que fue recurrente en las entrevistas que sostuvimos) es que deben cumplir con regulaciones excesivas. Estas quejas se pueden clasificar en tres categorías. Primero, las regulaciones imponen costos

${ }^{84}$ El sesgo de selección se debe a lo siguiente. Primero, la muestra de 121 empresas evaluadas no es aleatoria, sino que considera Profo únicamente en sectores “dinámicos” donde las firmas crecieron rápidamente. Por el contrario, no se evaluó la rentabilidad de Profo de empresas en sectores menos dinámicos, ni tampoco en aquellos donde el porcentaje de fracaso de los Profo fue alto. Segundo, el estudio considera la rentabilidad de un grupo de empresas que completó exitosamente los programas, dejando fuera a aquellas empresas que desaparecieron o que por alguna otra razón abandonaron los programas, lo que sobrestima su rentabilidad social. 
que encarecen lo que producen. Segundo, deben competir con empresas informales que, ya sea evaden la regulación o bien son favorecidas por fiscalización más laxa. Tercero, el costo de cumplir con los trámites que se les exige es alto porque la burocracia es excesiva. A continuación examinamos estos argumentos.

\subsubsection{Regulaciones y costos fijos}

Los costos en que se incurren para cumplir con tales regulaciones, como las laborales, ambientales o municipales, suelen ser similares independientemente del tamaño de la empresa ${ }^{85}$. Por eso, típicamente la regulación es más costosa proporcionalmente para las pyme. Esto tiene varias consecuencias.

La primera es que muchas empresas eligen evadir la regulación. Sin embargo, evadir es más difícil mientras mayor es el tamaño de la empresa - para los fiscalizadores es más fácil y barato concentrarse en empresas de cierto tamaño, simplemente porque son las menos-, y por eso las que no cumplen tienden a ser las más pequeñas.

En segundo lugar, y por la misma razón, las regulaciones penalizan el crecimiento de las empresas más chicas, porque a medida que aumentan su tamaño se va haciendo más difícil evadir la fiscalización.

Tercero, el mayor costo proporcional que les imponen las regulaciones a las pyme motiva en parte que a las empresas pequeñas se les exima de algunas o se les impongan estándares menos exigentes. En efecto, muchas de las regulaciones en el ámbito laboral, sanitario y tributario implican que si la empresa crece sobre un cierto umbral debe cumplir con normativas de las que antes estaba exenta, los estándares que se le exigen son mayores y va a ser objeto de una supervisión mucho más estricta de parte de las autoridades. Hay varios ejemplos de regulaciones de este tipo: el porcentaje de trabajadores jóvenes que pueden ser capacitados con beneficio tributario disminuye a medida que la empresa crece; si una empresa contrata más de 20 trabajadoras debe pagarles una sala cuna o instalar una en la empresa; si la empresa crece sobre 100 trabajadores debe tener un departamento de prevención de riesgos; si las empresas consumen más de cierta cantidad de combustible debe efectuar un estudio de impacto ambiental. La regula-

${ }^{85}$ Véase Levenson y Maloney (1997). 
ción diferenciada por tamaño tiene la virtud de disminuirles los costos fijos a las empresas más pequeñas. Sin embargo, una consecuencia inevitable de esta asimetría es castigar el crecimiento de la empresa.

Hay evidencia indirecta de que el costo de las regulaciones en países en desarrollo motiva que existan menos empresas pequeñas y medianas. En efecto, Tybout (2000, pp. 15 a 18) muestra que la distribución de tamaños de empresas en países desarrollados es muy distinta de la de países en desarrollo. Tal como lo discutimos en la sección 3, en países desarrollados las empresas son más grandes en promedio porque el capital físico y humano es más abundante. Por eso hay muy pocas empresas que emplean menos de 10 trabajadores, un número mayor que emplea entre 10 y 50 y la categoría dominante son aquellas empresas que emplean más de 50 trabajadores. En países en desarrollo la categoría dominante debería ser la de empresas pequeñas y, relativamente, debería haber pocas empresas grandes. Sin embargo, en la práctica la distribución de tamaños tiene forma de $U$ : dominan las microempresas que emplean menos de 10 trabajadores, pero la tendencia es más empresas que emplean a lo menos 50 trabajadores, superando a las empresas que emplean entre 10 y 50 trabajadores. Este patrón es consistente con costos regulatorios que inhiben el crecimiento de las empresas más pequeñas.

En Chile existe cierta evidencia de este patrón, y no sólo por el gran número de microempresas. Volviendo al Cuadro $\mathrm{N}^{\circ}$ 9, que resume la evolución de la distribución de tamaños de plantas manufactureras entre 1980 y 1997, se aprecia que la participación de las plantas de 100 o más trabajadores aumentó significativamente (de $11 \%$ a casi $20 \%$ ), mientras que la de las más pequeñas (hasta 19 trabajadores) cayó de $42 \%$ a menos de $30 \%$. Como ya se dijo, esta evolución es consecuencia del aumento de la disponibilidad de capital. Sin embargo, esto mismo implica que la caída de la participación de las plantas pequeñas debería haberse repartido entre las plantas más pequeñas. En cambio, la participación de las plantas que emplean entre 20 y 99 trabajadores casi no cambió.

Hechos 60. Los costos de la regulación son proporcionalmente mayores para las empresas pequeñas. Las regulaciones que a las empresas pequeñas les disminuyen el costo de cumplirlas moderan esta desventaja del tamaño pero penalizan el crecimiento. 


\subsubsection{Costos de tramitación y pyme}

Otro aspecto de la regulación que es proporcionalmente más costoso para las empresas pequeñas son los trámites para obtener permisos de distintos tipo, como, por ejemplo, sanitarios, de obras, certificaciones, etc. Si bien la obtención de este tipo de permisos no distingue entre empresas pequeñas o grandes, las empresas más pequeñas no cuentan con personal calificado para desarrollar este tipo de trámites. Cumplir con la normativa requiere normalmente que el pequeño empresario deba dedicarse a su tramitación restándole tiempo a la gestión de su negocio. Así, la simplificación de los trámites para obtener permisos o las ventanillas únicas beneficiarían de manera especial a las pyme.

Hecho 61. La tramitación de permisos y autorizaciones suele ser particularmente onerosa para las empresas pequeñas porque muchas veces debe hacerlas el gestor de la empresa.

¿Cuánto es posible mejorar? El Cuadro $\mathrm{N}^{\circ} 19$, construido con información recopilada por Djankov et al. (2001), permite comparar el costo de establecer legalmente una empresa en Chile y en otros países, y nos da una idea del costo impuesto por la regulación. De acuerdo con estos autores, en Chile se requieren diez trámites para establecer una empresa y, de acuerdo con lo plazos oficiales, se necesitan 28 días hábiles para completarlos (columnas 1 y 2) ${ }^{86}$. El costo pecuniario oficial de estos trámites es el equivalente al 13\% del PGB per cápita (columna 3); si se suma el costo del tiempo, se llega a poco más del 24\% del PGB per cápita, o \$US 1.150,9. Estos costos son menores que en el promedio de los 85 países considerados: nuestro número de trámites es parecido al promedio (10 vs. 10,48), pero en Chile toma menos días completarlos (28 vs. 47) y el costo es menor $(24,28 \%$ del PGB per cápita vs. 65,98\%; si en Chile el costo fuera similar, alcanzaría los US\$ 3.127,50). Pero son suficientemente altos como para explicar

${ }^{86}$ Es importante notar que estos tiempos y costos son oficiales; no incluyen las demoras debidas a ineficiencia de los organismos públicos particulares que aplican la regulación cuando éstos no cumplen con los plazos oficiales ni los costos impuestos por funcionarios corruptos. Por lo tanto, el dato es probablemente una cota inferior de los costos de establecer una empresa. 


\begin{tabular}{lccccc}
\hline & $\begin{array}{c}(1) \\
\text { Número de } \\
\text { trámites }\end{array}$ & $\begin{array}{c}(2) \\
\text { Números } \\
\text { de días }\end{array}$ & $\begin{array}{c}(3) \\
\text { Costo } \\
\text { pecuniario } \\
\text { como \% } \\
\text { del PGB } \\
\text { per cápita }\end{array}$ & $\begin{array}{c}\text { Costo total } \\
\text { incluido } \\
\text { tiempo } \\
\text { como } \\
\text { \% PGB } \\
\text { per cápita }\end{array}$ & $\begin{array}{c}\text { Costo en } \\
\text { US según } \\
\text { PGB cápita } \\
\text { de Chile }\end{array}$ \\
& & & & & \\
& & & & & \\
Canadá & 2 & 2 & 1,45 & 2,25 & 106,9 \\
Estados Unidos & 4 & 4 & 0,49 & 1,69 & 80,1 \\
Chile & $\mathbf{1 0}$ & $\mathbf{2 8}$ & $\mathbf{1 3 , 0 8}$ & $\mathbf{2 4 , 2 8}$ & $\mathbf{1 . 1 5 0 , 9}$ \\
Mundo & 10,48 & 47 & 47,08 & 65,98 & $3.127,5$ \\
\hline
\end{tabular}

Nota: La columna 1 muestra el número de trámites que se requieren para iniciar una empresa en cada uno de los países y el promedio mundial. La columna 2 muestra el número de días hábiles que toma hacer esos trámites. La columna 3 corresponde al costo directo en dinero de los trámites, expresados como porcentaje del PGB per cápita de cada país. La columna 4 incluye, además del costo directo, el costo del tiempo que toma hacer las gestiones, expresados ambos como porcentaje del PGB per cápita de cada país. La columna 5 corresponde a lo que costaría hacer los trámites en los distintos países si su producto per cápita fuera el de Chile.

Fuente: Djankov et al. (2001).

por qué un número muy grande de micro y pequeñas empresas elige la informalidad: el costo de cumplir con los trámites oficiales equivale a más de un mes de ventas de la microempresa promedio y (suponiendo un margen de utilidad de $20 \%$ sobre ventas) a cerca de la mitad de sus utilidades anuales.

Más aún, el resto del mundo no es la vara de comparación adecuada respecto de cuán bien lo hacemos, al menos si queremos que el ambiente sea favorable para el desarrollo de las pyme. En efecto, si se compara a Chile con Canadá y los Estados Unidos, los países que lo hacen mejor, se concluye que el margen para mejorar es apreciable. En Canadá se necesitan apenas dos trámites y dos días para establecer legalmente una empresa; en Estados Unidos son cuatro trámites y cuatro días. De esta forma, si fuéramos como Canadá el costo total sería de apenas US\$ 106,9; o de US\$ 80,1 si fuéramos como los Estados Unidos ${ }^{87}$. Nótese que el menor costo no se debe a que ellos

${ }^{87}$ Es importante notar que al reducir el número de trámites también se reduce la posibilidad de demoras y de corrupción. 
sean desarrollados y nosotros no; se debe casi exclusivamente a que ellos exigen menos trámites.

Hecho 62. El costo de establecer una empresa en Chile es aún muy alto y se podría reducir considerablemente. Esto sugiere, además, que el costo de cumplir con la regulación en general aún es muy alto y explica por qué la informalidad es la única opción de la mayoría de las microempresas.

Si bien la sección que le dedicamos a este punto es breve (las recomendaciones concretas requieren examinar el proceso que siguen los trámites, lo que cae fuera del ámbito del trabajo), debería quedar claro que la simplificación de trámites necesarios y la eliminación de trámites innecesarios debería ser prioritaria. En este sentido, proponemos que a la brevedad se elimine una serie de trámites que, con seguridad, son innecesarios y perjudican particularmente a las pyme.

\subsection{3. ¿Regulaciones especiales para las pyme?}

En vista de lo anterior, ¿cuál debería ser la política de regulación? No es posible contestar esta pregunta en general, ya que la conveniencia de una regulación pareja o diferenciada según tamaño dependerá de los costos y beneficios en cada caso particular. Distintas exigencias tienen consecuencias diversas y el costo varía en mayor o menor medida con el volumen de producción dependiendo de la naturaleza de la regulación. Asimismo, los costos incrementales de crecer más allá de un cierto umbral también son específicos a cada regulación. Por otra parte, es importante tener en mente que algunas regulaciones que mitigan externalidades (p. ej. las normas de emisión) probablemente son convenientes aun si "perjudican” a una empresa de menor tamaño.

Una evaluación del impacto de las diversas regulaciones que afectan a las pyme cae fuera del ámbito de este trabajo, entre otras razones porque la mayoría no le son específicas y requerirían un análisis detallado de impacto. Sin embargo, algunas distinciones son útiles para establecer principios generales. Para ello conviene distinguir la regulación que afecta a las pyme en dos categorías: aquellas 
que controlan externalidades y aquellas que regulan sus relaciones laborales.

En la primera categoría la regulación más importante es la medioambiental. En este caso es difícil justificar una política diferenciada de emisiones, ya que el costo social de degradar el medioambiente es idéntico si la fuente es una empresa pequeña o grande. Lo importante en este caso es que exista un mecanismo que obligue a las empresas a reconocer el costo económico de la externalidad (por ejemplo, un sistema de permisos transables), y que finalmente produzcan aquellos que son más eficientes, independientemente de su tamaño. Por lo tanto, sólo cabría una diferenciación en los aspectos operativos para evaluar la externalidad producida, que es lo que hoy ocurre al exigirse un estudio de impacto a los proyectos de mayor tamaño y sólo una declaración de impacto a los más pequeños.

En la segunda categoría, son varias las normas que regulan las relaciones laborales y que distinguen según el tamaño de la empresa. Por ejemplo, las que imponen menores exigencias en cuanto al número mínimo de trabajadores necesarios para formar un sindicato dependiendo del número total de personas que trabajan en la empresa, las que otorgan beneficios tributarios por capacitación diferenciados dependiendo del número de trabajadores empleados, y los ya mencionados requerimientos de salas cuna. Como lo dijimos anteriormente, por lo general estas normas buscan disminuirles costos a las empresas pequeñas pero castigan su eventual crecimiento. Hay, sin embargo, otras normas laborales que son de carácter general y no se aplican de manera diferenciada a las empresas pequeñas. Ejemplos son el salario mínimo y el encarecimiento de los despidos ante la mayor probabilidad de que éstos terminen en juicios laborales. En el contexto de las pyme y la política pública hacia ellas, muchas de estas normas laborales esconden una cierta contradicción de la política pública, que discutimos a continuación ${ }^{88}$.

En efecto, la lógica que subyace en estas regulaciones es que parte de las utilidades de los empresarios, incluidos los dueños de pyme, se obtiene a costa de pagar menores sueldos a los trabajadores, ofrecerles malas condiciones de seguridad y un entorno laboral inapro-

${ }^{88}$ Esta contradicción la señaló Andrés Velasco en un artículo de opinión en la revista Capital de marzo de 2001. 
piado. Esto les permitiría a los empresarios obtener rentas ${ }^{89}$. Así, por medio de las leyes laborales se buscaría establecer las bases necesarias para que los trabajadores pudieran alcanzar una legítima participación en las rentas de las empresas. Sin embargo, y por otro lado, la mayoría de los programas de apoyo a las pyme propuestos y existentes para exportar, asociarse, innovar, capacitarse y financiarse y reprogramar deudas se basa en la premisa de que estas empresas son incapaces por sí mismas de sobrevivir en los mercados sin que medie una política de ayuda pública. En otras palabras, estas empresas operarían en condiciones económicas precarias y su sobrevivencia dependería de las políticas de apoyo estatal. Pero si así fuera, se seguiría que la generalidad de las pyme no tiene rentas que compartir.

Hecho 63. La política regulatoria y de fomento para las pyme es contradictoria. Por un lado, las normas laborales suponen que tienen rentas para compartir con sus trabajadores; por el otro, la mayoría de las políticas de apoyo y fomento parte de la premisa de que las pyme no pueden sobrevivir sin ayuda —es decir, no tienen rentas-.

Esta contradicción sugiere que la política pública hacia las pyme no es consistente. En nuestra opinión el problema se debe a que es inadecuado motivar políticas públicas basadas en el tamaño de las empresas porque esta condición esconde la gran heterogeneidad que existe. La contradicción es doblemente costosa para el país. Por un lado, el supuesto de que las pyme no pueden sobrevivir sin un apoyo estatal, el cual es errado, lleva a que se subsidie a muchas empresas que fracasarán en cualquier caso. Por otro lado, las políticas laborales encarecen la contratación de trabajadores, particularmente en empresas pequeñas y medianas. Esto se refleja en menor producción y menos empleo del que se darían de otra suerte. Los menores salarios y peores condiciones de trabajo que caracterizan a las pyme reflejan, en parte, la menor capacidad de contratar mano de obra calificada; no se deben a que los trabajadores no tengan suficiente poder de negociación para extraer rentas.

${ }^{89}$ Una persona gana una renta económica cuando recibe una remuneración mayor que su costo de oportunidad. En este caso las ganancias de los empresarios estarían por encima del costo de oportunidad de sus aportes a la empresa. 
EPÍLOGO: POLÍTICAS PARA PYME, 2002-2009

Cuando escribimos Las pyme la creencia generalizada era que, por una serie de distorsiones y fallas de mercado, las empresas de menor tamaño salían demasiado, estaban sobreendeudadas, no tenían acceso a financiamiento de largo plazo, se gestionaban mal, eran tecnológicamente atrasadas y su participación en el total de ventas era insuficiente -incluso, algunos sostenían que iban camino a desaparecer-. El Estado debía apoyarlas con programas de fomento, asistencia y entrenamiento, coordinar la asociatividad, reprogramar sus créditos, subsidiar sus garantías, abrir líneas de crédito de largo plazo y enseñarles a gestionar mejor.

Desde el punto de vista de políticos y gobiernos y también del foco de las políticas públicas, poco ha cambiado. Por ejemplo, a pesar de que el número de firmas crece todos los años en Chile, el mensaje que acompañó al proyecto de ley para empresas de menor tamaño (el así llamado Estatuto) reitera que estas empresas tienen problemas para desarrollarse:

La distribución de beneficios [del desarrollo económico] no ha sido del todo equitativa, parte de ello debido a desigualdades en el acceso a oportunidades para emprender. En la actualidad, existen en Chile 721 mil empresas formales activas, esto es inscritas en el Servicio de Impuestos Internos (SII) y con ventas positivas registradas en el año 2006, de las cuales un $79 \%$ corresponde a microempresas, un $17 \%$ a pequeñas empresas y un 2,5\% a medianas empresas. No obstante esta alta participación en términos numéricos, este grupo de empresas, denominadas como Empresas de Menor Tamaño (EMT), aporta solamente al $15 \%$ del total de ventas de las empresas del país y su participación directa en las exportaciones nacionales no supera el $10 \%$ del total.

[...] la baja participación de estas empresas en los niveles de ventas totales constituye una primera indicación de la dificultad que enfrentan para desarrollarse, la cual ciertamente no obedece a una única razón. En efecto, una observación común que surge de los diferentes estudios del sector de EMT, es el alto grado de heterogeneidad que lo caracteriza y a sus problemas para desarrollarse ${ }^{1}$.

\footnotetext{
${ }^{1}$ Mensaje del proyecto de ley, enero 4 de 2008.
} 
Y el artículo tercero del Estatuto, que está a punto de ser ley y que muchos describen como el principal logro del gobierno de la Presidenta Bachelet en materia de las pyme, muestra que el foco sigue siendo que el gobierno ayude y fomente:

\begin{abstract}
El Ministerio de Economía, Fomento y Reconstrucción deberá impulsar el desarrollo de las empresas de menor tamaño y facilitarles la utilización de los instrumentos de fomento dispuestos por los órganos del Estado.

Le corresponderá a la Subsecretaría de Economía, Fomento y Reconstrucción generar coordinaciones para que, en conjunto con los ministerios sectoriales, se formulen las políticas y planes de fomento considerando las particularidades de las empresas de menor tamaño.

Asimismo, le corresponderá impulsar con sus servicios dependientes o relacionados una política general para la mejor orientación, coordinación y fomento del desarrollo de las empresas de menor tamaño, así como realizar un seguimiento de las respectivas políticas y programas y generar las condiciones para el acceso de estas empresas a fuentes útiles de información, contribuyendo a la mejor utilización de los instrumentos de fomento disponibles para ellas.
\end{abstract}

En esencia, el eje de las políticas públicas sigue siendo el fomento, pese a que no hay evidencia de que haya funcionado en el pasado o que vaya a funcionar en el futuro. Peor aun, nuestro Estado nunca ha evaluado el impacto de su legión de programas, y seguramente tampoco lo hará en el futuro; más improbable aun es que cierre los programas que no funcionan. Pese a todo, se insiste con que el problema de las empresas de menor tamaño es que sus dueños no saben hacer bien las cosas. Por eso es que un ministerio tiene que impulsar "[...] una política general para la mejor orientación, coordinación y fomento del desarrollo de las empresas de menor tamaño"2.

Las conclusiones a las que llegamos en Las pyme son muy distintas. La evidencia muestra que en Chile la situación de las empresas medianas y pequeñas no es muy diferente a la que debiera esperarse en una economía que asigna los recursos razonablemente bien. La

${ }^{2}$ Cabe preguntarse si acaso nuestro Estado es el más indicado para enseñar sobre gestión. Por ejemplo, poco después de escrito Las pyme, la propia institución encargada del fomento de empresas (la Corfo), perdió US\$100 millones en depósitos a plazo porque sus prácticas de gestión y control internas eran incompetentes. 
entrada y salida frecuente de empresas de cualquier tamaño no sólo es esperable sino que deseable, pues forma parte del proceso de experimentación y selección de firmas que hace crecer la productividad, la otra cara de la moneda del aprendizaje. En realidad, Las pyme mostró que casi todas las supuestas distorsiones y fallas de mercado que solían identificar los analistas pyme no son tales. Con esta tensión en mente, a continuación discutimos brevemente qué se ha hecho en materia de las pyme desde 2002.

\section{Financiamiento}

El financiamiento caro e insuficiente es un tema recurrente del discurso pyme (esto, por supuesto, no impide que periódicamente se proteste por el endeudamiento excesivo del que serían víctimas estas mismas empresas). Las pyme concluyó que no había prueba de que el financiamiento fuera insuficiente. Más aun, en un mercado financiero que funciona bien no se les presta a todas las empresas y los créditos son mayoritariamente de corto plazo. Con todo, Las pyme identificó problemas y posibles mejoras. Comenzamos con tres avances. Luego revisamos los desaciertos.

\subsection{Tres avances}

Uno de los problemas que detectó Las pyme era el impuesto de timbres y estampillas. Éste aumenta el costo del crédito y en ese entonces atenuaba la intensidad de la competencia entre bancos porque introducía un significativo costo de cambio. En estos años algo se avanzó, pues en 2006 (cuatro años después de que el problema fuera diagnosticado) se eliminó su pago cuando se reprograma un crédito, eliminándose así el costo de cambio de banco. Al mismo tiempo, se rebajó la tasa para nuevos créditos, desde $1,608 \%$ anual a $1,5 \%$ en 2007, 1,35\% en 2008 y 1,2\% a partir de $2009^{3}$.

En Las pyme propusimos crear una central de garantías para que las garantías pudieran trasladarse entre bancos mediante asientos con-

${ }^{3} \mathrm{El}$ impuesto fue suspendido para las operaciones de crédito que se cursaran entre el 1 de enero y el 31 de diciembre de 2009 y su tasa se rebajó a la mitad durante la primera mitad de 2010, para luego volver a 1,2\%. 
tables. Algo se avanzó, pues en julio de 2007 y como parte de la Ley de Reformas al Mercado de Capitales II, se creó un registro electrónico único de prendas. Además, desde diciembre de 2007 opera un subsidio a la movilidad de las garantías de las pyme y se estima que se han materializado cerca de 10.000 traslados de garantías. Lamentablemente, no hay datos públicos que permitan evaluar si lo que se hizo es suficiente.

Por último, en 2002 (fecha en que entregamos Las pyme) también propusimos crear una fecu ${ }^{4}$ para las pyme, esto es, cuentas financieras estandarizadas especialmente diseñadas para este tipo de empresas. Cinco años después, en 2007, el Servicio de Impuestos Internos introdujo una fecu certificada para empresas acogidas al régimen de simplificación tributaria, beneficiando potencialmente a 290 mil empresas, aunque la mayoría no necesariamente son las pyme.

Si bien la fecu ha sido reconocida por la Asociación de Bancos y está disponible en la página web de la Superintendencia de Bancos, nuestra impresión es que no ha sido muy exitosa. La razón, quizás, es que mientras no sea obligatoria, no se irá mejorando y perfeccionando gradualmente, lo que ha sido clave en el éxito de un instrumento similar en Suecia. Por eso, la fecu debería ser obligatoria para endeudarse, porque los bancos no tienen incentivos para promover de motus propio un instrumento como éste —si tiene éxito y mejora la información sobre cada empresa, los bancos se verían obligados a competir más intensamente por financiarlas-.

Tal vez convenga ligar a la fecu-pyme con la simplificación tributaria. En febrero de 2007 se promulgó una ley que simplificó el régimen tributario de las empresas con ventas inferiores a \$95 millones anuales (unas 4.500 UF). Estas empresas ya no tienen que llevar contabilidad completa y pueden usar el Reporte Financiero Simplificado. ¿Por qué no ligar este reporte con el desarrollo de la fecu-pyme?

\subsection{Reiterando errores}

Un mito del financiamiento pyme es que la disponibilidad de crédito de largo plazo es insuficiente. Los hechos muestran que en

\footnotetext{
${ }^{4}$ Las fecu (fichas estadísticas codificadas uniformes) son los informes mediante los cuales las sociedades anónimas chilenas dan a conocer sus estados financieros a la Superintendencia de Valores y Seguros.
} 
ninguna parte las empresas pequeñas se endeudan a plazos largos, a menos que se trate de créditos respaldados con una hipoteca. La razón es que la mayoría de las empresas sale al cabo de un tiempo, y no sería juicioso prestarles por plazos largos.

A pesar de esto, el gobierno sigue creyendo que los plazos cortos son un problema e insiste en subsidiar créditos de largo plazo, a pesar de que no hay ningún estudio de impacto que respalde tal política. Desconociendo que el acceso y el mayor costo se debe a que el costo medio de financiar a una pyme es mayor y que ellas son más riesgosas, a partir de 2007 Corfo puso a disposición de los bancos US\$200 millones para que les dieran créditos de plazos más largo a las pyme. A esto se agregaron US\$100 millones del programa Chile Emprende Contigo y una línea de crédito del BancoEstado para financiar la inversión en activo fijo, equipamiento tecnológico y construcciones. Hacienda también dispuso aumentar fuertemente los montos destinados a financiar microempresas a través del BancoEstado.

En Chile también se subsidian las garantías. Los programas que ya existían en 2002 siguen basados en la premisa, falsa a nuestro juicio, de que corrigen fallas de mercado. Más aun, el tamaño de los fondos se ha incrementado: en agosto de 2007 se amplió el Fondo de Garantías para Pequeños Empresarios administrado por la Corfo en US\$10 millones, y en septiembre se licitaron derechos de garantías por 7,2 millones de UF. La Corfo también creó el Fondo de Garantía para Inversiones destinado a complementar las garantías que pudieran ofrecer las pyme y acceder a créditos de largo plazo para financiar proyectos de inversión. Durante 2007, su primer año de funcionamiento, otorgó garantías por US\$30 millones y el fondo se incrementó hasta US\$100 millones en 2008. La meta, según Hacienda, era generar garantías por hasta US $\$ 1.000$ millones, equivalentes al 10\% del saldo de las colocaciones del sistema financiero con vigencia superior a un año.

No está de más mencionar que nuestro gobierno sigue creyendo que el capital de riesgo es para las pyme. En efecto, uno de los anuncios del plan Chile Emprende Contigo de 2007 indica como beneficio para las microempresas y las pyme los US\$30 millones que Corfo destinaría para financiar fondos de capital de riesgo. La realidad, por supuesto, es que las pyme y los capitalistas de riesgo tienen muy poco que ver. Tal como se dice en Las pyme, en los Estados Unidos que, lejos, tiene la industria de capital de riesgo más desarrollada del mundo, 
menos del $2 \%$ del financiamiento de las pyme proviene de capitalistas de riesgo — vale decir, financian apenas dos de cada cien dólares de activos que tiene una pyme-.

La insistencia en corregir las supuestas fallas del mercado financiero seguramente distrae a nuestro Estado y le impide corregir comportamientos de sus ministerios y organismos que dañan financieramente a las pyme. En efecto, es frecuente que algunos de ellos se financien extendiendo arbitrariamente los plazos de pago de facturas. Esto es desafortunado, porque la principal fuente de financiamiento de una pyme es su flujo de caja. El problema es bastante notorio, y quizás por eso existe una iniciativa, aún no materializada, que formalizaría el redescuento de facturas mediante una plataforma de internet administrada por Chile Compra, quien conectaría a los bancos interesados. Así, sigue el argumento, las pyme podrían descontar sus facturas y cubrirse de los descalces de caja de ministerios y organizaciones del Estado.

Sin embargo, un momento de reflexión sugiere que esta solución es absurda, porque implica financiar al Estado con el capital de trabajo de las pyme y además cobrarles intereses por descontar las facturas. Lo que corresponde es que el Estado aprenda a programar sus flujos de caja y se convierta en un buen pagador. En realidad, es un tanto incomprensible que una iniciativa como ésta no genere una reacción airada de las pyme y sus dirigentes gremiales.

\section{El fomento y la gestión de las pyme}

Como se dijo, el eje de las políticas para pyme sigue siendo el fomento, cuestión que el Estatuto reitera. La premisa, hoy como en 2001, es que las pyme necesitan ayuda del Estado para capacitarse y aprender a hacer mejor lo que hoy hacen mal. Por supuesto, hoy como en 2001, nuestro Estado cree innecesario evaluar el impacto de sus programas, mucho menos considerar la posibilidad de cerrar aquellos que no funcionan.

Así, por ejemplo, en 2007 el gobierno aumentó en \$2.570 millones el presupuesto de los programas para mejorar la gestión de microempresas y pyme. La lista de objetivos pedagógicos del programa es larga: potenciar la participación en cadenas exportadoras y clusters; 
fortalecer a las empresas proveedoras de firmas exportadoras; potenciar la asociatividad y las alianzas estratégicas entre las pyme para desarrollar mercados; y extender estos programas hacia localidades y sectores aún no cubiertos.

El programa fue usado por 427 microempresas y pyme que iniciaron procesos de incorporación de sistemas de gestión de calidad a un costo de \$622 millones. Otros \$455 millones fueron usados por 528 empresas que iniciaron programas de desarrollo de proveedores. Y con el cofinanciamiento de la Corfo (\$375 millones), 242 empresas iniciaron proyectos asociativos. Además, Corfo elaboró un reglamento para el nuevo Programa de Emprendimientos Locales y organizó jornadas regionales en todo el país. 515 empresas y 1.712 empresarios ingresaron al programa. El impacto de estos programas y cuánto valor crean es cuestión que, por supuesto, no se evaluó.

Uno de los defectos de los programas de fomento que detectó Las pyme es que sus objetivos suelen ser vagos y generales, y no consideran las especificidades del negocio de cada empresa. El programa de apoyo tecnológico desarrollado en 2008 sugiere que poco ha cambiado. En este caso se trataba de aumentar los niveles de digitalización en la gestión de estas empresas por medio de asesorías y provisión de soluciones tecnológicas, un objetivo un tanto vago que se sostiene en la premisa de que las pyme no ocupan tecnología porque son ignorantes.

Otro caso de objetivos vagos y generales es el programa de subsidios para financiar cursos de corta duración en Chile o en el extranjero que la Corfo impulsó en 2007. La Corfo decidió que en algunos sectores los clusters de empresas son una buena idea y destinó US\$2 millones para que algunas empresas se informaran de que eran parte de un cluster con potencial y aprendieran a desarrollarlo. Nuevamente, se trata de soluciones impuestas desde afuera basadas en las creencias del que financia la iniciativa, pero que poco tienen que ver con las necesidades de cada pyme.

Una idea recurrente en el discurso pyme es que les conviene asociarse para compartir costos fijos, y que no lo hacen porque no se dan cuenta de las ventajas de hacerlo. Por el contrario, Las pyme sugirió que la asociatividad era una mala idea en la mayoría de los casos, y que sólo funciona cuando hay un interés común entre los asociados y medios para alinear sus incentivos. Los programas de asociatividad nunca se han hecho cargo de esto y no es sorprendente 
que sean ineficaces. Un ejemplo es el programa que implementó Corfo durante 2007 y hasta julio de 2008 para incentivar la transferencia tecnológica (de nuevo, un objetivo que la Corfo decidió que era deseable). El programa consistía en asesorías para incorporar tecnologías a grupos asociativos y se realizaron 149 misiones tecnológicas, cuatro programas de difusión tecnológica y 50 consultorías especializadas. Cuál fue el impacto y retorno del programa es algo que, por supuesto, no ha sido evaluado.

Así las cosas, quizás la principal virtud de lo hecho desde 2002 en materia de programas de fomento es que los montos gastados no han aumentado mucho ${ }^{5}$. La reflexión final es que seguramente, hoy como en 2001, los principales beneficiados con los programas de fomento y capacitación son los consultores que se dedican a intermediarlos. Las pyme advirtió un hecho obvio, a saber, que existen buenos consultores, capaces de agregar valor al negocio de una pyme y otros que difícilmente harán aportes relevantes al negocio. Si se les remunera por el número de proyectos gestionados, se atraerá a los especialistas en generar proyectos; si es por valor creado en la pyme, a los buenos consultores. En 2001 la remuneración de los consultores dependía de gestionar proyectos, no de los resultados logrados; en 2009 también. Sea como sea, la teoría de los grupos de interés explica por qué el impacto de los programas no se evalúa y ninguno se cierra - hay un grupo de interés que se beneficia y los defiende, mientras que los costos se reparten entre millones de contribuyentes-.

\section{La burocracia, el costo de hacer negocios y el Estatuto}

El gobierno de la Presidenta Bachelet estima que su principal logro en materias de pyme y microempresas (las así llamadas empresas de menor tamaño) es la aprobación del Estatuto para empresas de menor tamaño (a veces también se le llama Estatuto pyme). Se afirma que este estatuto reconoce que la carga regulatoria debe ajustarse al tamaño de las empresas e introduce una nueva forma de regular y fiscalizar. Seguramente, con esto se quiere decir que, por fin, el Estado comenzará a simplificar sistemáticamente los trámites. Sin embargo, el Estatuto no sugiere tal cosa.

\footnotetext{
${ }^{5}$ Hay que notar que la legión de programas para empresas agrícolas que maneja el Indap siguen existiendo. El monto destinado a estos programas es muy grande.
} 
Una razón es que se parte de la premisa de que basta escribir algo en una ley para que ocurra. Por el contrario, la práctica indica que cuando nuestro Estado escribe leyes no piensa en los procesos ni en la implementación. También es cierto que el Estatuto no se hace cargo de la estructura de la maraña regulatoria y dispone coordinaciones que, en la práctica, son imposibles porque el encargado de coordinar no tendrá autoridad para hacerlo. Por último, como ya se dijo, el eje de las políticas para pyme sigue siendo el fomento y la ayuda, no facilitar el proceso de ensayo y error que ocurre mediante la entrada y salida de firmas. Con esto en mente, a continuación revisamos brevemente el Estatuto.

\subsection{Normas y trámites}

El Estatuto introduce los permisos provisorios por un año, incluyendo los que otorga la autoridad sanitaria, para nuevas empresas con capital menor que UF 5.000. Y una vez obtenido el permiso provisorio, las municipalidades pueden otorgar patentes provisorias. Seguramente esto facilitará la creación de nuevas empresas, pero al mismo tiempo es improbable que el efecto sea grande, porque no se enfrenta el problema de fondo, a saber, que el número de trámites y ventanillas es excesivo. Lo que cabe hacer es simplificar el trámite de iniciación de empresas. Así, idealmente el empresario llenaría un solo formulario podado de los requisitos innecesarios e inútiles que hoy se imponen, y el Estado se encargaría de coordinar internamente a su legión de instituciones públicas que exigen trámites, incluidas las municipalidades. La autorización de funcionamiento de la empresa debiera ser inmediata y sólo revertirse por razones fundadas.

El Estatuto también cambia el procedimiento para dictar reglamentos y normas que afectan a las empresas de menor tamaño, principalmente porque obliga a darles publicidad a las nuevas normas a través de páginas web. Así:

Todos los ministerios u organismos que dicten o modifiquen normas jurídicas generales que afecten a empresas de menor tamaño [...] deberán mantener a disposición permanente del público, los antecedentes preparatorios necesarios que éstos estimen pertinentes para su formulación [...]. 
Además, entre los antecedentes que deben exponerse en la página web se incluye una estimación simple del impacto social y económico que la nueva regulación generará en las empresas de menor tamaño. Más aun, estas normas se le deben informar al Ministerio de Economía, quien [...] deberá publicar en su página web todas las normas vigentes sobre empresas de menor tamaño [...].

Es difícil imaginar que estas obligaciones puedan causar daño. Pero al mismo tiempo, también es difícil creer que servirán de mucho. Para comenzar, nada ocurrirá si no se cumple con ellas, porque el Estatuto expresamente indica que “[...] el incumplimiento de las obligaciones [...] no afectará en caso alguno la validez del acto”. Tampoco es clara la utilidad de exponer antecedentes preparatorios en una página web, pues para que tal cosa sea eficaz es necesario que exista revisión independiente y que ésta tenga consecuencias ${ }^{6}$. Por último, la estructura de la maraña regulatoria del Estado implica que poco se gana con informar al Ministerio de Economía, pues éste no tiene potestad para coordinar las regulaciones hechas por otros ministerios. De nuevo, el problema es el exceso de regulaciones y nada de eso cambia. Más generalmente, en Chile la maraña regulatoria no se puede desenredar sin un mandato directo de la Presidenta de la República, porque la estructura del sector público es tal que los ministerios son delegados de la Presidenta $^{7}$. Si no hay una orden expresa de la Presidenta, nada obliga, por ejemplo, al Ministerio del Medio Ambiente a coordinarse con el de Economía. Por eso, informar al ministro de Economía de una nueva regulación que afecta a las pyme no ayuda mucho — si al ministro no le gusta, no tiene poder para cambiarla-.

Las limitaciones del Estatuto se pueden ilustrar con el destino del gerente que designó el gobierno en marzo de 2007 para identificar los procedimientos y requisitos administrativos sanitarios, regulatorios y ambientales que entrababan proyectos de inversión. Este gerente debía proponer mejoras, tanto a los procesos como a las leyes,

\footnotetext{
${ }^{6}$ Por lo demás, la Ley No 20.285 incluye entre las causales de secreto a "los antecedentes o deliberaciones previas a la adopción de una resolución, medida o política, sin perjuicio que los fundamentos de aquéllas sean públicos una vez que sean adoptadas".

${ }^{7}$ Véase L. Sierra, "Urbanismo por decreto: Centralismo y confusión institucional en la ciudad chilena”, en A. Galetovic (editor), Santiago: Dónde estamos y hacia dónde vamos (Santiago: Centro de Estudios Públicos, 2006).
} 
pero hasta la fecha no se conocen las acciones concretas que propuso ni, mucho menos, las que se adoptaron. Lo más probable es que haya sido ineficaz, porque si bien le reportaba al Comité Económico de Ministros, no tenía poder para mandarlo ni para implementar los mejoramientos.

\subsection{Fiscalización y cumplimiento}

El Estatuto debiera reducir la discreción de los fiscalizadores, porque los obliga a describir en una página web sus procedimientos. Dice el artículo sexto:

Los servicios públicos que realicen procedimientos de fiscalización a empresas de menor tamaño, deberán mantener publicados en sus sitios web institucionales, y disponibles al público en sus oficinas de atención ciudadana, los manuales o resoluciones de carácter interno en los que consten las instrucciones relativas a los procedimientos de fiscalización establecidos para el cumplimiento de su función, así como los criterios establecidos por la autoridad correspondiente que guían a sus funcionarios y fiscalizadores en los actos de inspección y de aplicación de multas y sanciones.

El incumplimiento de dichas normas por los funcionarios fiscalizadores, la interpretación extensiva o abusiva de la ley o de las disposiciones de los manuales o resoluciones a que se refiere el inciso anterior, dará lugar a la nulidad de derecho público del acto fiscalizador, además de las responsabilidades administrativas que correspondan.

Por supuesto, no es primera vez que una ley le impone obligaciones de transparencia a nuestro Estado. Tal como sugieren las sucesivas leyes de transparencia, hasta que no hay una institución a la cual se puede reclamar expeditamente cuando existe un conflicto con la autoridad (en ese caso el Consejo para la Transparencia), nuestro Estado suele ignorar disposiciones como las de este artículo. Pero pareciera que si se aplica apropiadamente y las instituciones que fiscalizan se ven obligadas a detallar con rigor sus procedimientos, este artículo impulsaría un avance significativo en la dirección correcta.

El Estatuto también introduce algunas innovaciones en fiscalización. En el ámbito sanitario, se incorpora la autodenuncia voluntaria de 
incumplimiento de la normativa, en cuyo caso la empresa puede solucionar su problema sin sanción. En el ámbito laboral, la ley permite reducir las multas a las empresas de menor tamaño cuando éstas acrediten que han corregido el incumplimiento causa de la infracción. Además, se extiende a empresas con más de nueve trabajadores el sistema de sustitución de multas por programas de capacitación o de asistencia al cumplimiento. En el ámbito ambiental, la ley establece que, cuando se detecten incumplimientos a las normas, las empresas podrán ingresar a un programa de cumplimiento. Además, para incentivar la adopción de sistemas de producción limpia, se permite que las empresas acuerden con la autoridad un programa de adopción de normas sanitarias, ambientales y de eficiencia energética por sobre el mínimo legal. Qué utilidad tenga esto es cuestión que está por verse, sin embargo. De nuevo, inquieta que el Estatuto no simplifique y elimine trámites.

\subsection{Cierre de empresas en problemas}

En Chile, nos informa el Mensaje que acompañó el envío del proyecto de ley del Estatuto, existen 133.000 empresas que, estando vigentes en los registros del Servicio de Impuestos Internos, nada venden. Los redactores del Mensaje admiten no conocer la razón; pero eso no les impide ver un problema y atribuírselo a la ignorancia de los empresarios pyme. En este caso, los empresarios pyme serían incapaces de gestionar una quiebra y tratar con sus acreedores, y seguramente por ello se crea un nuevo consultor, el asesor económico de insolvencias. Este asesor estará encargado de "[...] llevar a cabo un estudio sobre la situación económica, financiera y contable del deudor”. Una vez hecho esto, y de explicarle al empresario pyme por qué está en problemas, el asesor tratará de ponerlo de acuerdo con sus acreedores, aunque todo lo que proponga es voluntario y en nada obliga a las partes en conflicto. Para hacer todo esto tiene 90 días.

No es necesario aburrir al lector con la legión de requisitos, inhabilidades, controles, registros, superintendencias, multas, penas y demases con los que la ley regula a este nuevo asesor; sin intención de ofender, la verdad es que uno se pregunta si quienes redactaron el largo artículo undécimo del Estatuto tienen alguna experiencia práctica con el 
cierre de empresas. Aquí sólo haremos un par de observaciones basadas en el sentido común y en un par de hechos que establecimos cuando escribimos Las pyme.

Para comenzar, llama la atención que se diseñe un sistema tan complejo de asesoría para tratar con la quiebra, porque ocurre que la gran mayoría de las empresas que sale no quiebra. También es cierto que el asesor es, en esencia, un costo fijo más. ¿Es razonable pensar que una empresa cuyo principal problema es que les debe a muchos, que en cualquier caso vende poco, y que seguramente tiene pocos activos, estará dispuesta a pagar montos no despreciables para que le expliquen por qué está en problemas? Por último, ¿no será que la gente no cierra las empresas inactivas porque teme una pesadilla burocrática con el Servicio de Impuestos Internos? Tal vez el problema de las empresas que no cierran se resuelve rediseñando el trámite para simplificarlo y garantizando que una empresa con su situación tributaria al día no será revisada cuando solicite su cierre definitivo.

Por supuesto, algunas pyme quiebran y los procedimientos para declarar la quiebra y reasignar los activos de la empresa deben ser expeditos. El Estatuto aumenta desde UF 1.000 a UF 2.000 UF el umbral de capital para que las empresas puedan acogerse a una liquidación sumaria y acorta de un año a seis meses el período de rehabilitación de las empresas que se acogen a este sistema. Pero si se trataba de facilitar la quiebra de las pyme y microempresas (casi todas las empresas en Chile) ¿no era mejor perfeccionar de una vez por todas la Ley de Quiebras que, dicen los expertos, tiene defectos serios?

\subsection{Proveedores}

El Estatuto también considera que las empresas de menor tamaño son como cualquier consumidor respecto de sus proveedores, y les aplica en gran medida la ley de protección del consumidor.

De manera similar, y seguramente como reacción a los casos de poder de compra conocidos por el Tribunal de Defensa de la Libre Competencia, el Estatuto también incluye un par de regulaciones que operan cuando una empresa de menor tamaño es proveedora de otra, presumiblemente grande. Así, la ley le prohíbe a una empresa (v.gr. 
una cadena de supermercados) que le compra a una pyme, pedir mejores condiciones comerciales que las que recibe un competidor ${ }^{8}, \mathrm{y}$ también prohíbe cláusulas contractuales o conductas abusivas en desmedro de los proveedores o el incumplimiento sistemático de deberes contractuales contraídos con ellos (uno se pregunta por qué se necesita reiterar en una ley que las obligaciones contractuales deben cumplirse). Por último, la ley permite demandar a un comprador colectivamente o a través de una asociación gremial.

\subsection{Más burocracia}

Como se dijo, el fomento es el eje de las políticas para pyme según el Estatuto. Por eso, y como suele suceder, la nueva ley también crea nueva burocracia y cambia nombres. Según el ministro de Economía, la Subsecretaría de Economía “[...] cambia de nombre a Subsecretaría de Economía y EMT, para profundizar la coordinación de políticas para el sector, con el resto de los ministerios sectoriales e impulsar una política con sus servicios relacionados”. Por qué un cambio de nombre tiene tales efectos es cuestión que uno bien se puede preguntar.

También se crea la División de EMT (Empresas de Menor Tamaño) en el Ministerio de Economía y se agrega el cargo de jefe de División de Empresas de Menor Tamaño (el cual ya fue llenado). Y se crea un Consejo Consultivo Público-Privado de las EMT, presidido por el ministro de Economía y con participación de instituciones públicas (Corfo, Sercotec y Prochile), seis representantes de confederaciones gremiales, uno de una asociación exportadora, un académico, un representante de las municipalidades, un representante de las ONG y un representante del Consejo de Innovación. Este Consejo no tiene poder para decidir, tiene 15 integrantes, y su finalidad es difusa, pero en

${ }^{8}$ El lector nos excusará si entendimos algo mal, pero la redacción del susodicho artículo es, por decirlo de alguna manera, un tanto confusa:

La imposición por parte de una empresa a un proveedor, de condiciones de contratación para sí, basadas en aquellas ofrecidas por ese mismo proveedor a empresas competidoras de la primera, para efectos de obtener mejores condiciones que éstas; o, la imposición a un proveedor de condiciones de contratación con empresas competidoras de la empresa en cuestión, basadas en aquellas ofrecidas a ésta. 
cualquier caso, uno no puede más que admirarse de la fe ciega que parecen tener nuestros gobiernos y políticos en los comités de este tipo.

\section{Conclusión}

Es un tanto desafortunado que Las pyme se mantenga vigente ocho años después de escrito, porque poco ha cambiado desde entonces. La premisa del Estado sigue siendo que su rol es fomentar y ayudar a las pyme - el Artículo 3 del Estatuto es claro al respecto-. Más aun, muy poco se ha hecho desde 2002 por simplificar y eliminar trámites; los pocos avances han ocurrido lentamente (por ejemplo, tomó cuatro años eliminar el pago del impuesto de timbres y estampillas cuando se reprograman deudas) y las acciones emblemáticas como el Estatuto introducen aun más burocracia y una institución —el Consejo Consultivo Público-Privado de las EMT— que probablemente será irrelevante en el mejor de los casos. Es muestra de lo pobre que ha sido la labor de nuestros gobiernos el que sus actos se comuniquen cada cierto tiempo en forma de pomposos planes con nombres marketeros — v.gr. Chile Compite, Chile Emprende Contigo - que recopilan promesas vagas y un par de de medidas concretas que debieran ser parte del trabajo rutinario de gobierno.

¿Cómo debieran enfocarse las políticas para las pyme? Un esfuerzo serio por simplificar partiría desde la Presidencia de la República (por la estructura del Estado chileno, sólo sirven las órdenes de la Presidenta). Una vez hecho un catastro sistemático de trámites, regulaciones y programas, se eliminarían rápidamente aquellos que no sirven o son redundantes. Al mismo tiempo, por un tiempo el énfasis se desplazaría desde las leyes y los planes hacia los procesos, pues la mayoría de las simplificaciones no necesitan cambios de ley (tampoco requieren anunciarse empaquetados en planes rimbombantes). Al mismo tiempo, nuestro Estado comenzaría a hacerse cargo de la estructura de la maraña regulatoria y, desde la Presidencia de la República, instalaría una oficina que, con la debida autoridad, se encargaría de coordinar al enorme aparato del Estado y de darles cierta coherencia a las regulaciones que tienen impactos en varios sectores. Por último, nuestro Estado usaría sus poderes donde es indispensable. Por ejemplo, 
impulsaría la central de garantías para que los bancos compitan, la creación de registros comerciales y de firmas para evitar que para cada trámite sea necesario legalizar títulos, firmas y escrituras, crearía contratos estandarizados que ahorrarían costos de transacción y, en general, averiguaría todo el tiempo qué cosas les podrían hacer la vida más barata y fácil a todas las empresas.

Más generalmente, nuestro Estado cambiaría su manera de ver el mundo. En vez de creer que todo lo sabe y que su rol es enseñarles a empresarios ignorantes, se daría cuenta de que en una economía de mercado el aprendizaje ocurre mediante ensayo, error y selección, la otra cara de la entrada y salida permanente de firmas. Ese Estado les preguntaría todo el tiempo a las empresas de verdad cuáles son sus problemas, haría lo posible por evitar y solucionar los problemas que él mismo crea, e iría aprendiendo gradualmente, perfeccionando sus procesos y regulaciones y eliminando aquello que no funciona. Pero quizás eso sea pedirle demasiado.

\section{Alexander Galetovic y Ricardo Sanhueza Diciembre de 2009}

\section{REFERENCIAS}

Acs, Z. y D. Audretsch: "Innovation, Market Structure, and Firm Size”. En The Review of Economics and Statistics 69, 567-574, 1987.

Agraria, Consultorías Profesionales: "Evaluación Profos agropecuarios”, mimeo, 1999.

Akerlof, G.: "The Market for Lemmons: Quality Uncertainly and the Market Mechanism”. En Quarterly Journal of Economics 89, 488-500, 1970.

Alarcón, C. y G. Stumpo: "Pequeñas y medianas empresas industriales en Chile”. En Serie Desarrollo Productivo No 78. Santiago: Cepal, 2000.

Alchian, A. y H. Demsetz: "Production, Information Costs, and Economic Organization”. En American Economic Review 62, 777-795, 1972.

Álvarez, R. y G. Crespi: “La importancia relativa de las pequeñas y medianas empresas: un análisis de sus determinantes en la industria manufacturera”. En Cuadernos de Economía 38, 347-365, 2001.

"Determinants of Technical Efficiency in Small Firms: Evidence from the Chilean Manufacturing Industry”. En Journal of Small Business Economics, por aparecer, 2002.

Álvarez, R., G. Crespi y R. Fuentes: "Posición competitiva y análisis del comportamiento estratégico de la micro y pequeña empresa nacional”. Informe final preparado para el Ministerio de Economía-Sercotec-Corfo. Santiago: Departamento de Economía, Universidad de Chile, 1999. 
Anand B., y A. Galetovic: "Information, Non-excludability and Finantial Market Structure”. En Journal of Business 73, 357-402, 2000.

Ang J., J. Lin y F. Tyler: "Evidence on the Lack of Separation Between Business and Personal Risks among Small Businesses”. En Journals of Small Business Finance 4, 197-210, 1995.

Arrau, P.: "Perspectivas de la industria de capital de riesgo en Chile", mimeo, Gerens S. A., 2001.

Asimet: II Encuentro de la pequeña y mediana empresa industrial. Santiago: Asimet, 2001.

Audretsch, D.: "New-firm Survival and the Technological Regime”. En The Review of Economics and Statistics 73, 441-450, 1991.

- Innovation and Industry Evolution. Cambridge: MIT Press, 1995a. "Innovation, Growth and Survival”. En International Journal of Industrial Organization 13, 441-457, 1995b.

Audretsch, D. y T. Mahmood: "New Firm Survival: New Results Using a Hazard Function”. En Review of Economics and Statistics 77, 97-103, 1995.

Avery, R., R. Bostic y K. Samolyk: "The Evolution of Small Business Finance: The Role of Personal Wealth”. En Journal of Banking and Finance 22, 10191061, 1998.

Aw, B., X. Chen y M. Roberts: "Firm-Level Evidence on Productivity Differentials and Turnover in Taiwanese Manufacturing”. En Journal of Development Economics 66, 51-86, 2001.

Baldwin, J.: The Dynamics of Industrial Competition. Nueva York: Cambridge University Press, 1995.

Baldwin, J. y P. Gorecki: “Firm Entry and Exit in Canadian Manufacturing Sector”. En Canadian Journal of Economics 24, 300-323, 1991.

Baldwin, J. y M. Rafiquzzaman: "Selection versus Evolutionary Adaptation: Learning and Post-Entry Performance”. En International Journal of Industrial Organization 13, 501-522, 1995.

Bartelsman, E. y M. Doms: "Understanding Productivity Growth”, mimeo, 1997.

Basch, M.: “Chile: Improving Market Mechanisms”. En M. Basch y C. Morales (eds.), Expanding Access to Financial Services in Latin America. Washington: Banco Interamericano de Desarrollo, 1995.

Bash, M. y R. Fuentes: "Determinantes de los spreads bancarios: el caso de Chile”. Research Network Working Paper R329, Banco Interamericano de Desarrollo, 1998.

Benavente, J. y G. Crespi: "The Impact of an Associative Strategy (the PROFO Program) on Small and Medium Enterprises in Chile”, mimeo, University of Sussex, 2000.

Berger, A.: "The Big Picture of Relationship Finance”. En J. Blanton, A. Williams y S. Rhine (eds.), Business Access to Capital and Credit. Washington: A Federal Reserve System Conference, 1999.

Berger, A. y G. Udell: "Relationships Lending and Lines of Credits in Small Firm Finance”. En Journal of Business 68, 351-382, 1995.

"The Economics of Small Business Finance: The Roles of Private Equity and Debt Markets in the Financial Growth Cycle”. En Journal of Banking and Finance 22, 1998. 
Besanko, D., D. Dranove y M. Shanley: The Economics of Strategy. Nueva York: John Willey and Sons, 1996.

Besanko, D. y A. Thakor: "Collateral and Rationing: Sorting Equilibria in Monopolistic and Competitive Markets”. En International Economics Review 28, 671-689, 1987a.

- "Competitive Equilibrium in the Credit Market under Asymmetric Information”. En Journal of Economics Theory 42, 167-182, 1987b.

Bester, H.: "Screening vs. Rationing in Credit Market with Imperfect Information". En American Economic Review 75, 850-855, 1985.

Boot, A.: "Relationship Banking: What Do We Know?”. En Journal of Financial Intermediation 9, 7-25, 2000.

Bravo, D. y D. Contreras: Competencias básicas en la población adulta. Santiago: Departamento de Economía de la Universidad de Chile y Gobierno de Chile, 2001.

Caballero, R. y M. Hammour: "Creative Destruction and Development: Institutions, Crises, and Restructuring”. En Annual World Bank Conference on Development Economics 2000, 213-236, 2001.

Cabrera, A., S. de la Cuadra, A. Galetovic y R. Sanhueza: "Financiamiento de las pyme: mitos y realidades", informe preparado para la Sociedad de Fomento Fabril, 2002.

Camhi, A., E. Engel y A. Micco: "Dinámica de empleo y productividad en manufacturas: evidencia micro y consecuencias macro”. En F. Morandé y R. Vergara (eds.), Análisis empírico del crecimiento en Chile. Santiago: Banco Central y Centro de Estudios Públicos, 1997.

Carlton, D. y J. Perloff: Modern Industrial Organization, Glenview, Ill and London: Scott, Foresman/Little, Brown Higher Education, 1990.

Carmona, R.: “Exposición caso Drillco Tools”. En II Encuentro de la pequeña y mediana empresa industrial. Santiago: Asimet, 2001.

Caves, R.: "Industrial Efficiency in Six Nations: Introduction and Summary". En R. Caves (ed.), Industrial Efficiency in Six Nations. Cambridge: MIT Press, 1992.

"Industrial Organization and New Findings on the Turnover and Mobility of Firms”. En Journal of Economic Literature 36, 1947-1982, 1998.

Caves, R. y M. Porter: “From Entry Barriers to Mobility Barriers”. En Quarterly Journal of Economics 91, 241-261, 1977.

Caves, R. y T. Pugel: Intraindustry Difference in Conduct and Performance: Viable Strategies in U.S. Manufacturing Industries. Nueva York: New York University Press, 1980.

Chan, Y. y G. Kanatas: "Asymmetric Valuations and the Role of Collateral in Loan Agreements ”. En Journal of Money, Credit, and Banking 17, 84-95, 1985.

Church, J. y R. Ware: Industrial Organization: A Strategic Approach. Boston: IrwinMcGraw Hill, 2000.

Coase, R.: "The Nature of the Firm”. En Economica 4, 386-405, 1937.

Cole, R.: "The Importance of Relationships to the Availability of Credit”. En Journal of Banking and Finance 22, 959-977, 1998.

Comanor, W.: "Market Structure, Product Differentiation and Industrial Research". En Quarterly Journal of Economics 639-657, 1967.

Cubillos, F.: "Utilizando las tecnologías de información”. En II Encuentro de la pequeña y mediana empresa industrial. Santiago: Asimet, 2001. 
Davis, S., J. Haltiwanger y J. Schuh: Job Creation and Destruction. Cambridge: MIT Press, 1996.

Degryse, H. y P. van Cayseele: "Relationship Lending Within a Bank-based System: Evidence From European Small Business Data”. En Journal of Financial Intermediation 9, 90-109, 2000.

Djankov, S., R. La Porta, F. López de Silanes y A. Shleifer: “The Regulation of Entry”, mimeo, Harvard University, 2001.

Dunne, T., M. Roberts y L. Samuelson: "Patterns of Firm Entry and Exit in U.S. Manufacturing Industries”. En RAND Journal Economics 19, 495-515, 1988. "Plant Turnover and Gross Employment Flows in the U.S. Manufacturing Sector”. En Journal of Labor Economics 7, 48-71, 1989a.

"Firm Entry and Post-Entry Performance in the U.S. Chemical Industries". En Journal of Law and Economics 32, S233-271, 1989b.

- "The Growth and Failure of U.S. Manufacturing Plants". En Quarterly Journal of Economics 104, 671-698, 1989c.

Elsas, R. y J. P. Krahnen: "Is Relationship Lending Special? Evidence from Credit-File Data in Germany”. Working Paper, Johann Wolfgang Goethe University, Frankfurt, 1998.

Evans, D.: "The Relationships between Firm Growth, Size, and Age: Estimates for 100 Manufacturing Industries”. En Journal of Industrial Economics 35, 567-581, 1987a.

“Test of Alternatives Theories of Firm Growth”. En Journal of Political Economy 95, 657-674, 1987b.

Fenn, G., N. Liang y S. Prowse: “The Economics of the Private Equity Market”. En Staff Studies No 178, Board of Governors of the Federal Reserve System, 1995.

Fischer, R.: Las nuevas caras del proteccionismo. Santiago: Dolmen, 1997.

- Latin America and the Global Economy: Export Trade and the Threat of Protectionism. Londres: Macmillan, 2001a.

“Liberalización del comercio, desarrollo y política gubernamental”. En Estudios Públicos 84, 323-359, 2001b.

Fischer, R. y P. Serra: “Standards and Protection”. En Journal of International Economics 52, 377-400, 2000.

Fontaine, B.: “Créditos más baratos, ahora”. En Puntos de Referencia № 252. Santiago: Centro de Estudios Públicos, 2002.

Foster, L., J. Haltiwanger y C. Krizan: “Aggregate Productivity Growth: Lessons From Microeconomic Evidence”. En E. Dean, M. Harper y C. Hulten (eds.), New Directions in Productivity Analysis. Chicago: University of Chicago Press, 2000.

Foxley, J.: "Reformas a la institucionalidad del crédito y el financiamiento a empresas de menor tamaño: la experiencia chilena con sistemas de segundo piso”. Serie Financiamiento del Desarrollo No 74. Santiago: Cepal, 1998.

- "Limitantes al financiamiento de las empresas de menor tamaño: un estudio en terreno con principales oferentes en Chile”, Proyecto conjunto Ministerio de Economía-Corfo-Banco del Estado-Cepal: Políticas de financiamiento de pequeñas y medianas empresas en Chile, 1999.

Freixas, X. y J. Rochet: Microeconomics of Banking. Cambridge: MIT Press, 1997. 
Fuentes, R. y C. Maquieira: "Why Borrowers Repay: Understanding High Performance in Chile’s Financial Market”. En M. Pagano (ed.), Defusing Default: Incentives and Institutions. Washington: Banco Interamericano de Desarrollo, 2001.

Galbraith, J.: American Capitalism. Boston: Houghton Mifflin, 1956.

Geroski, P.: Market Dynamics and Entry. Oxford: Blackwell, 1991.

"What Do We Know About Entry". En International Journal of Industrial Organization 13, 421-440, 1995.

Geroski, P. y J. Schwalbach: Entry and Contestability: An International Comparison. Oxford: Blackwell, 1991.

Gompers, P. y J. Lerner: The Venture Capital Cycle. Cambridge: MIT Press, 2000.

Halcartegaray, F.: “Exposición caso Calzados Guante”. En II Encuentro de la pequeña y mediana empresa industrial. Santiago: Asimet, 2001.

Hall, B.: "The Relationship Between Firm Size and Firm Growth in the U.S. Manufacturing Sector”. En Journal of Industrial Economics 35, 583-606, 1987.

Hallberg, K.: “A Market-Oriented Strategy for Small and Medium-Sized Enterprises”. En Discussion Paper № 40, International Finance Corporation, 2000.

Harhoff, D. y T. Körting: "Lending Relationships in Germany: Empirical Results From Survey Data”. En Journal of Banking and Finance 22, 1317-1354, 1998.

Held, G.: "Conclusiones y propuestas de política: Acceso de empresas de menor tamaño al crédito y al financiamiento". Informe preparado para el Ministerio de Economía/Corfo/Banco del Estado/Cepal, 2000.

Hopenhayn, H. y R. Rogerson: "Job Turnover and Policy Evaluation: A General Equilibrium Analysis”. En Journal of Political Economy 101, 915-938, 1993.

International Finance Corporation (IFC): Making Small Business Lending Profitable. Proceedings of the Global Conference on Credit Scoring. Washigton: Banco Mundial e IFC, 2001.

Irarrázabal, I.: Desempeño económico y viabilidad de la microempresa en Chile. Santiago: Focus Consultores, 2001.

James, C.: "Some Evidence on the Uniqueness of Bank Loans". En Journal of Financial Economics 19, 217-235, 1987.

Japelli, T. y M. Pagano: “Information Sharing in Credit Markets”. En Journal of Finance 43, 1693-1718, 1993.

"Information Sharing in Credit Markets: Theory and Evidence". En M. Pagano (ed.), Defusing Default: Incentives and Institutions. Washington: Banco Interamericano de Desarrollo, 2001.

Johansson C. y L. Samuelson: "The Design and Use of Management Accounts in Small and Medium-Sized Companies", Working Paper Series in Business Administration $\mathrm{N}^{\circ}$ 2, Department of Business Administration, Stockholm School of Economics, 1998.

Jovanovic, B. y G. Macdonald: "The Life Cycle of a Competitive Industry”. En Journal of Political Economy 102, 1994.

Klein, E. y V. Tokman: Regulation and the Informal Economy. Boulder: Reiner Publishers, 1996.

Klemperer, P.: "Markets with Consumer Switching Costs". En Quarterly Journal of Economics 102:2, 375-394, 1987.

Larraín, C.: “Tasa máxima convencional, cobranza extrajudicial e industria del crédito del consumo”, mimeo, Gerens S. A., 2000. 
"Financiamiento de la pequeña empresa en EE.UU.: Lecciones para Chile”. En Diario Financiero, 14 de diciembre, 2001.

Levenson, A. y W. Maloney: "The Informal Sector, Firm Dynamics and Institutional Participation”, mimeo, University of Illinois, 1997.

Liu, L.: "Entry, Exit, Learning, and Productivity Change in Chilean Manufacturing”. En Journal of Development Economics, 42, 217-242, 1993.

Lizana, C.: “Exposición caso Vitroquímica S. A.”. En II Encuentro de la pequeña y mediana empresa industrial. Santiago: Asimet, 2001.

Lora E., P. Cortés y A. Herrera: "Los obstáculos al desarrollo empresarial y el tamaño de las empresas en América Latina”. RES-IBD Working Paper 447. Washington D. C.: Banco Interamericano de Desarrollo, 2001.

Lummer, S. y J. McConnel: "Further Evidence on the Bank Lending Process and the Capital Market Response to Bank Loan Agreements”. En Journal of Financial Economics 25, 99-122, 1989.

Machauer, A. y M. Weber: "Number of Bank Relationships: An Indicator of Competition, Borrower Quality or Just Size?” Working Paper, University of Mannheim, 2000.

Mata, J.: "Firm Growth During Infancy”. En Small Business Economics 6, 27-39, 1994.

Mata, J. y P. Portugal: "Life Duration of New Firms”. En Journal of Industrial Economics 42, 227-246, 1994.

Mata, J., P. Portugal y P. Guimaraes: "The Survival of New Plants: Start Up Conditions and Post-Entry Evolution”. En International Journal of Industrial Organization 13, 459-481, 1995.

Mayer, C.: "Financial Systems, Corporate Finance and Economic Development”. En G. Hubbard (ed.), Asymmetric Information, Corporate Finance and Investment. Chicago: University of Chicago Press, 1990.

Mills, D. y L. Schumann: "Industry Structure with Fluctuating Demand”. En American Economic Review 75, 758-767, 1985.

Ministerio de Economía: "Políticas de apoyo financiero al desarrollo productivo: propuesta del Ministerio de Economía”, mimeo, Ministerio de Economía, 2000.

Myers, S.: "Presidencial Adress: The Capital Structure Puzzle”. En Journal of Finance 39, 575-592, 1984.

Myers, S. y N. Majluf: “Corporative Financing and Investment Decisions when Firms Have Information that Investors do not Have”. En Journal of Financial Economics 13, 187-221, 1984.

Nachman, D. y T. Noe: “Optimal Design of Securities Under Asymetry Information”. En Review of Financial Studies 7, 1-44, 1994.

Ongena, S. y D. Smith: “Bank Relationships: A Review”. En S. A. Zenios and P. Harker (eds.), Performance of Financial Institutions. New York: Cambridge University Press, 2000.

Pagano, M.: Defusing Default: Incentives and Institutions. Washington: Banco Interamericano de Desarrollo, 2001.

Pavitt, K. y S. Wald: The Conditions of Success in Technological Innovation. Paris: OECD, 1971.

Petersen, M. y R. Rajan: "The Benefits of Firm-Creditor Relationships: Evidence from Small Business Data”. En Journal of Finance 49, 3-37, 1994. 
"The Effect of Credit Market Competition on Lending Relationships”. En Quarterly Journal of Economics 110, 407-443, 1995.

Porter, M.: “The Structure within Industries and Companies’ Performance”. En Review of Economics and Statistics 61, 214-227, 1979.

Roberts, M. y J. Tybout: "Producer Turnover and Productivity Growth in Developing Countries”. En The World Bank Research Observer 12, 1-18, 1997.

Sahlman, W.: “The Structure and Governance of Venture-Capital Organizations”. En Journal of Financial Economics 27, 473-521, 1990.

Scherer, F.: Industrial Market Structure and Economic Performance. Chicago: Rand McNally, 1980.

Scott, J., y W. Dunkelberg: "Bank Consolidation and Small Business Lending: A Small Firm Perspective”. En J. Blanton, A. Williams y S. Rhine (eds.), Business Access to Capital and Credit. Washington: A Federal Reserve System Conference, 1999.

Shockley, R. y A. Thakor: "Bank Loan Commitments: Data, Theory and Tests”. En Journal of Accounting and Economics 8, 159-172, 1987.

Shy, O.: The Economics of Network Industries. Nueva York: Cambridge University Press, 2001.

Silver, D.: The Venture Capital Sourcebook. Chicago: Irwing, 1996.

Snodgrass, D. y T. Biggs: "Industrialization and Small Firms: Pattern and Policies”, mimeo, International Center for Economic Growth, 1996.

Stiglitz, J. y A. Weiss: “Credit Rationing in Markets with Imperfect Information”. En American Economics Review 71, 393-410, 1981.

"Credit Rationing and Collateral”. En J. Edwards, C. Mayer y S. Schaefer (eds.), Recent Developments in Corporate Finance. New York: Cambridge University Press, 101-135, 1986.

Sutton, J.: Sunk Costs and Market Structure: Price Competition, Advertising and the Evolution of Concentration. Cambridge: MIT Press, 1991.

“Gibrat’s Legacy”. En Journal of Economic Literature 35, 40-59, 1997.

Technology and Market Structure: Theory and History. Cambridge: MIT Press, 1998.

Taggart, R.: "Secular Patterns in the Financing of US Corporations". En B. Friedman (ed.), Corporate Capital Structure in the United States. Chicago: The University of Chicago Press, 1985.

Tybout, J.: "Manufacturing Firms in Developing Countries: How Well Do They Do, and Why". En Journal of Economic Literature 38, 11-44, 2000.

Tirole, J.: The Theory of Industrial Organization. Cambridge: MIT Press, 1988.

U.S. Small Business Administration: The Annual Report on Small Business and Competition. Washington: U.S. Small Business Administration, 1995.

Wagner, J.: "The Post-entry Performance of New Small Firms in German Manufacturing Industries”. En Journal of Industrial Economics 42, 141-154, 1994.

Palabras clave: pyme (pequeñas y medianas empresas); financiamiento; dinámica industrial; productividad; fomento. 